WHC-EP-0673

UC.90R

\title{
Permanent Isolation Surface Barrier Development Plan
}

\author{
N. R. Wing \\ Date Published \\ January 1994
}

Prepared for the U.S. Department of Energy Office of Environmental Restoration and Waste Management

\section{(Q. Westinghouse \\ P.O. Box 1970 \\ Hanford Company Richland. Washington 99352 \\ Manford Operations and Engineering Contractor for the \\ U.S. Department of Energy under Contract DE-AC06-87RL10930}




\section{EXECUTIVE SUMMARY}

Permanent isolation surface barriers are being considered for use in the disposal of certain types of waste at the Hanford Site and elsewhere. A technology development program has been designed to address the various technical issues associated with the performance of the barrier systems. All of the tasks that compose this overall barrier development program have been designed to provide crucial information needed to address each of the technical issues.

This document, the Permanent Isolation Surface Barrier Development Plan (Barrier Development Plan), is the baseline planning document for the development of permanent isolation surface barriers on the Hanford Site. The plan identifies, describes, and logically relates the tasks that are required to resolve the technical concerns regarding barriers. The document is intended to provide information regarding technical developments, cost estimates, and scheduled completion dates of barrier development tasks. The plan also provides general direction to and integration of the Hanford Site barrier development effort.

Fifteen groups of tasks have been identified to complete the development of permanent isolation surface barriers. These 15 task groups are as follows:

1. Project management

2. Biointrusion control

3. Water infiltration control

4. Erosion/deposition control 
5. Physical stability testing

6. Human interference control

7. Barrier construction materials procurement

8. Prototype barrier designs and testing

9. Model applications and validation

10. Natural analog studies

11. Long-term climate change effects

12. Interface with regulatory agencies

13. Resource Conservation and Recovery Act of 1976 (RCRA) equivalency

14. Technology integration and transfer

15. Final design.

Individual tasks within the task groups have been identified and are described and logically related to other barrier development tasks in this document. It should be noted that the results of recent technical peer reviews and a Value Engineering workshop (DOE-RL 1993a) have been incorporated into this revision of the Permanent Isolation Surface Barrier Development Plan.

The cost of completing the tasks identified in this plan is estimated to be approximately $\$ 15.8$ million in fiscal year 1994 dollars. Subject to availability of funds, all tasks are scheduled to be completed by the end of fiscal year 1998 . 


\section{ACKNOWLEDGEMENTS}

Members of the Hanford Site Permanent Isolation Surface Barrier Development Program (BDP) (both past and present) have made significant contributions to the preparation of this document. The team spirit and cooperation displayed by these individuals are not only appreciated, but have been demonstrated to be one of the significant strengths of the barrier development work being conducted at the Hanford Site.

The BDP is also appreciative of the support and encouragement for the development of permanent isolation barriers provided by the U.S. Department of Energy's Environmental Restoration (ER) Program and by the technical peers who have reviewed the program. The ER Program has provided significant funding support and the peer reviewers have provided technical reviews and encouragement to continue the development of permanent isolation surface barriers. I also am appreciative of the technical editing support provided by Dixie Crockford. Her suggestions and constructive comments have significantly contributed to this document. 


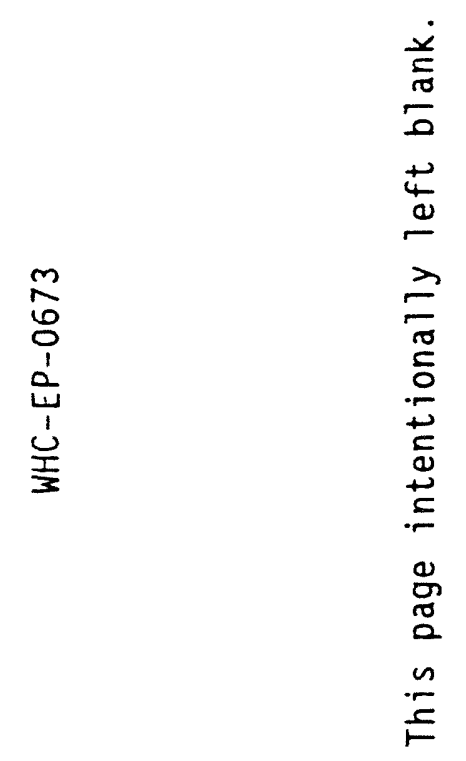

茴

$\stackrel{n}{E}$ 


\section{CONTENTS}

1.0 INTRODUCTION . . . . . . . . . . . . . . . . . . . . . . 1 1.l THE NEED FOR PERMANENT ISOLATION SURFACE BARRIERS . . . . . . . 1

2.0 METHODOLOGY FOR PERMANENT ISOLATION SURFACE

BARRIER DEVELOPMENT . . . . . . . . . . . . . . . . . . . . . . . 7

2.1 ORGANIZATION ....................... 7

2.2 APPROACH . . . . . . . . . . . . . . . . . . . . . . . . 7

2.2.1 Preliminary Performance Objectives . . . . . . . . . . 7

2.2.2 Barrier Development Program Goal . . . . . . . . . 8

2.2.3 Planning . . . . . . . . . . . . . . . . . . . 8

2.2.4 Quality Assurance .. . . . . . . . . . . . . . . . . . 11

2.2.5 Outside Input to this Revision of the Barrier

Development Plan .............. 11

3.0 FUNCTIONAL REQUIREMENTS FOR PERMANENT

ISOLATION SURFACE BARRIERS . . . . . . . . . . . . . . . . . . . 15

4.0 DEVELOPMENT TASK PLANS . . . . . . . . . . . . . . . . . . . . . . . 23

4.1 TASK ORGANIZATION . . . . . . . . . . . . . . . . . . . . . . . 23

4.2 TASK DESCRIPTIONS . . . . . . . . . . . . . . . . . . . . . . 23

4.2.1 Project Management Tasks . . . . . . . . . . . . . . 23

4.2.2 Biointrusion Control Tasks . . . . . . . . . . . . . 25

4.2.3 Water Infiltration Control Tasks . . . . . . . . . . 33

4.2.4 Erosion/Deposition Control Tasks . . . . . . . . . . . 43

4.2.5 Physical Stability Tasks . . . . . . . . . . . . . . . 51

4.2.6 Human Interference Control Tasks . . . . . . . . . . . 54

4.2.7 Barrier Construction Materials Procurement Tasks . . . 58

4.2.8 Prototype Barrier Designs and Testing Tasks . . . . . . 60

4.2.9 Model Applications and Testing Tasks . . . . . . . . . 63

4.2.10 Natural Analog Study Tasks . . . . . . . . . . . . . 66

4.2.11 Long-Term CTimate Change Effects Assessment . . . . . . 73

4.2.12 Interface with Regulatory Agencies . . . . . . . . . . 76

4.2.13 Resource Conservation and Recovery Act Equivalency . . 81

4.2.14 Technology Integration and Transfer. . . . . . . . . 85

4.2.15 Final Design Tasks . . . . . . . . . . . . . . . . . . 89

4.3 INTERRELATIONSHIP AND LOGIC AMONG TASKS . . . . . . . . . . . . . . . 89

5.0 TASK COST SUMMARY . . . . . . . . . . . . . . . . . . . . . . . . . 90

6.0 TASK MASTER SCHEDULE......................... . 95

7.0 PUBLISHED PERMANENT ISOLATION BARRIER DOCUMENTS . . . . . . . . . 103

8.0 DRAWINGS PRODUCED BY THE BARRIER DEVELOPMENT PROGRAM . . . . . . . . . 111

9.0 REFERENCES............................ . 114

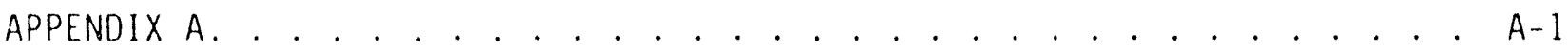




\section{LIST OF FIGURES}

1 Conceptual Permanent Isolation Surface Barrier . . . . . . . . . . 2

2 Cross Section of a Permanent Isolation Surface Barrier . . . . . . 3

3 Barrier Development Tasks... . . . . . . . . . . . . 10

4 Potential Problems of the Current Waste Management Situation . . . 16

5 Functional Performance of Barriers . . . . . . . . . . . . . . . 17

6 The Placement of Surface and Subsurface Markers . . . . . . . . . . 19

7 Typical Permanent Isolation Surface Barrier. . . . . . . . . . . . 20

8 The Field Lysimeter Test Facility . . . . . . . . . . . . . . . . . 36

9 The Small-Tube Lysimeter Facility. . . . . . . . . . . . . . . . 39

10 Admix Gravel Test Plot . . . . . . . . . . . . . . . . 45

11 The PNL Aerosol Wind Tunnel Research Facility . . . . . . . . . . . 47

12 The Use of Computer Simulation Models by

13 Regulatory Interface . . . . . . . . . . . . . . . . . 80

14 Barrier Development Program Master Schedule . . . . . . . . . . . . 94

15a Barrier Development Program Schedule (by Task) . . . . . . . . . . 95

15b Barrier Development Program Schedule (by Task) . . . . . . . . . . 96

15c Barrier Development Program Schedule (by Task) . . . . . . . . . . 97

15d Barrier Development Program Schedule (by Task) . . . . . . . . . . 98

15e Barrier Development Program Schedule (by Task) . . . . . . . . . . 99

\section{LIST OF TABLES}

1 Cost Estimate Summary for Major Task Groups by Fiscal Year . . . . 91

2 Cost Estimate Summary for Major Task Groups by Cost Element . . . . 92 


\section{ACRONYMS AND ABBREVIATIONS}

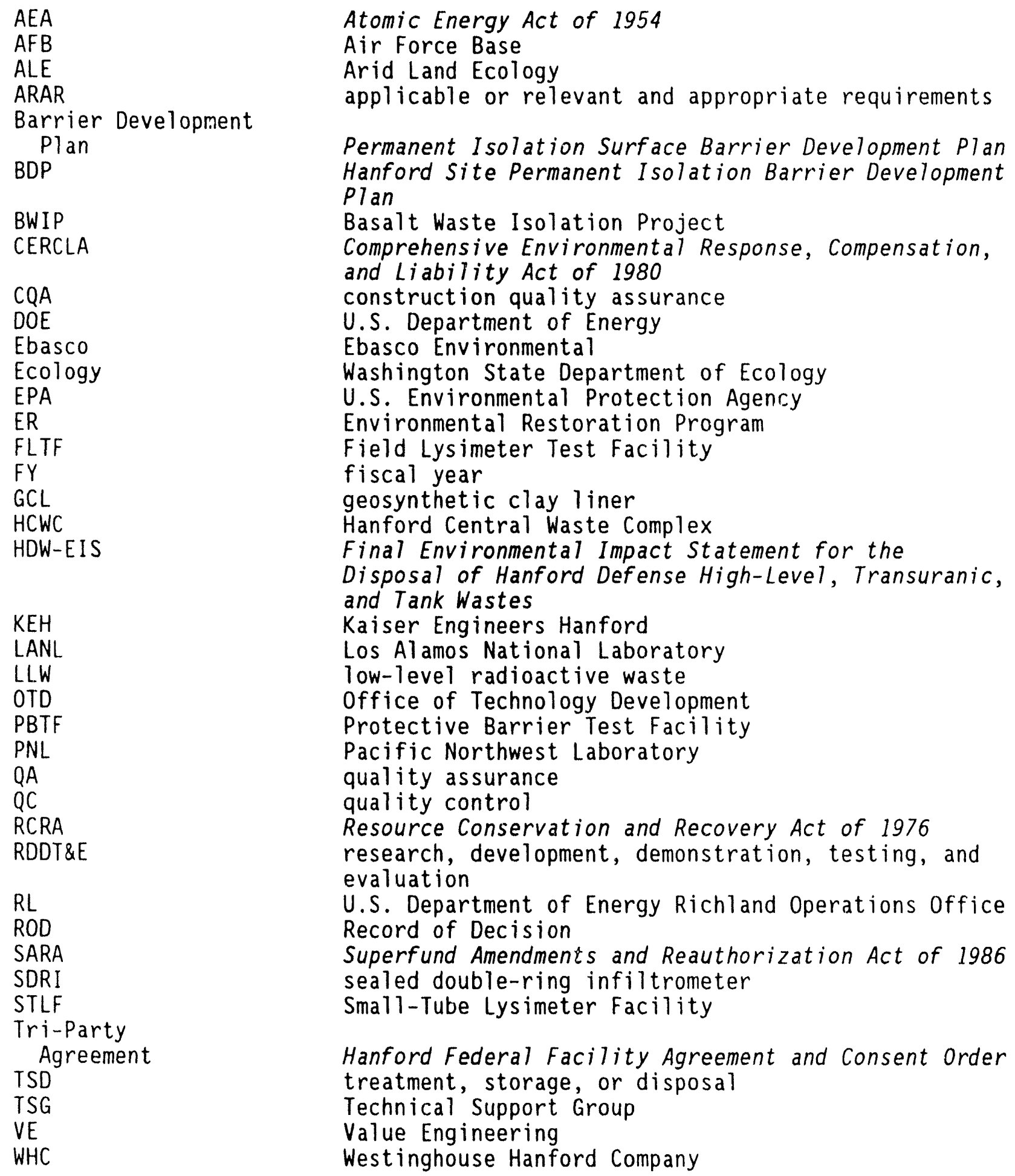




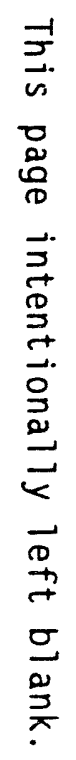

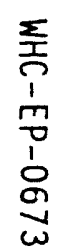


WHC-FP-0673

\section{PERMANENT ISOLATION SURFACE BARRIER DEVELOPMENT PLAN}

\subsection{INTRODUCTION}

The exhumation and treatment of wastes may not always be the preferred alternative in the remediation of a waste site. In-place disposal alternatives, under certain circumstances, may be the most desirable alternatives to use in the protection of human health and the environment. The implementation of an in-place disposal alternative will likely require some type of protective covering that will provide long-term isolation of the wastes from the accessible environment. Even if the wastes are exhumed and treated, a long-term barrier may still be needed to adequately dispose of the treated wastes or any remaining waste residuals. Currently, no "proven" longterm barrier is available. The Hanford Site Permanent Isolation Surface Barrier Development Program (BDP) was organized to develop the technology needed to provide a long-term surface barrier capability for the Hanford Site. The permanent isolation barrier technology also could be used at other sites.

Permanent isolation barriers use engineered layers of natural materials to create an integrated structure with redundant protective features. Drawings of conceptual permanent isolation surface barriers are shown in Figure 1 and Figure 2. The natural construction materials (e.g., fine soil, sand, gravel, riprap, asphalt) have been selected to optimize barrier performance and longevity. The objective of current designs is to use natural materials to develop a maintenance-free permanent isolation surface barrier that isolates wastes for a minimum of 1,000 years by 1 imiting water drainage to near-zero amounts; reducing the likelihood of plant, animal, and human intrusion; controlling the exha?ation of noxious gases; and minimizing erosion-related problems.

\subsection{THE NEED FOR PERMANENT ISOLATION SURFACE BARRIERS}

Permanent isolation surface barriers were identified in the Hanford Waste Management Plan (DOE-RL 1987) and the Final Environmental Impact Statement for the Disposal of Hanford Defense High-Level, Transuranic, and Tank Wastes (HDW-EIS) (DOE-RL 1988) as integral components in the final disposal schemes for near-surface disposal of the following wastes:

- Single-shell tank wastes

- Transuranic-contaminated soil sites

- Pre-1970 buried suspect transuranic-contaminated solid wastes

- Grouted low-activity and low-level wastes from double-shell tanks.

In addition to the waste types identified above, other forms of waste may require permanent isolation surface barriers. These other forms of waste include decommissioned facilities, low-level waste sites, and hazardous waste sites. In addition, permanent isolation barriers have been identified as an integral component of the large-scale remediation approach to cleaning up the Hanford Site.

Existing short-term barrier designs currently are available (U.S. Environmental Protection Agency [EPA] 1982, 1990). In general, the 


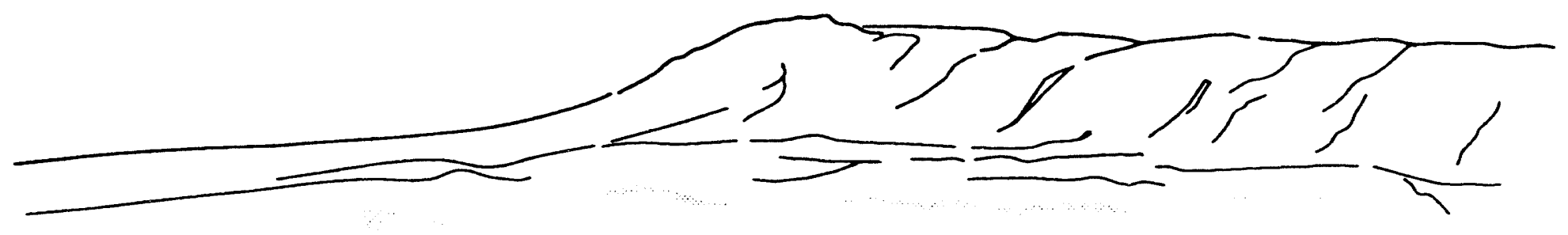




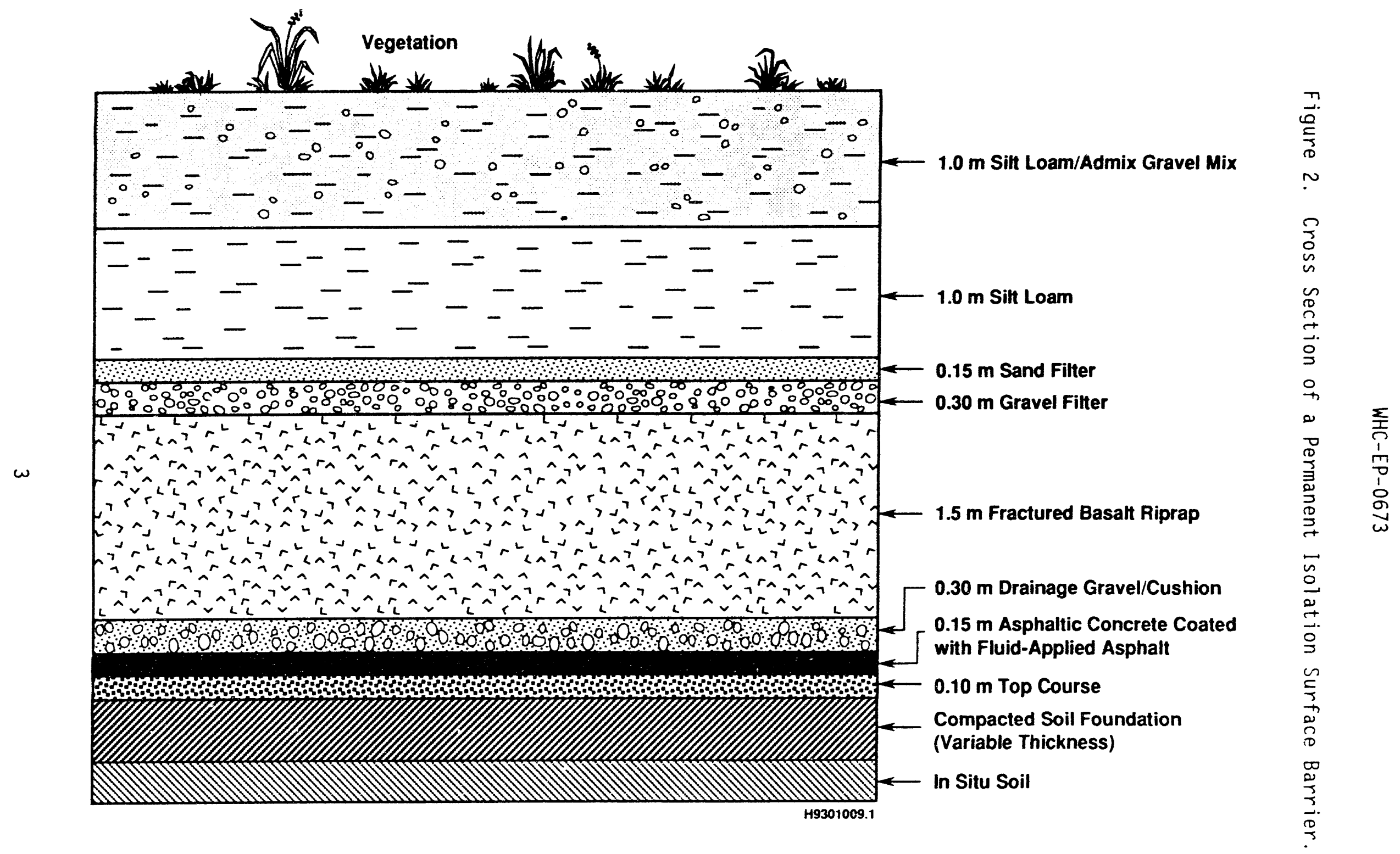


design life of these covers is for relatively short periods--such as the 30-year post-closure period specified by the Resource Conservation and Recovery Act of 1976 (RCRA). The performance of barriers during this relatively short period can be monitored, and maintenance activities can be performed to correct any problems that might be encountered. However, for some waste management situations, it is desirable to isolate wastes for much longer periods than the 30-year post-closure period (i.e., hundreds to a thousand years or more). For these waste management situations, the relatively short-term (RCRA) designs might not be satisfactory. For example, many synthetic construction materials that might be effective for decades (e.g., geosynthetics) cannot be relied on to perform satisfactorily (or even exist) more than 1,000 years. Consequently, a long-term, permanent isolation barrier is necessary. The objective of work being conducted by the BDP is to develop and assess the performance of various permanent isolation surface barrier designs.

The development, testing, and evaluation of permanent isolation barriers is critical to support the Hanford Site mission of environmental restoration. Currently, no "proven" long-term barrier is available. The development of permanent isoiation surface barriers is necessary to meet three key long-term Hanford Federal Facility Agreement and Consent Order (Tri-Party Agreement) milestones (EPA et al. 1989). A barrier (final cover) is needed to support specific milestones: Milestonc M-45-00, Initiate Full-Scale Tank Farm Closure Demonstration Project, by June 2004; Milestone M-09-01, Complete Preparation of Supplemental EIS by June 2002; and Milestone M-09-00, Complete Closure of All 149 Single-Shell Tanks, by June 2018.

The development of protective barriers is consistent with the HDW-EIS. The U.S. Department of Energy's (DOE) Record of Decision (ROD) for the HDW-EIS was issued on April 8, 1988 (U.S. Federal Register 1988). In the ROD, DOE stated that the decision on how certain types of waste are to be disposed of was being deferred until additional development and evaluation activities had been conducted. One of these development and evaluation activities identified in the ROD is the demonstration of barrier performance by "instrumented field tests and modeling."

In addition, a barrier probably will be needed to support future Comprehensive Environmental Response, Compensation, and Liability Act of 1980 (CERCLA) and RCRA actions to protect human health and the environment. For example, in the Low-Level Burial Grounds Dangerous Waste Permit Application (DOE-RL 1989), the following statement is made.

If the radiological performance assessment indicates that the RCRAcompliant covers proposed in this permit application do not meet long-term DOE-RL [U.S. Department of Energy Richland Operations Office] objectives, an enhanced cover design will be developed and proposed in an amended closure plan. The DOE-sponsored research for the development of enhanced cover designs for the Hanford Site is in progress...

In this statement, the DOE-sponsored research program referred to is the BDP. 


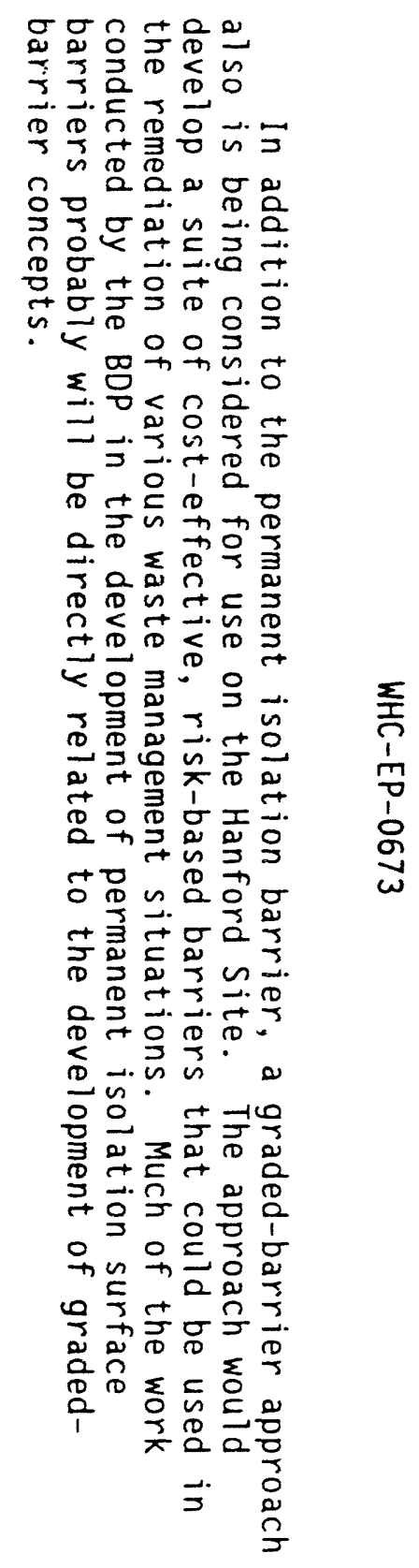




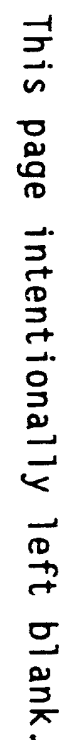

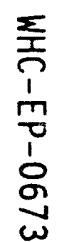




\subsection{METHODOLOGY FOR PERMANENT ISOLATION SURFACE BARRIER DEVELOPMENT}

\subsection{ORGANIZATION}

The Operations and Engineering Contractor for the DOE Hanford Site (Westinghouse Hanford Company [WHC]) and the DOE Research and Development Contractor for the Hanford Site (Pacific Northwest Laboratory [PNL]) are jointly developing and testing permanent isolation surface barriers.

A multiyear program (i.e., the BDP) has been organized to develop, test, and evaluate various barrier designs. A team of engineers and scientists from WHC and PNL are directing the performance of tests and experiments to design and assess the effectiveness of permanent isolation surface barriers. The Hanford Site's Architect/Engineering Contractor, Kaiser Engineers Hanford (KEH), has played an important role in providing design support for barrier-related projects. Most recently, KEH developed the definitive design drawings and construction specifications for a prototype barrier scheduled to be constructed in late fiscal year (FY) 1993 to early FY 1994.

In addition to the work being performed by Hanford Site contractors, outside contractors, universities, and consultants are used by the BDP to perform specific tasks and to provide independent technical peer reviews. The $\mathrm{BDP}$ is also maintaining close contact and collaborating with scientists and engineers at other DOE operations offices as well as with colleagues around the world.

\subsection{APPROACH}

As discussed previously, permanent isolation surface barriers have been identified as an integral component in the final disposal of certain types of waste at the Hanford Site. The approach being taken to develop, test, and verify the performance of protective barriers is described in the following subsections.

\subsubsection{Preliminary Performance Objectives}

To aid in the development of protective barriers, a preliminary set of performance objectives for the barriers has been defined. These objectives are intended to be broad enough to encompass the various regulatory requirements for the types of wastes anticipated to be disposed of using barriers at the Hanford Site (and elsewhere). The following summarizes the preliminary performance objectives established for the development of permanent isolation barriers:

- Function in a semiarid to subhumid climate

- Limit the recharge of water through the waste to the water table to near-zero amounts $\left(0.05 \mathrm{~cm}\right.$ of water per year $\left[1.6 \times 10^{-9} \mathrm{~cm} / \mathrm{s}\right]$ was the design objective selected, based on preliminary performance assessments that supported the preparation of the HDW-EIS) (DOE-RL 1988) 
WHC-EP-0673

- Be maintenance free

- Minimize the likelihood of plant, animal, and human intrusion

- Limit the exhalation of noxious gases

- Minimize erosion-related problems

- Meet or exceed RCRA cover performance requirements

- Isolate wastes for a minimum of 1,000 years

- Be regulatorily and publicly acceptable.

\subsubsection{Barrier Development Program Goal}

The objectives previously noted have provided the basis for formulating a barrier development program and for evaluating the adequacy of various barrier designs. These objectives also have been used in the preparacion of a statement (provided below) that summarizes the goals of the BDP.

The BDP goal is to provide defensible evidence that final barrier design(s) will control water infiltration, plant and animal intrusion, anc wind and water erosion for a minimum of 1,000 years; and will protect human health and the environment in accordance with applicable or relevant and appropriate requirements. Warning marker system conceptual designs will be provided to inform inadvertent human intruders in case institutional control is lost.

Evidence of barrier performance will be obtained by conducting laboratory experiments, field tests, computer modeling, and other studies that establish confidence in the barrier's ability to meet its $1,000+$ year design 1 ife. The stability and performance of natural analogs that have existed millennia and the reconstruction of climate changes during the past 10,000+ years will establish bounding conditions of possible future changes and will serve to focus experimental designs and increase confidence in the barrier's ability to meet its design life.

\subsubsection{Planning}

This document, the Permanent Isolation Surface Barrier Development Plan (Barrier Development Plan), is the baseline planning document for the development of permanent isolation surface barriers on the Hanford Site. The objectives of the Barrier Development Plan are as follows:

- To provide general direction to and integration of the Hanford Site permanent isolation surface barrier development effort

- To identify, describe, and logically relate the tasks that are required to resolve the technical concerns regarding the design and performance of permanent isolation surface barriers

- To provide a status report of technical progress made 
WHC-EP-0673

- To provide estimates of staffing, materials, and cost that can be used in budget preparation

- To provide a schedule for barrier development activities.

This plan emphasizes the development of barriers for abovegrade (mounded barrier) application to existing waste sites. However, barrier development tasks described herein also are relevant and applicable to at-grade or belowgrade barriers at new waste disposal sites.

Fifteen groups of tasks have been identified in the Barrier Development Plan to resolve the technical concerns and complete the development and design of protective barriers. These task groups are the following:

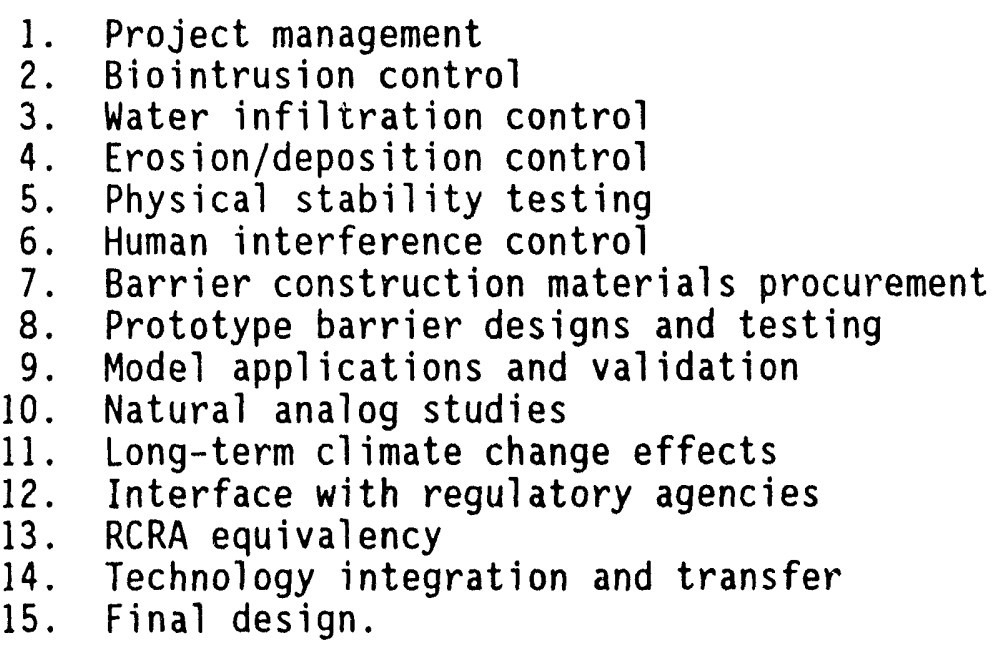

The project management task group has a pervasive influence in the BDP by integrating, coordinating, and providing direction to each of the other 14 task groups. Figure 3 illustrates how the information and data generated within each of the task groups (with the exception of the project management task group) are input into the final design(s) of the permanent isolation surface barrier. Specific test plans and other detailed documents have been or are being prepared to plan, schedule, execute, and report on each of the technology development activities within these task groups. The results of tasks performed are documented and used (1) as input to other tasks whose activities are dependent upon the results, (2) to improve computer simulation models, and (3) to develop detailed, final barrier designs. Appendix $A$ contains a list of BDP documents that have been published to date.

When all of the barrier development tasks are completed, detailed designs of permanent isolation surface barriers will be prepared. By this time, computer simulation models will have been validated by field data and the detailed barrier designs will be subjected to confirmatory testing. The results of field and laboratory tests as well as results of validated computer simulation models will be used to document the performance of the protective barriers. Detailed barrier designs that meet the performance objectives are considered final designs and are ready for construction. Those detailed designs that do not meet the performance objectives either will be modified such that the performance objectives can be met or will be discontinued. 


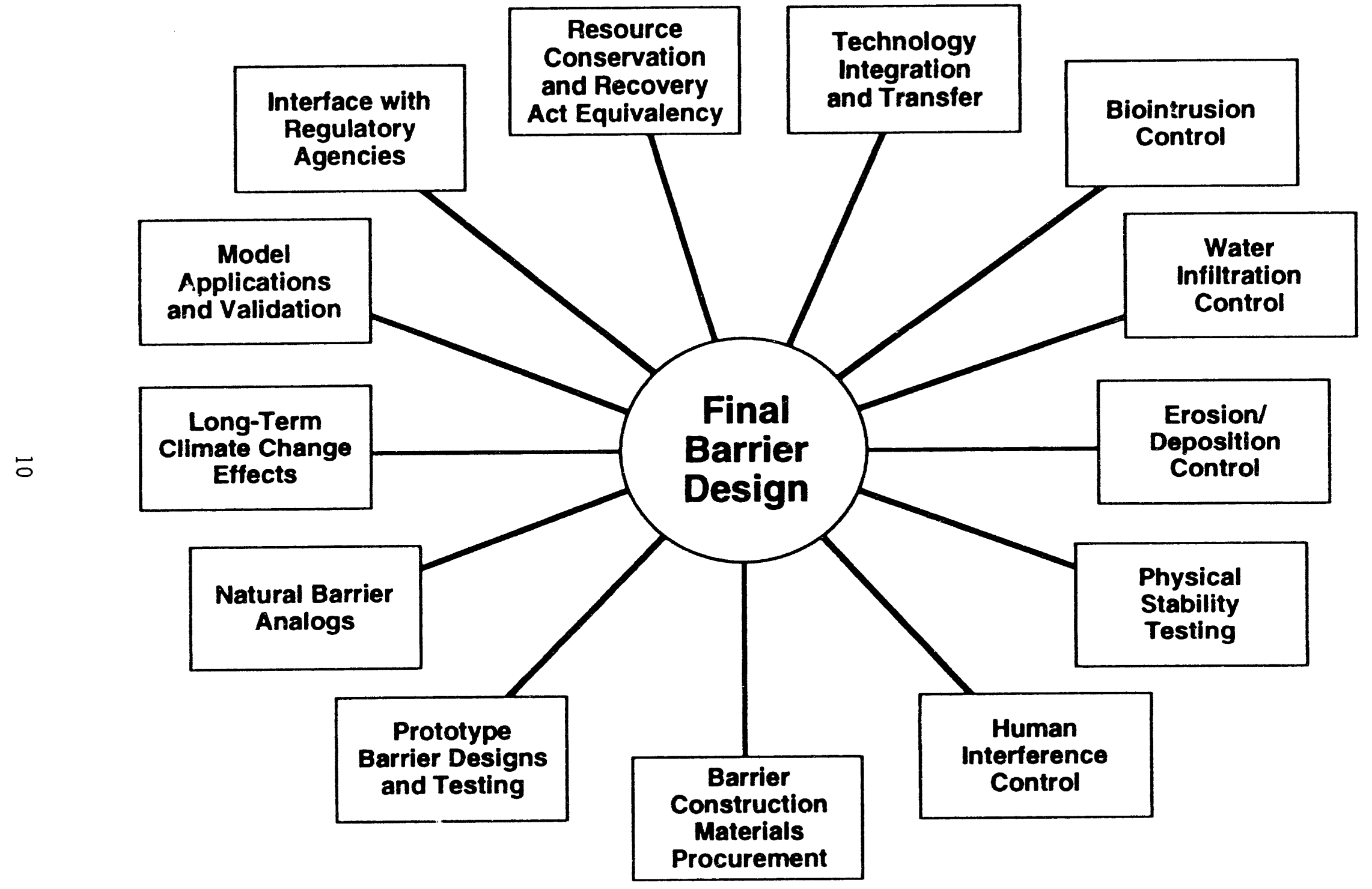


WHC-EP-0673

\subsubsection{Quality Assurance}

All of the permanent isolation surface barrier development tasks shall be performed in a manner that complies with applicable quality assurance (QA) program requirements. Specific quality requirements will be developed for each task as required. These QA requirements shall be applicable to all barrier development activities, regardless of whether the activities are performed by the Hanford Operating and Engineering Contractor; Research and Development Contractor; Architect/Engineering Contractor; or outside contractors.

Throughout the development of permanent isolation surface barriers, various types of scientific and engineering documentation will be generated. This documentation will consist of experimenta? plans, test plans, reports test equipment calibration records, field log books, supporting documents, barrier design standards, design guides, specifications, files, presentations, graphics, and bibliographies. This documentation will be prepared, reviewed, and placed in archives according to approved QA procedures.

Throughout the life of the BDP, periodic expert technical peer reviews will be held. These peer reviews are intended to provide an independent assessment of the BDP. Peer reviewers may be asked to assess the scope of, need for, and results of tasks being conducted or planned as part of the BDP. In addition, the peer reviewers may be asked to review, assess, and comment on specific aspects of the overall BDP (e.g., the prototype barrier).

\subsubsection{Outside Input to this Revision of the Barrier Development Plan}

The results of recent expert technical peer reviews and a Value Engineering (VE) workshop have been incorporated into this revision of the Barrier Development Plan. This outside input has proven to be valuable in focusing the BDP on the specific activities that will be needed to bring the BDP to closure while maintaining technical defensibility and providing for regulatory agency input. Descriptions of the expert technical peer reviews and VE workshop are provided in the following subsections.

\subsubsection{Expert Technical Peer Review. A panel of technical experts was} organized during FY 1992 to peer review the BDP and to provide a specific review of a preconceptual prototype barrier design initiated during FY 1990. The technical peer review of the BDP and the prototype was conducted in three phases.

A contract was established with Ebasco Environmental (Ebasco) to assemble an independent peer review panel made up of individuais with expertise in various barrier-related disciplines. The peer review panel assembled by Ebasco comprised the following individuals. The general areas of technical expertise and the company to which each of the panel members was affiliated a) so is noted. 
WHC-EP-0673

\section{Barrier Design/Construction/Monitoring}

Dr. David E. Daniel

Dr. Gregory N. Richardson

Hydrogeology/Modeling

Or. Lorne G. Everett

Plants/Biointrusion/Erosion

Dr. Charles C. Reith

Climate/Natural Analogs

Dr. W. Geoffrey Spaulding
University of Texas at Austin

Hazen and Sawyer

Metcalf and Eddy Consultants, Inc.

Jacobs Engineering

Dames and Moore

These individuals were considered to have backgrounds broad enough to suitably address the technical diversity of the BDP, yet focused enough to provide a meaningful review as well.

As noted, the peer review of the BDP and prototype barrier was conducted in three phases. The first phase of the peer review process was conducted March 9 to 11, 1992. The objectives of the first phase of the peer review process were twofold: (1) to assess the scope of, need for, and results of tasks being conducted or planned as part of the BDP, and (2) to evaluate the most recent prototype barrier design. The first objective was aimed primarily at obtaining an independent assessment regarding the scope of and need for performing the various barrier development tasks that have been identified by the barrier development team. In the second objective, the experts were to review, assess, and comment on the preconceptual prototype design initiated during FY 1990.

After the conclusion of the first phase of the peer review process, the experts were requested to provide a written report containing their comments on and recommendations for the overall BDP and the prototype barrier. The peer review panel's findings and observations on the first phase of the peer review process have been documented in their entirety in a detailed report (Wing 1992). The report represents a consensus position of the peer review panel regarding each major issue of concern. Although a consensus position was required, panel members also were encouraged to provide relatively focused recommendations based on their specific areas of technical expertise.

The peer reviewers were generally supportive of the BDP. Several recommendations for improving the prototype design were suggested. In addition, the peer reviewers strongly recommended enhanced interactions between the barrier development team and the appropriate regulatory agencies. These enhanced interactions would increase the probability of regulatory acceptance of permanent isolation barriers when the technology development effort has been completed and the technology has matured to the point that it is ready for implementation in actual waste site remediation activities.

Following the receipt of the panel's comments and recommendations from the first phase of the peer review process, the barrier development team began 
an aggressive effort to modify (as appropriate) the prototype barrier design. This effort was conducted over approximately a 3-month period. On June 22 to 23, 1992, the peer review panel was again brought to the Hanford Site to review the progress made. Presentations were given on the latest revision of the prototype barrier design with its corresponding schedule. In addition, the status of the prototype barrier testing and monitoring plan was also presented.

The peer reviewer panel was pleased with the progress made since the first phase of the review process. Only relatively minor modifications to the prototype design were recommended. These comments and recommendations were summarized in succinct statements and are included in their entirety in Wing (1992).

The peer review panel provided one more review of the definitive design drawings and construction specifications during the first part of september 1992. Comments were incorporated as appropriate.

2.2.5.2 Value Engineering Workshop. A VE workshop for the BDP was convened during the week of February 8 to 12, 1993. All of the BDP's stakeholders (technologists, end users, regulators) were invited to participate in the workshop. The primary objective of the workshop was to provide an assessment of the scope of, need for, and results of tasks being conducted or planned as part of the barrier program. This objective was selected as the primary focus of the VE workshop for the following reasons.

- Most of the BDP tasks were at various stages of completion and a "rebaselining" of these tasks was needed, especially after the expert peer reviews mentioned previously.

- Resources to conduct barrier development tasks were limited.

- Multiple organizations and end users expressed and continue to express a need for a permanent isolation surface barrier. Different types of barrier designs may be needed to satisfy the different technical and programmatic design requirements of the various organizations and end users.

- Regulatory agencies have assumed much of the responsibility for ensuring the public of the technical adequacy of technologies being developed for use in the remediation of actual wastes sites.

The VE workshop enabled input to be received from each of the BDP's various stakeholders regarding the scope of and need for performing the various barrier development tasks that have been identified by the barrier development team. A technical expert, Dr. David E. Daniel from the University of Texas at Austin, was contracted to serve as an independent technical peer reviewer and someone familiar with national barrier needs. Dr. Daniel provided a national perspective on the state of the art in barrier technology development. In addition to this national perspective, Dr. Daniel provided an outside independent assessment regarding the scope of, need for, and priority for performing the various barrier development tasks that were identified by Hanford Site's barrier development team. Another industry expert, Dr. R. David Bennett of the U.S. Army Corps of Engineers, Waterways Experiment 
Station, participated in the VE workshop. Dr. Bennett's comments were insightful and his participation in the workshop contributed significantly.

The primary objective of the VE workshop was satisfied successfully. One of the most significant accomplishments of the workshop included the "buy in" by all stakeholders on the approach agreed to for bringing the Hanford Site barrier development effort to completion. This approach is documented in a draft report on the proceedings of the VE workshop prepared by the U.S. Army Corps of Engineers, Kansas City District, who served as the facilitators for the workshop (DOE-RL 1993).

The results of the expert technical peer reviews and VE workshop have provided significant input to and helped to focus the BDP. The objective of this revision of the Barrier Development $\mathrm{Plan}$ is to capiure the technical and programmatic recommendations made by outside technical experts and stakeholders. The resulting comprehensive, yet streamlined plan will direct the Hanford Site's barrier development effort to a successful closure.

Throughout this revision of the Barrier Development Plan, the status of various tasks is updated. Where appropriate, a discussion is provided of how a particular task has been affected by the results of the technical peer reviews and VE workshop. In the future, as other barrier-related peer reviews, workshops, and conferences (both national and international) are convened, programmatic changes will be incorporated, as appropriate, into the barrier development effort being conducted at the Hanford Site. 
WHC-EP-0673

\subsection{FUNCTIONAL REQUIREMENTS FOR PERMANENT ISOLATION SURFACE BARRIERS}

As discussed previously, certain types of waste at the Hanford Site (and elsewhere) may be disposed of using in-place stabilization techniques. Much of the waste that would be disposed of by in-place stabilization currently is located in relatively shallow subsurface structures such as solid waste burial grounds, tanks, vaults, and cribs. Unless protected in some way, the wastes could be transported to the accessible environment via the following pathways (Figure 4).

- Water infiltration--The infiltration and percolation of water through the waste zone resulting in the leaching and subsequent transport of mobile radionuclides and other contaminants to the water table.

- Biointrusion--The penetration of deep-rooting plants and burrowing animals into the waste zone below. The deep-rooting plants could draw radionuclides and other contaminants into their root systems and subsequently translocate the contaminants to the abovegrade portion of the plant. The contaminants in the abovegrade portion of the plant then could be dispersed by animals that eat the plants or by wind. Animals burrowing directly into the waste zone could contact contaminants and subsequentiy bring them to the earth's surface as part of the soil castings. Erodible loose soil brought to the surface by burrowing animals could contribute to accelerated erosion of the fine-soil surface layer. In addition, the presence of animal burrows may provide preferential pathways for infiltrating water to gain access to the waste zone.

- Wind and water erosion--The removal of the surface soils at a waste site as a result of erosive forces. Erosion-related problems could provide a direct pathway for contaminant transport if the erosive forces are strong enough to remove the surface soils and expose the buried wastes to the accessible environment. A more probable scenario is for wind and water erosion to reduce the thickness of soils overlying a waste zone so that another transport pathway (i.e., water infiltration) becomes a more serious concern.

- Human interference--The inadvertent or intentional intrusion of humans into the waste sites (assuming institutional control is lost) and subsequent dispersion of contaminants. A basic assumption is that the barrier will not be required to be designed to deter the intentional human intruder.

- Gaseous release--The diffusion of noxious gases from the waste zone to the accessible environment. Permanent isolation surface barriers have been proposed to protect wastes disposed of "in place" from the transport pathways identified previously (Figure 5). The protective barrier consists of a variety of different materials (e.g., fine soil, sand, gravel, riprap, asphalt, etc.) placed in layers to form an abovegrade mound directly over the waste zone. Surface markers 


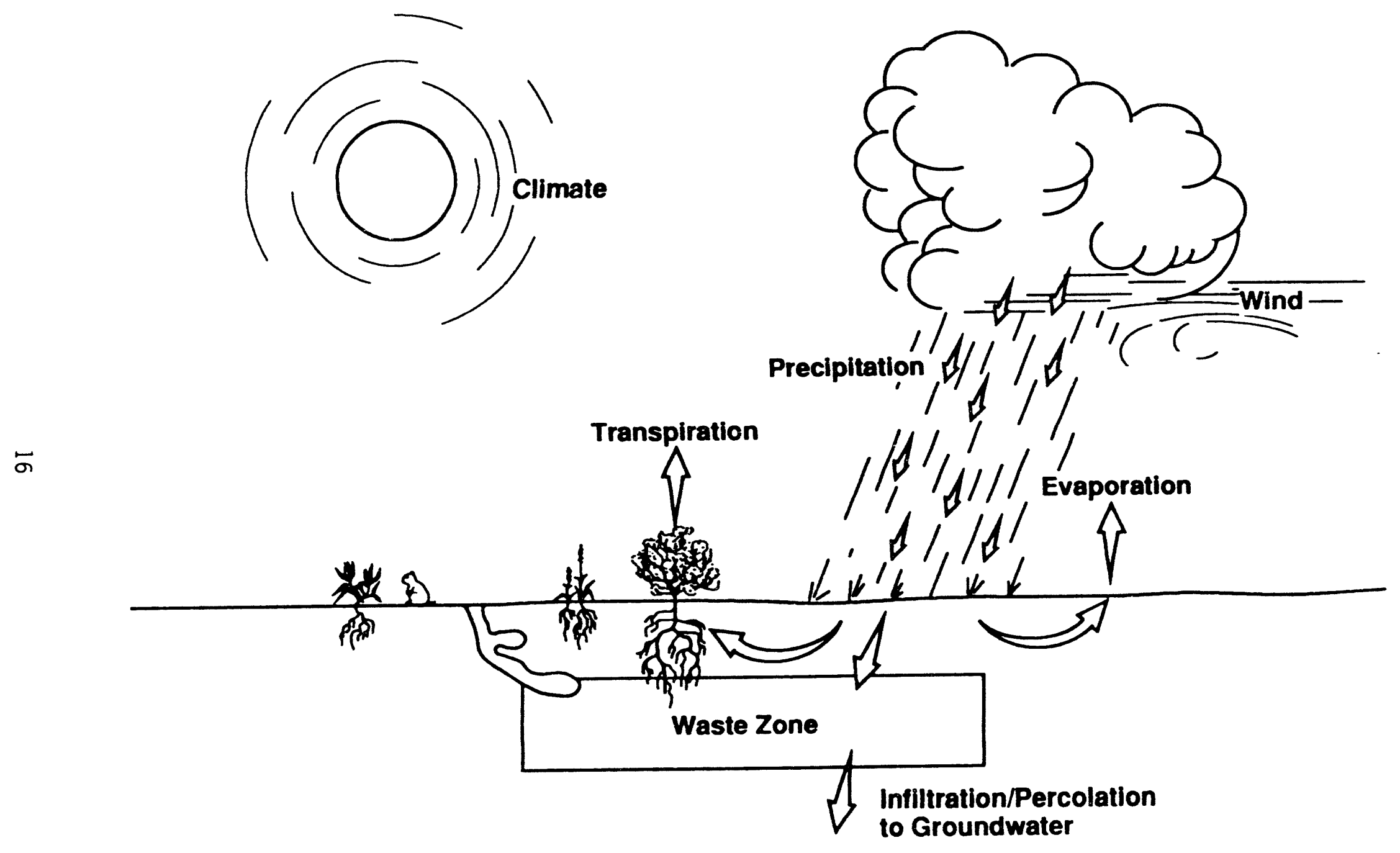

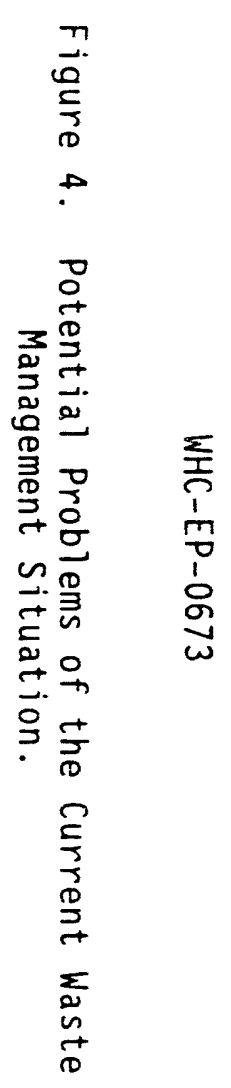




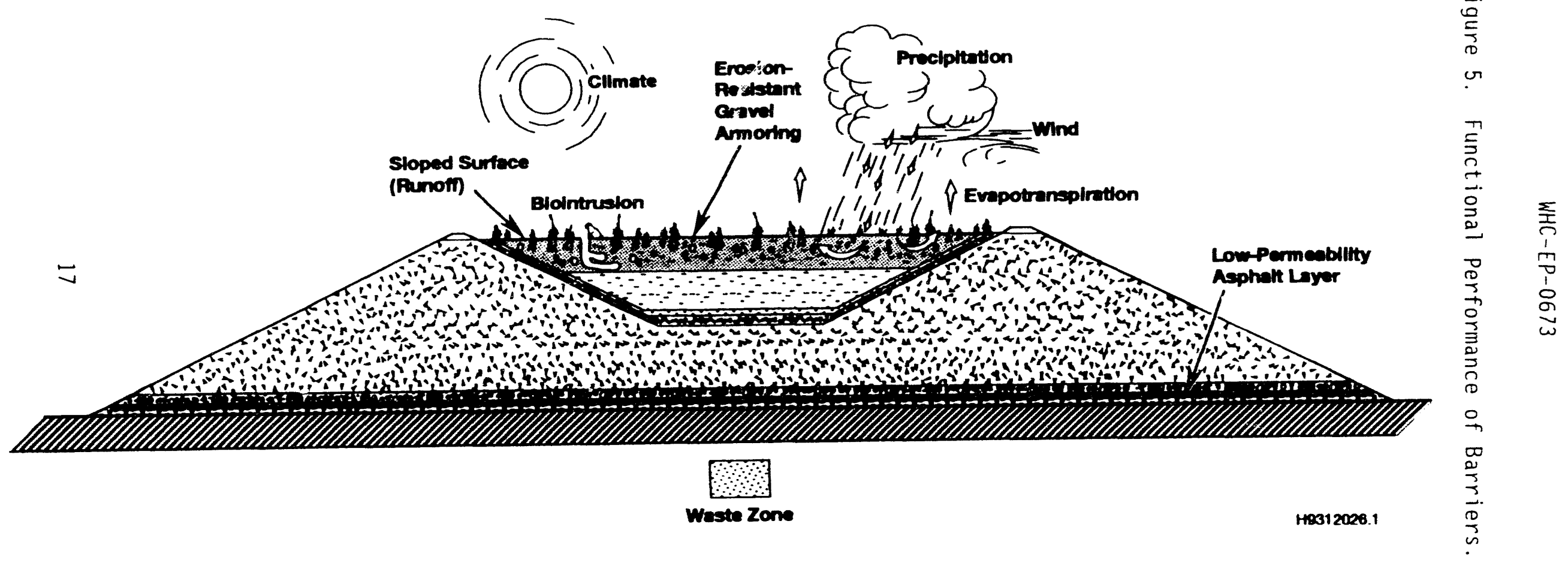


are being considered for placement around the periphery of the waste sites to inform future generations of the nature and hazards of the buried wastes. In addition, throughout the protective barrier, subsurface markers could be placed to warn any inadvertent human intruders of the dangers of the buried wastes (Figure 6).

The protective barrier design consists of a fine-soil layer overlying other layers of coarser materials such as sands, gravels, and basalt riprap (Figure 7). Each of these layers serves a distinct purpose. The fine-soil layer acts as a medium in which moisture is stored until the processes of evaporation and transpiration recycle any excess water back to the atmosphere. The fine-soil layer also provides the medium for establishing plants that are necessary for transpiration to take place. The coarser materials placed directly below the fine-soil layer create a capillary break that inhibits the downward percolation of water through the barrier. The placement of the silt loam directly over the underlying coarser materials also creates an environment that encourages planis and animals to limit their natural biological activities to the upper, fine-soil portion of the barrier, thereby reducing biointrusion to the lower layers. The coarser materials also will help to deter inadvertent human intruders from digging deeper into the barrier profile. Low-permeability layers, placed in the barrier profile below the capillary break, also will be used in the protective barriers. The purpose of the low-permeability layers is (1) to divert away from the waste zone any percolating water that gets through the capillary break and (2) to limit the upward movement of noxious gases from the waste zone. The coarse materials located above the low-permeability layers also serve as a drainage medium to channel any percolating water to the edges of the barrier.

As discussed previously, the following preliminary performance objectives have been established for permanent isolation surface barriers:

- Function in a semiarid-to-subhumid climate

- Limit the recharge of water through the waste to the water table to near-zero amounts $(0.05 \mathrm{~cm} / \mathrm{yr}$, which is equivalent to $1.6 \times 10^{-9} \mathrm{~cm} / \mathrm{s}$ )

- Be maintenance free

- Minimize the likelihood of plant, animal, and human intrusion

- Isolate waste for a minimum of 1,000 years

- Minimize erosion-related problems

- Meet or exceed RCRA cover performance requirements

- Limit the exhalation of noxious gases

- Be regulatorily and publicly acceptable.

Because of the need for the barrier to perform for at least 1,000 years without maintenance, natural construction materials (e.g., fine soil, sand, gravel, cobble, crushed basalt riprap, asphalt, etc.) have been selected to 
Figure 6 . The Placement of Surface and Subsurface Markers.
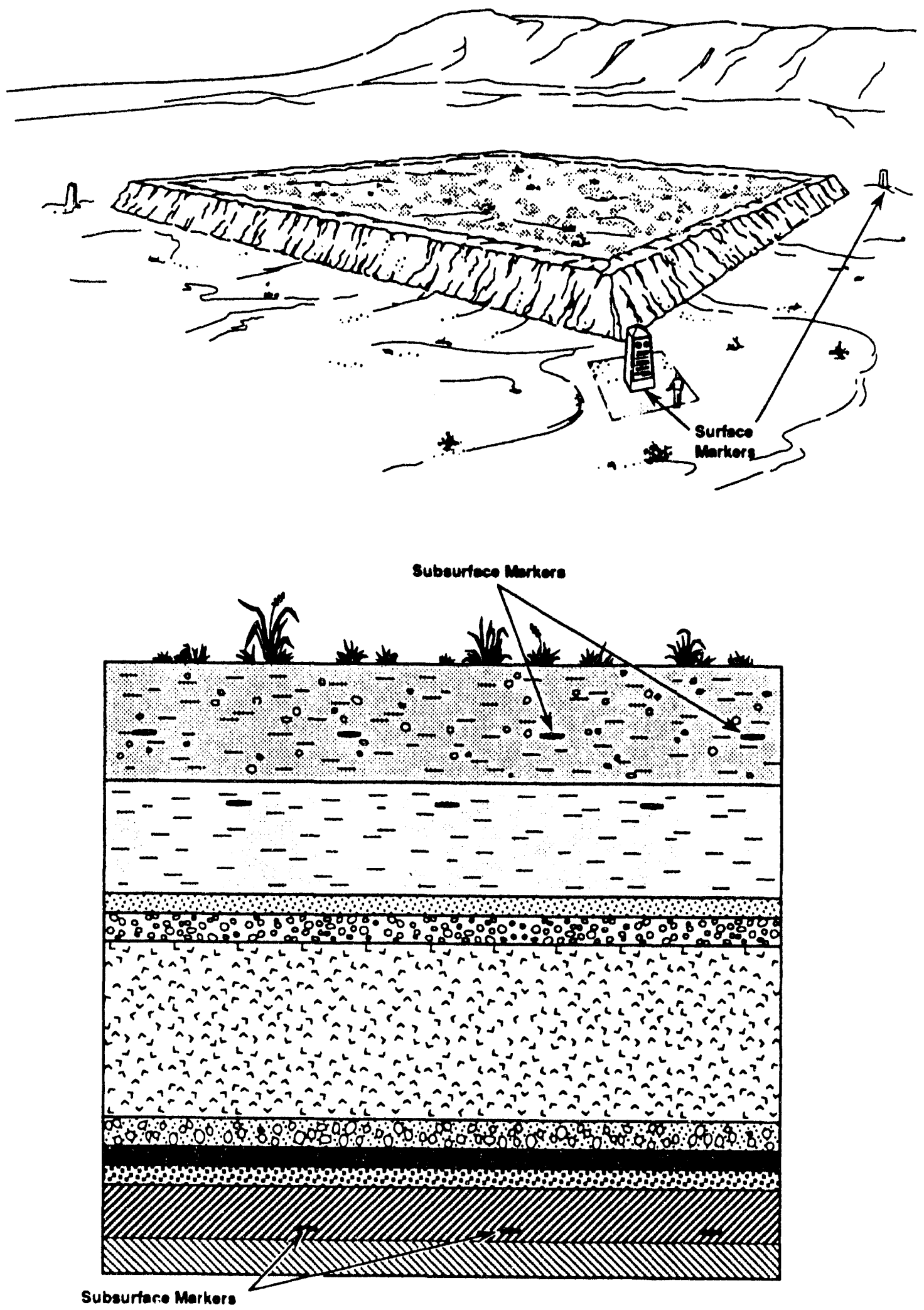

Hesc4018.1 


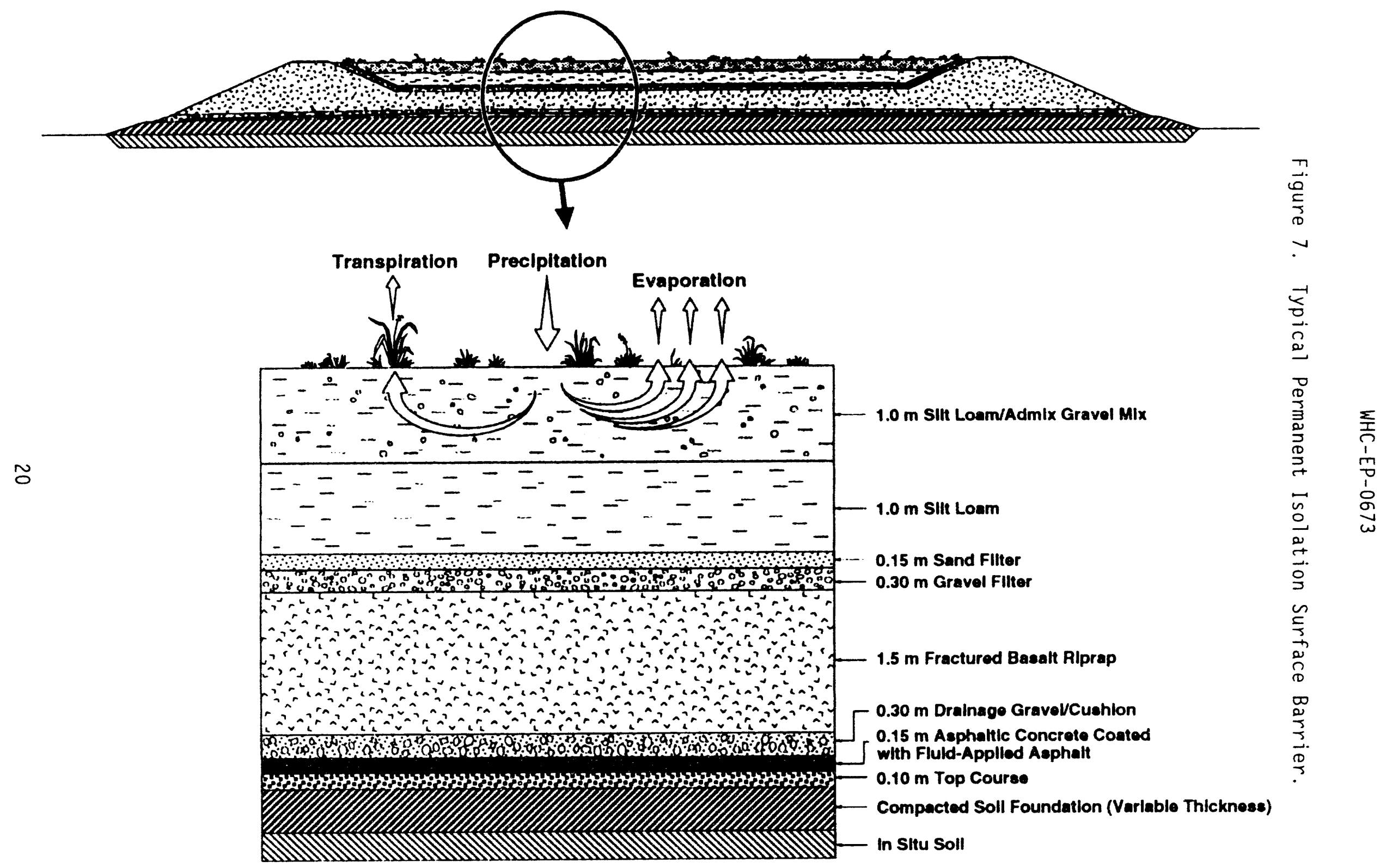


optimize barrier performance and longevity. Most of these natural construction materials are available in large quantities on the Hanford Site and are known to have existed in place for thousands of years or longer (e.g., basalt). In contrast to the natural construction materials, the ability of synthetic construction materials to survive and function properly for at least 1,000 years is not known. Because of this uncertainty, synthetic construction materials are not relied on in current designs to perform satisfactorily (or even exist) through centuries or millennia.

The need for a maintenance-free barrier that lasts for a minimum of 1,000 years necessitates the use of passive systems for achieving the preliminary performance objectives. Active systems are impractical because they require human involvement to operate, monitor, and maintain. For example, the use of an active leachate collection and removal system requires monitoring the collection of leachate and removing it from the collection system via a sump pump or similar device. The various components of the leachate collection and removal system would need to be maintained periodically as well. This level of human activity over extremely long periods of time is impractical and would mean passing on this generation's legacy of waste to future generations--an undesirable option.

The permanent isolation barrier is intended to remain functional throughout its design 1 ife with minimum or no human intervention.

Consequently, in designing a permanent isolation barrier, it is important to understand the natural processes that are expected to act on the barrier during its design life. An understanding of how the natural processes affect barrier performance enables a design to be developed that passively meets performance objectives. 
WHC-EP-0673

This page intentionally left blank. 
WHC-EP-0673

\subsection{DEVELOPMENT TASK PLANS}

\subsection{TASK ORGANIZATION}

Fifteen groups of tasks have been identified to complete the development of permanent isolation surface barriers. Individual tasks within a task group are designated by an identification code. This identification code consists of an acronym for the task group title and a corresponding number for the particular task within the task group. The 15 groups of tasks are as follows:

- Project management (MGT)

- Biointrusion control (BIO)

- Water infiltration control (WTR)

- Erosion/deposition control (EROD)

- Physical stability testing (PHYS)

- Human interference control (HUM)

- Barrier construction materials procurement (MATLS)

- Prototype barrier designs and testing (BAR)

- Model applications and validation (MOD)

- Natural analog studies (NAT)

- Long-term climate change effects (CLIM)

- Interface with regulatory agencies (REG)

- RCRA equivalency (RCRA)

- Technology integration and transfer (TECH)

- Final design (DES).

\subsection{TASK DESCRIPTIONS}

Each of these task groups will be described in terms of objective and content. Tasks and activities within each task group will be identified and described. The status of the tasks and activities also will be provided.

\subsubsection{Project Management Tasks}

The project management of the BDP is an important and complex task. This task comprises three major activities: (1) project coordination, (2) project financial management, and (3) preparation of project management documentation. Each of these three interrelated activities is described in the following subsections.

4.2.1.1 Project Coordination (MGT-1). The BDP is a relatively large program that involves numerous individuals. Because of the complexity of designing permanent isolation surface barriers, many different disciplines are required to address the technical concerns related to the use of barriers in the disposal of various types of waste at the Hanford Site. The coordination of these various disciplines is essential in maintaining an integrated, logical program.

In addition to the coordination of the various technical disciplines, the BDP must maintain close coordination with many other groups and individuals located on the Hanford Site as well as offsite. These groups and individuals 
WHC - EP-0673

include line and program management; $Q A$ personnel; end users of barrier technology; regulatory agencies (see Section 4.2.12); and others who are in a position to influence the fate of the barrier program. By maintaining close coordination with these groups and individuals, the BDP will be better able to meet the needs of its "customers" while at the same time keeping other interested parties informed.

The results of many of the tasks and activities being conducted in the BDP are used as input by other tasks and activities that need the data. Some of the "successor tasks" logically should not be initiated until the "predecessor tasks" have been entirely completed. Because some of the predecessor tasks require several years to complete, some of the "successor tasks" may not be able to be initiated until several years of the BDP have elapsed. Because only a finite amount of time has been allotted for the development of permanent isolation surface barriers, the need to have all of the tasks logically related is critical.

Several specific project coordination tasks and activities that are conducted from year to year are as follows:

- Providing technical guidance and overall direction to the BDP

- Integrating all of the barrier development tasks into a coordinated, logically related program

- Planning and convening periodic workshops that assemble barrier development team members to plan and coordinate barrier development activities

- Interfacing with other organizations or programs that are interested in the use of permanent isolation surface barriers

- Educating decision makers on barrier-related issues.

4.2.1.2 Project Financial Management (MGT-2). The budgeting of available funds and other limited resources has proven to be a critical factor in the planning and scheduling of barrier development tasks. The competition for technology development dollars has necessitated that project funds be wisely invested in those tasks and activities that will bring the greatest results and lead to project closure in a technically defensible, efficient, and costeffective manner. To ensure that project dollars are used effectively, a Barrier Technical Advisory Board has been established to coordinate and prioritize proposed tasks and to provide guidance on task scope and objectives. In addition, periodic workshops and technical peer reviews are conducted with stakeholders as well as with individuals from onsite and offsite to obtain an independent assessment or "second opinion" of BDP recommendations. 
WHC-EP-0673

This task comprises the following activities:

- Preparing budgets for tasks to be performed throughout the life of the BDP

- Preparing Cost Account Authorizations, Cost Account Plans, Activity Data Sheets, and Technical Task Plans, as appropriate

- Managing work orders, purchase requisitions, and contracts

- Ensuring that BDP tasks are conducted in a fiscally responsible manner

- Convening meetings with the Barrier Technical Advisory Board as needed

- Conducting workshops and technical peer reviews to obtain an independent assessment of BDP recommendations.

4.2.1.3 Preparation of Project Management Documentation (MGT-3). Throughout the development of permanent isolation surface barriers, various types of project management documentation are generated. This documentation includes such things as statements of work, project management plans, quality assurance plans, memoranda of understanding, and internal and external correspondence. In addition, various programmatic and technical documents are generated, such as functions and requirements documents (Wing 1993) and periodic updates of the Barrier Development Plan. In addition, numerous technical and programmatic presentations are prepared and given each year.

This task provides for the preparation of these documents.

(Please refer to references $8,11,76$, and 82 in Section 7.0.)

\subsubsection{Biointrusion Control Tasks}

The objective of the biointrusion control task group is to confirm that the protective barrier design can prevent burrowing animals (vertebrates and invertebrates) and plant roots from penetrating into the waste zone beneath the barrier. In addition, biointrusion studies have been performed to determine the effects of burrowing animals and plant roots on barrier performance. Studies designed to address biointrusion concerns have been conducted using current climatic conditions $(-160 \mathrm{~mm} / \mathrm{yr}$ of average annual precipitation) as well as using conditions simulating a wetter climate $(\sim 480 \mathrm{~mm} / \mathrm{yr}$ has been assumed to represent the average annual precipitation in a wet-climate scenario. Many climate change effects tasks are being performed to provide a quantitative prediction of the amount of precipitation that could be expected in a wet-climate scenario [see Section 4.2.11]). Wet climates may result in changes in species composition and increases in biomass. The permanent isolation surface barrier must be demonstrated to perform satisfactorily in conditions and with species that will likely interact with the barrier during its intended design life. 
WHC-EP-0673

At the VE workshop convened in February 1993, the issue of biointrusion was discussed among the workshop participants. The recommendation resulting from the discussions was to discontinue any additional plant or animal intrusion studies, with the exception of routine observations and monitoring of biointrusion on the prototype barrier planned for construction in late 1993 to early 1994. Also, the biointrusion work that has been conducted to date should be summarized in a final status report and published.

The rationale for the recommendation to discontinue future biointrusion studies was based on the results of 1 iterature reviews and biointrusion tests already conducted. The design of the permanent isolation barrier makes it difficult for deep-rooting plants and burrowing animals to gain access to the waste zone deep below the surface of the barrier. Costs associated with conducting additional biointrusion studies could not be justified by the potential benefits to be gained. The following paragraphs provide a summary of the biointrusion findings to date.

Plant roots need water to survive. Because the capillary barrier is expected to be effective in keeping water from moving past the fine-soil/sand interface, the plant-available water below the capillary barrier is expected to be limited enough so that plant root growth will not be sustained.

This phenomenon has been observed in a clear-tube lysimeter at the field Lysimeter Test Facility. In the fall of 1988, a deep-rooting sagebrush was planted in the surface soils of the clear-tube lysimeter. As the sagebrush matured, the root system of the plant developed into a network that penetrated the fine-soil layer. However, as the roots reached the textural interface between the fine soils and the coarser sands below, their growth was stopped. The roots next to the inside wall of the clear-tube lysimeter were observed to penetrate just a few millimeters into the sand. No plant roots were observed to penetrate past the sand layer and into the graded filter.

The plant lived for more than 3 years within the lysimeter but appeared stressed by late 1991 and died in 1992. During its 3-year life, the lysimeter was subjected to tests that involved the application of supplemental precipitation. For 2 of the 3 years, twice the annual average precipitation ( $2 X$ or $-320 \mathrm{~mm}$ ) was added. For 1 of the 3 years, three times the annual average precipitation ( $3 X$ or $\sim 480 \mathrm{~mm}$ ) was added. During this 3-year testing period, no water was observed to move below the fine-soil layer. In this lysimeter, the capillary barrier was effective in keeping plant roots from moving past the fine-soil/sand interface, even under conditions simulating a wetter climate.

However, the capillary barrier concept does have its limits (see Section 4.2.3). During the winter of 1992 to 1993, when record snowfalls were recorded at the Hanford Site, the storage capacity of the fine-soil reservoir was exceeded. The routine supplemental irrigation treatments, when combined with the unusually large amount of precipitation received during that winter, resulted in greater than $3 X(>520 \mathrm{~mm})$ precipitation being added to the cleartube lysimeter. The net result was that the moisture in the lysimeter wetted the sand below the fine-soil layer and began draining past the capillary barrier. The sublayer filter material and riprap materials were visibly wetted, but no drainage occurred from the base of the lysimeter. The lysimeters with vegetation did not drain even though they received the same 
amount of moisture $(520 \mathrm{~mm})$. If the sagebrush had been living during the winter of 1992 to 1993, the storage capacity of the soil probably would not have been exceeded and the underlying graded filter materials would have remained dry.

In March 1993, following the unusually wet winter, another sagebrush was planted in the clear-tube lysimeter. By early June, the roots of the sagebrush grew past the fine soil/sand interface and into the graded filter-following the water that had percolated past the capillary barrier. By July, the soils in the subject clear-tube lysimeter were dried out by the combined effects of surface evaporation and plant transpiration. As a result, the moisture content in the soils of the lysimeter were reduced such that the effectiveness of the capillary barrier was resiored. The plant roots that penetrated below the capillary barrier probably will not be able to survive as the plant-available water continues to be depleted. It will be interesting to observe how this lysimeter performs over the next few years. Is the capillary barrier restored to its original effectiveness? Do the plant roots below the capillary barrier die as expected? Do the plant roots that have penetrated the capillary barrier (even if they are dead) provide a preferential pathway for moisture drainage? Destructive sampling of large vegetated lysimeters and observations on the prototype barrier (see Section 4.2.8.3) will further define the ability of the capillary barrier to resist root penetrations. As the information from this and other lysimeters and studies becomes available, it will be incorporated into future barrier designs as needed.

As described previously, the textural break at the capillary interface between the fine soil and sand layers is expected to limit substantially root penetration into the lower portion of the barrier profile. However, if plant roots can penetrate through the fine-soil layers, the coarser materials used in the lower portions of the barrier profile will provide an additional deterrent to plant-root intrusion. As an example, the use of gravels and fractured basalt below the capillary break probably will discourage plant-root intrusion by limiting plant-available water. Consequently, plant roots are not expected to come into direct contact with the low-permeability layers that lie beneath the sands, gravels, and fractured basalt. However, should the plant roots come into direct contact with the low-permeability materials, the compacted asphalt is expected to limit root penetration deeper into the barrier profile. Previous work performed by PNL, using asphalt layers on uranium mill-tailing sites, indicated that compacted asphalt emulsion layers are effective in preventing root intrusion (Baker et al. 1984). Tests have been conducted at the Smali-Tube Lysimeter Facility (STLF) to verify the effectiveness of asphalt layers in preventing root intrusion under Hanford Site conditions.

In addition to the barrier construction materials and the properties derived from their placement (textural break, coarse materials, and compacted asphalt layers), the sheer thickness of the protective barrier is anticipated to exceed the maximum rooting depths of most plants expected to grow on the barrier. Current permanent isolation barrier designs are approximately $5 \mathrm{~m}$ thick. The thickness of the barrier, in addition to the thickness of the overburden materials backfilled over the waste zone before barrier construction, provide a substantial buffer between the barrier's surface and the upper portions of the buried wastes. The penetration of plant roots into 
the prototype barrier is planned to be monitored. Lessons learned from these observations will be incorporated into future designs.

With regard to burrowing animals, the permanent isolation barrier also should be an effective deterrent. The fine-soil layer that serves as a water retention medium in current designs is $2.0 \mathrm{~m}$ thick. Because the fine-soil layer is placed directly over a coarser sandy layer to create the capillary break (see Section 4.2.3.5), an animal would have to burrow down $2 \mathrm{~m}$ before contacting the capillary break interface. The results of a literature survey show that virtually all animals that currently inhabit or are expected to inhabit the Hanford Site during the design life of the permanent isolation barriers normally do not have a need to burrow deeper than $1 \mathrm{~m}$ (Gano and States 1982). Favorable biological conditions (i.e., food, shelter, moisture, soil temperature, etc.) for most of the animals are found within the top 0.5 to $1 \mathrm{~m}$ of the earth's surface. Because there is no need or incentive for these animals to burrow deeper than $2 \mathrm{~m}$ and because the layers below the fine soil are "hostile" (e.g., dry, sterile, composed of large rocks, etc.), the possibility of animals expending additional energy to dig deeper into the barrier profile is very low.

There are animals on the Hanford Site, however, that are known to have burrowed deeper than $2 \mathrm{~m}$, particularly the Western harvester ant. If burrowing animals were to penetrate the top fine-soil layer of the barrier, the highly compacted asphalt layers would likely deter any deeper burrowing.

As was the case for plant-root intrusion, the thickness of the barrier in addition to the resistance offered by the low-permeability asphalt layers and the basalt layers (crushed and fractured layers) are expected to further discourage animals from burrowing through the barrier and into the waste zone.

From the results of the testing performed to date (Cadwell et al. 1989; Landeen et a1. 1990; Landeen 1990, 1991), the presence of small-mammal burrows does not appear to have a significant effect on the deep percolation of water through the barrier. Large mammals do appear to cause increased deep penetration of water in the fine-soil layer, but it was observed that much of this water was later removed. The current barrier design does not include design features to reduce the hazards of deep water penetration through largemammal burrows because there has been no demonstrated need, based on work conducted to date. In addition, the presence of the low-permeability asphalt layers lower in the barrier profile will act like an umbrella to shed any percolating water away from the waste.

For completeness, the status of the tasks in the following sections of the Biointrusion Control task group is provided.

4.2.2.1 Animal Response to Climate Changes (BIO-1). A climate change is anticipated at the Hanford Site during the 1,000+ year design life of the protective barrier. In response to this climate change, the types of animal and plant species that will inhabit or interact with the protective barriers is also expected to change. The changes in climate as well as the corresponding changes in vegetation species and abundance will be predicted in task CLIM-2 (see Section 4.2.11.2). The objective of this task is to use the data generated in task CLIM-2 to project the species composition and densities of animals (vertebrates and invertebrates) that will likely inhabit or 
interact with the protective barrier during its intended life. Once the animal species have been identified, other tasks will be performed to evaluate the effect that these species will have on the barrier and its ability to function properly.

This task comprises the following activities:

- Coordinating the activities of this task with the climate change effects task activities as well as with other tasks that depend on the information provided by this task (mostly completed but discontinued per recommendations made at the February 1993 VE workshop)

- Preparing a test plan (discontinued per recommendations made at the February 1993 VE workshop)

- Performing the tasks outlined in the test plan (discontinued per recommendations made at the February 1993 VE workshop)

- Reporting results and make recommendations for final barrier design. (A final report on biointrusion will be prepared in FY 1994. Animal response to climate will be included in this final report.)

4.2.2.2 Animal Burrow Characteristics (BI0-2). To conduct manipulative tests and experiments involving the burrows of animals expected to inhabit or interact with a protective barrier during its intended $1 \mathrm{ife}$, an understanding of the characteristics and parameters of the various burrow systems is needed. Based on the Barrier Development Team's predictions of the species that are expected to be present during the design life of the protective barrier (refer to section 4.2.2.1), scientists have been able to quantitatively characterize existing burrow systems of the animal species (vertebrates and invertebrates) of concern. Parameters such as burrow depth, volume, and density have been measured. The ability of the burrows to "heal" with time also has been evaluated and used to estimate the life expectancy of burrow systems.

Preliminary estimates have been made of the volume of soils that are brought to the surface of a protective barrier by the burrowing activities of animals. The soils excavated by burrowing animals are thought to be more susceptible to accelerated erosion than the surrounding soils that have not been disturbed by animal activity. Computer simulation models have used the data provided by this task to estimate the amount of soil that will be brought to the surface of a protective barrier by animal burrowing and made susceptible to accelerated erosion (see BI0-6). The information generated by this task also will be used to define realistic surface configurations for proposed wind-tunnel tests that will physically test the erodibility of burrowing-animal soil casts (see EROD-2).

This task comprises the following activities:

- Coordinating the activities of this task with BI0-1, BI0-6, and EROD-2 (mostly completed but discontinued per recommendations made at the February 1993 VE workshop)

- Preparing a test plan (completed) 
- Performing the tasks outlined in the test plan (partially completed but discontinued per recommendations made at the February 1993 VE workshop)

- Reporting the results (completed for past tests; a final report on animal intrusion will be prepared in FY 1994).

(Please refer to reference 22 in Section 7.0.)

4.2.2.3 Burrowing Effects on Water Infiltration (BIO-3). Animal intrusion tests have been performed to determine the degree to which animal burrows (for both small and large mammals) affect the infiltration of water through a protective barrier. One conjecture is that the presence of burrows could provide preferential pathways or conduits through which infiltrating water could bypass the fine-soil layer of the protective barrier and subsequently migrate deeper into the barrier profile or possibly into the waste zone below. Lysimeters, neutron probes, and other techniques have been used to assess the effects of animal burrows on water infiltration and percolation. The results of this task have been provided to the modeling task.

This task comprises the following activities:

- Preparing a test plan addressing animal intrusion concerns (completed)

- Performing the tasks outlined in the test plan (mostly completed but discontinued per recommendations made at the February 1993 VE workshop)

- Providing the results to task MOD-1 (partially completed but discontinued per recommendations made at the February 1993 VE workshop)

- Recommending final barrier design (recommendations made for the design of the prototype barrier; a final report on animal intrusion will be prepared in FY 1994).

(Please refer to references $22,32,37$, and 47 in Section 7.0 . Section 8.0 provides references to engineered drawings prepared to support construction of the Animal Intrusion Lysimeter Facility.)

\subsubsection{Barrier Material Effectiveness in Controlling Biointrusion (BI0-4).} Current designs of protective barriers use construction materials that consist of fine soils, sands, gravels, low-permeability asphalts, cobbles, and crushed basalt riprap. Literature reviews and tests, when needed, will be performed to determine the effectiveness of these barrier construction materials in deterring animal intrusion (vertebrates and invertebrates) into the barrier.

This task comprises the following activities:

- Preparing a test plan (completed)

- Performing the tasks outlined in the test plan (discontinued per recommendations made at the February 1993 VE workshop) 
WHC-EP-0673

- Reporting results (a final report on animal intrusion will be prepared in FY 1994).

4.2.2.5 Plant Intrusion Tests $(B 10-5)$. The intrusion of plant roots into a buried waste site could provide a transport pathway for radionuclides to the accessible environment. Because of tha potential for root intrusion, field tests may be required to determine if the roots of plants expected to grow on the barrier, given current and future climatic conditions, will penetrate the various layers of the protective barrier and come in contact with the buried wastes below.

Potential field tests have been considered in which layers of nonradioactive tracers would be placed at various depths throughout a test barrier profile. If the roots of the plants growing on a test barrier penetrated a tracer layer, some of the tracer material would be taken up by the plant roots and transiocated to the leafy portion of the plant. By regularly harvesting and analyzing plants for tracer uptake, the depth to which plant roots have penetrated could be determined.

However, a major drawback to field tests such as the one described above is that the length of time required for a plant community to mature on a test plot may exceed the length of time allocated for the development of protective barriers. As a result, other methods for determining the potential for plantroot intrusion must be considered.

Conducting a literature review is one method that could be performed in accomplishing the objectives of this task. Once the species and abundance of plants expected to grow on the barrier have been determined (see task $C^{\prime}$. IM-2), a review of the literature can be performed to determine what information is available on the rooting depths of the species of interest. The information obtained from the literature review will provide insights into what species will likely pose a root-intrusion problem to barrier performance and, conversely, what species will likely have no root-intrusion effect on barrier performance. The results of the literature review also will be useful in directing any field work that may need to be performed on deep-rooting species that may inhabit protective barriers.

The use of natural analogs is another promising method that could be employed to determine if deep-rooting plants are able to penetrate layered systems such as protective barriers. Some Hanford formation sediments, in which fine soils overlie coarser materials, are analogous to protective barrier designs. These naturally occurring layered systems may provide useful information concerning the potential for plant-root intrusion into the waste zone beneath a protective barrier. The use of mature vegetation in natural settings probably will provide the most representative information on plantroot intrusion in the time frame required for the development of permanent isolation surface barriers.

In addition to the methods discussed previously, additional information concerning plant-rooting depths is being generated (either directly or indirectly) by other barrier development tasks. However, the information generated by these other tasks may be of limited value from a plant-intrusion standpoint if the plants being used in the tasks are not allowed to mature 
fully. For the purposes of completeness, this information is presented in the remaining paragraphs of this section.

Several of the lysimeters at the Field Lysimeter Test Facility (see WTR-3) have been equipped with root observation tubes. These root observation tubes are made of clear plastic and serve as access tubes for down-hole cameras. The down-hole cameras enable observations to be made of the growing patterns and root depths of the various species of vegetation that have been transplanted on the lysimeters.

The small-tube lysimeters at the STLF also will provide plant-root depth information. Some of the small-tube lysimeters will be revegetated with plant species that are likely to be established on the surface of the protective barriers. These pl... species will be allowed to grow in the small-tube lysimeters throughouc the life of the experiment. At the conclusion of the experiment, some of the small-tube lysimeters could be opened up and the distribution and depth of plant roots will be examined.

Another barrier development task in which plant-root depth information may be provided is the natural analog study of plant community dynamics (see task NAT-7). As part of task NAT-7, the root depths of vegetation growing on undisturbed soils at the location where fine soils will be excavated to construct protective barriers will be determined.

This task comprises the following activities:

- Coordinating with plant root studies associated with tasks WTR-3, EROD-1, and NAT-7 (partially completed but discontinued per recommendations made at the February 1993 VE workshop)

- Obtaining the information on predicted plant species and abundance from task CLIM-2 (partially completed but discontinued per recommendations made at the February 1993 VE workshop)

- Performing a literature review on the rooting-depth characteristics of plants expected to grow on the barrier (partially completed but discontinued per recommendations made at the February 1993 VE workshop)

- Preparing a test plan for field studies (discontinued per recommendations made at the February 1993 VE workshop)

- Conducting the field studies per the test plan (discontinued per recommendations made at the February 1993 VE workshop)

- Evaluating the data and report (a final report on plant intrusion will be prepared in FY 1994).

4.2.2.6 Prediction and Integration (BIOPORT Model) (BI0-6). The information generated in some of the biointrusion tasks discussed previously has been integrated in this task and used to predict barrier performance over the intended design life of the structures. As a result of performing tasks BIO-1, BIO-2, and P.10-4, data has been collected on the characteristics of burrow systems created by the animals (vertebrates and invertebrates) expected 
WHC-EP-0673

to live on or interact with protective barriers during the next $1,000+$ years. These data have been input into a subroutine of the existing animal intrusion computer simulation model called BIOPORT. Minor modifications to the BIOPORT algorithm have enabled predictions to be made of the cumulative volume of animal burrows and the cumulative volume of soils displaced by burrowing activities. The results of the BIOPORT model can then be used as input for water-infiltration models (MOD-1) and wind-tunnel tests (EROD-2) that will enable predictions to be made of the movement of moisture through the barrier and the erosion of soil from the barrier, respectively.

This task comprises the following activities:

- Coordinating with and receiving input from tasks BIO-1, BIO-2, and BI0-4 (partially completed but discontinued per recommendations made at the February 1993 VE workshop)

- Making necessary modifications to the animal intrusion algorithm of BIOPORT (partially completed but discontinued per recommendations made at the February 1993 VE workshop)

- Running BIOPORT (partially completed but discontinued per recommendations made at the February 1993 VE workshop)

- Evaluating and reporting the results (a final report on animal intrusion will be prepared in FY 1994)

- Inputting the results of the BIOPORT model to dependent tasks (i.e., MOD-1 and EROD-2) (discontinued per recommendations made at the February 1993 VE workshop).

(Please refer to references 22 and 32 in Section 7.0.)

\subsubsection{Water Infiltration Control Tasks}

The objective of the water infiltration control task is to demonstrate that the protective barrier is capable of controlling water from infiltrating down through the barrier and into the waste zone below. The tasks and activities in this task group must be conducted using current, climatic conditions as well as using conditions simulating a wetter climate. Data on the hydrologic properties of the various barrier construction materials are needed. In addition, evapotranspiration data for the community of plants that are expected to grow on the barrier also are needed. These data are input to computer simulation models and used with data obtained from the Field Lysimeter Test Facility (FLTF) and other tasks to evaluate the ability of the barrier to limit the infiltration and percolation of water through the barrier. Because the water infiltration control task group is dependent on future climate predictions, close coordination has been maintained with the long-term climate change effects task group (Section 4.2.11).

4.2.3.1 Hydrologic Characteristics of Barrier Materials (WTR-1). The effectiveness of protective barriers is, to a large extent, dependent on the hydrologic characteristics of the materials used to construct them. For example, one of the functions of the fine-soil layer is to store meteoric 
precipitation until any excess moisture can be evapotranspired back to the atmosphere. The water-storage capacity of the fine-soil layer is dependent on the moisture retention characteristics of the soil layer as well as the layer geometry. Both laboratory and field characterization of water retention properties will assist in quantifying water storage limits for barrier soils.

In addition to fine soils, the hydrologic characteristics of other components of the protective barrier are needed to select alternate barrier components, conduct field tests, and run computer simulation models. The use of low-permeability components in barrier designs (see task WTR-4) also requires that the hydrologic characteristics of these components be determined.

The hydrologic characteristics of barrier materials has been determined on an as-needed basis throughout the development of permanent isolation surface barriers. For example, a characterization effort was conducted early in the BDP to determine if the particle-size distribution of the soils at the McGee Ranch was adequate for barrier purposes (Last et al. 1987). In addition, the hydrologic characterization data for soil and layer materials were obtained during the installation of the FLTF (see Task WTR-2) and were reported in Gee et al. (1989). The soils data are for material taken from a borrow area at McGee Ranch near the Yakima Barricade. All surface soils tested at the FLTFs large lysimeters are from this source, are silt loam (silt plus clay contents ranging from 40 to 80 percent), and are commonly called McGee Ranch soil.

Soils used in lysimeters at the STLF (see WTR-3) have not been characterized quantitatively nor has there been any detailed characterization of sands and subsoils used in four clear-tube lysimeters at the FLTF. These soils probably will be fully characterized upon completion of lysimeter testing.

Hydrologic characterization also was conducted during the design phase of the prototype barrier scheduled to be constructed in late FY 1993 to early FY 1994. During FY 1992, the physical properties of key prototype barrier components were measured in the laboratory and reported (Wing 1993). These measurements included particle-size distribution, optimum water contents, compaction curves, hydraulic conductivities, plasticity indexes, and liquid limits. These physical properties were needed for design activities such as determining layer thicknesses, specifying compaction techniques, selecting drainage layer materials, conducting tests, and running computer simulation models. The information obtained from the laboratory analyses was used in the definitive design of the prototype barrier.

Soil samples will also need to be collected as the prototype barrier is being constructed and tested. Both laboratory and field-measured hydrologic parameters will be used to estimate water storage capacity. Because the prototype has not yet been constructed, this task is ongoing. 
Although not completed, the Hydrologic Characteristics of Barrier Materials task has made considerable progress. This task comprises the following activities:

- Determining which barrier components need to be characterized (this task has been completed for past activities but is still ongoing to support prototype barrier construction activities)

- Determining the types of characterization methods needed for each component (this task has been completed for past activities but is still ongoing to support prototype barrier construction activities)

- Performing the characterization (this task has been completed for past activities but will be needed to support prototype barrier construction activities)

- Reporting the results to the appropriate end us rs (completed for characterization activities conducted to date).

(Please refer to references 10, 19, and 67 in Section 7.0.)

4.2.3.2 Field Lysimeter Test Facility and Other Lysimeters (WTR-2). The FLTF was constructed in FY 1987 near the Hanford Meteorological Station. The FLTF allows quantitative measurements to be made of water movement in and through various barrier configurations under "normal" and "wet" precipitation conditions. The drainage lysimeters are $2 \mathrm{~m}$ in diameter by $3 \mathrm{~m}$ deep and, the weighing lysimeters are boxes approximately $1.5 \mathrm{~m}$ on a side, which rest on $9,091-\mathrm{kg}(20,000-1 \mathrm{~b})$ scales. Initially, the FLTF consisted of 14 drainage lysimeters and 4 weighing lysimeters arranged in a parallel configuration (Figure 8). Subsequently, six additional clear-plastic tubes were filled with soils to serve as drainage lysimeters in comparing drainage rates for various barrier surfaces.

Each of the initial 18 lysimeters is equipped with state-of-the-art instruments and transducers that measure critical parameters such as soil moisture content, soil water tension, temperature gradients, and liquid- and vapor-phase transport. Both the drainage and weighing Tysimeters are designed to collect any infiltrating water that drains through the barrier materials that have been backfilled into each of the lysimeters. The four weighing lysimeters provide a direct and precise measurement of precipitation and evapotranspiration. The data collected at the FLTF are being used (1) to calibrate and test computer simulation models, and (2) to evaluate the effectiveness of various barrier designs. By altering various parameters in the lysimeters (e.g., soil layer thickness, the presence or absence of vegetation, the presence or absence or admix gravels, and the amount of precipitation), the performance of various barrier designs can be tested using a range of anticipated conditions.

In addition to the FLTF, other lysimeters either have been, are being, or are planned to be used in the BDP to determine the performance of permanent isolation surface barriers. For example, the effects that burrowing animals have on the infiltration of water through protective barriers were evaluated using lysimeters (see Task BI0-3). Smal1-tube lysimeters at the STLF have been used to determine the effects of gravel mulches, vegetation, and 
Figure 8. The Field Lysimeter Test Facility.

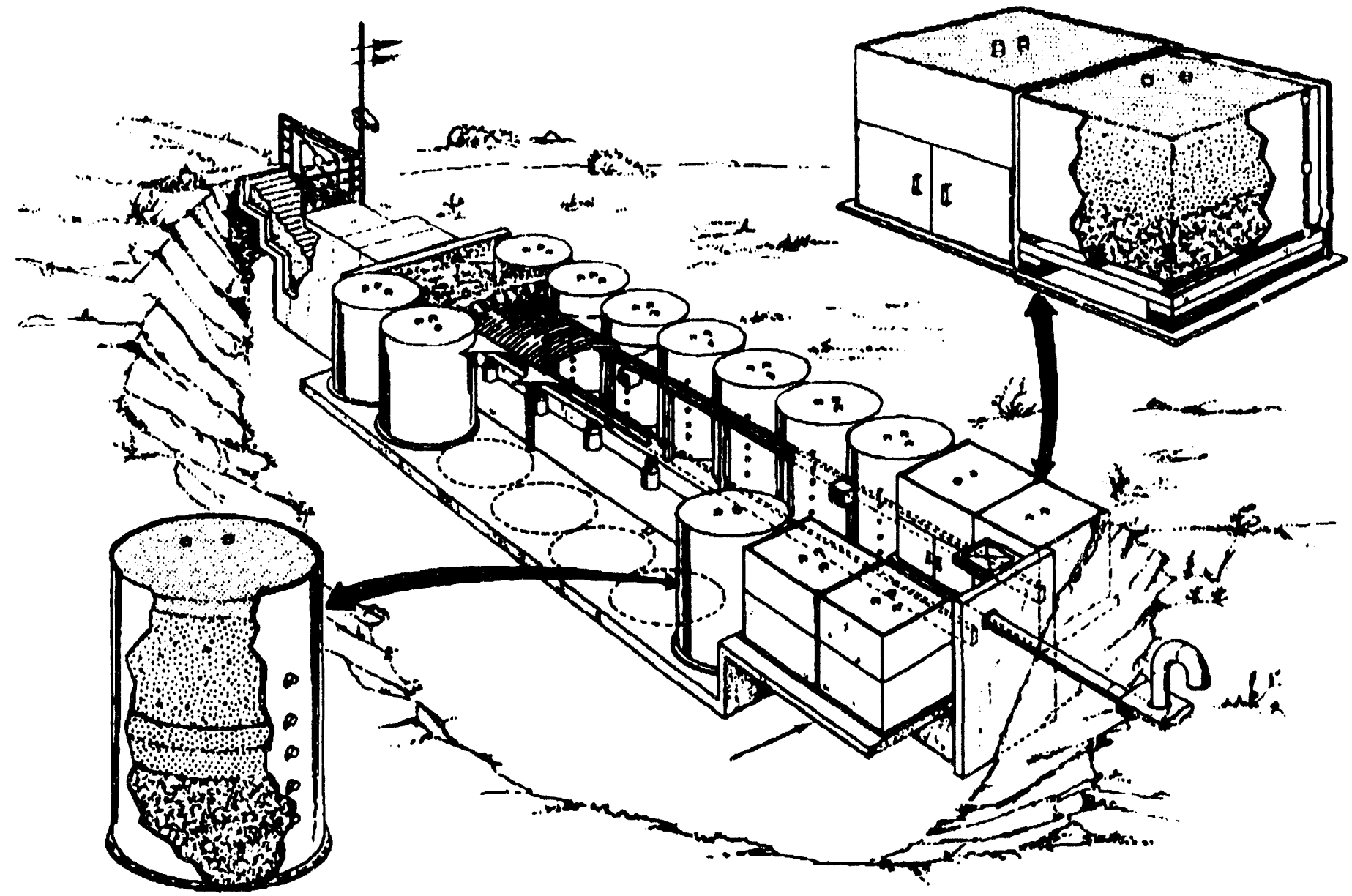

mos110ax 1 
variations in precipitation on soil water drainage and evapotranspiration (see Task WTR-3). Existing deep lysimeters south of the 200 Areas on the Hanford Site have been used to track the deep percolation of water through Hanford Site soils.

Lysimeter-type drainage collection systems have been designed for placement under a portion of the large-scale prototype barrier planned to be constructed in late FY 1993 to early FY 1994. In addition, a lysimeter has been placed under an asphalt test pad located adjacent to the prototype barrier. A collaborative lysimeter study among Hanford Site scientists and engineers and colleagues from the Los Alamos National Laboratory (LANL) also was initiated in FY 1993 (see Task RCRA-5). As part of this collaborative effort, a Hanford barrier is planned to be constructed in a large lysimeter at a facility located on the Hill Air Force Base (AFB) in Ogden, Utah. This lysimeter facility will enable the performance of a Hanford barrier to be compared with four other barrier designs--a RCRA cover, two LANL-designed multilayer barriers, and a monolithic soil cover. The use of all of these lysimeters has been coordinated to maximize the quality and quantity of information acquired and to ensure that the data generated are in a usable form for tasks dependent on the data.

A discussion on the need for continued use of the FLTF and other lysimeters by the BDP took place at the VE workshop convened in February 1993. The participants at the VE workshop recommended that all lysimeter studies be discontinued after FY 1993 except for the FLTF, the prototype barrier, and the lysimeter work planned for Hill AFB.

Six of the lysimeters at the FLTF will undergo exhumation and post-mortem testing in FY 1994. Once emptied, these lysimeters will be backfilled with materials in a configuration consistent with the prototype barrier design. The lysimeters also will be backfilled at the same time that the prototype barrier is being constructed. To facilitate testing, the lysimeters at the FLTF and the prototype barrier will be subjected to the same water application treatments. Tests for both the lysimeters and the prototype barrier will be conducted at the same time for a minimum of 3 years. The six lysimeters at the FLTF will enable a detailed analysis to be made of the one-dimensional flow characteristics of water through the various materials that compose the design configuration of the prototype barrier. The results from the six lysimeters at the FLTF will be compared with the results obtained from the testing activities conducted on the large-scale prototype barrier.

The other undisturbed lysimeters at the FLTF will continue to be tested and monitored for 3 years. The data collected will provide a record of the performance of various barrier designs for nearly a decade and for a wide range of climatic conditions.

For a discussion of the lysimeter activities to be conducted on the prototype barrier and at Hill AFB, please refer to tasks BAR-3 and RCRA-5, respectively. 
This task comprises the following activities:

- Preparing a test plan for tests to be conducted at the FLTF (coordinate with EROD-2, EROD-3, WTR-3, NAT-2, and the CLIM task group) (completed)

- Constructing the FLTF (completed)

- Conducting tests at the FLTF per the test plan (in progress)

- Evaluating the data generated at the FLTF and reporting (the initial planning, actual construction, and progress in data collection and analysis at the FLTF have been summarized in a series of reports)

- Coordinating all of the lysimeter tests being performed in the BDP (in progress)

- Performing post-mortem testing and exhumation of six lysimeters at the FLTF (backfill the emptied lysimeters with materials in a configuration consistent with the prototype barrier) (to be conducted in FY 1994)

- Comparing the results of the six lysimeters at the FLTF with the prototype barrier

- Making recommendations on final barrier designs.

(Please refer to references $12,14,15,19,31,44,48,49,50,62$, and 77 in Section 7.0. Section 8.0 provides references to engineered drawings prepared to support the construction of the FLTF.)

4.2.3.3 Small-Tube Lysimeter Facility (STLF) (WTR-3). The effects of gravel mulch and enhanced precipitation on drainage and evapotranspiration have been measured in combination weighing/drainage lysimeters fabricated from 12-in.-dia (30.5-cm-dia) plastic pipe (see task EROD-1). A 105-1ysimeter array was installed in FY 1988 adjacent to the FLTF near the Hanford Meteorological Station (Figure 9). Eighty of the 105 lysimeters have been used to test the effects of gravel mulches, vegetation, and variations in precipitation on soil water drainage and evapotranspiration. The remaining 25 lysimeters have been used in a companion study to test asphalt, clay, and solution grouts.

Each of the 80 small-tube lysimeters was backfilled with graded layers of gravel and fine soil. The factorial experiment consists of four levels of gravel mulch, two levels of precipitation, two levels of vegetation, and five replications. Wind-tunnel test results (see task EROD-2) have helped guide the selection of gravel treatments. Drainage has been measured directly from a valve located in the bottom of each of the small-tube lysimeters. Each of the lysimeters was weighed periodically from a hoist-mounted load cell. Water storage changes in each lysimeter have been estimated as the difference between the current weight of the drained lysimeter and its drained weight from the previous session. Estimates of evapotranspiration for each of the small-tube lysimeters have been made by subtracting the drainage values from the sum of precipitation and storage changes. Whole-plant gas-exchange 
Figure 9. The Small-Tube Lysimeter Facility.

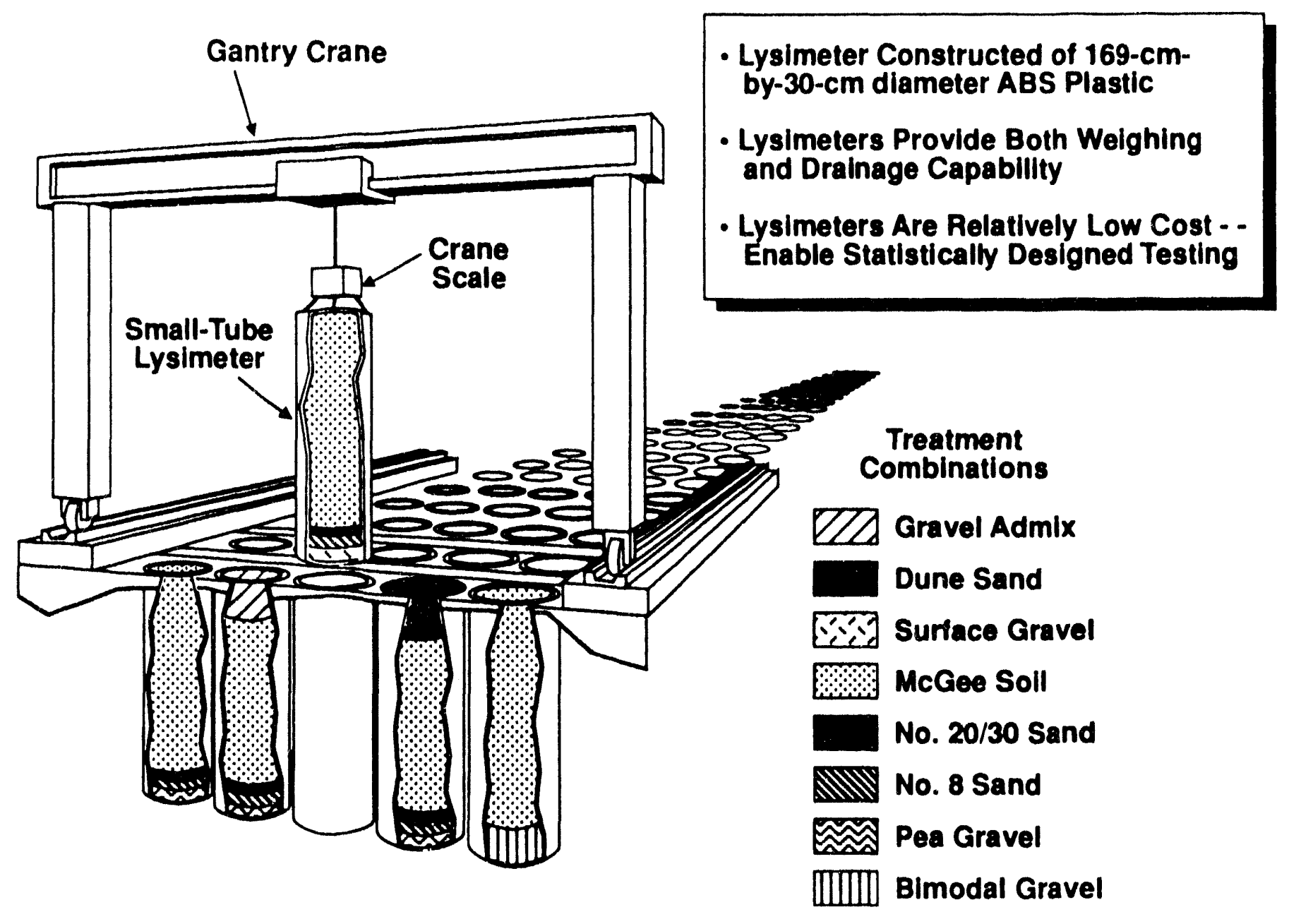

H9008010.16A 
chambers also have been designed and used on the small-tube lysimeters. The whole-plant gas-exchange chambers have been used to evaluate evapotranspiration for applicable small-tube lysimeter treatments.

This task comprises the following activities:

- Modelling alternate gravel designs (completed)

- Preparing a test plan (coordinate with EROD-2, EROD-3, WTR-2, NAT-2, and the CLIM task group) (completed)

- Constructing small-tube lysimeter array (completed)

- Conducting experiments (completed)

- Reporting results (status reports completed for activities conducted in past years).

(Please refer to references $13,34,51,55$, and 72 in Section 7.0. Section 8.0 provides references to engineered drawings prepared to support the construction of the STLF.)

4.2.3.5 Low-Permeability and Diversion Barrier Studies (WTR-4). Permanent isolation surface barriers are designed and constructed with a fine-soil layer directly overlying a layer(s) of coarser materials (e.g., sands and/or gravels). The difference in textures between the barrier materials at this interface creates a capillary barrier for percolating water.

In an unsaturated system, the capillary pressures are much less than atmospheric pressure. For significant quantities of water to flow into and through the coarser sublayers below the fine-soil layer, the water pressure must be raised to nearly equal atmospheric pressure. The overlying finetextured soils must become nearly saturated for the water pressure to approach atmospheric pressure and allow water to flow into the sublayers. This resistance to drainage explains the large storage capacity of the overlying fine-textured soil. Keeping the water in the fine-textured layer provides time for the processes of evaporation and transpiration to remove it.

The data obtained from lysimeter studies demonstrate that the capillary barrier is very effective in limiting the deep drainage of meteoric precipitation through the barrier. As a result of the data, the capillary barrier portion of the perman int isolation surface barrier is expected to be the real "workhorse" most of the time in ridding the barrier of excess moisture. However, the capillary barrier does have its limits, and there may be times when prolonged precipitation or snow melt events cause the fine-soil layer to become nearly saturated, thereby allowing soil water to migrate down through the lower layers of the barrier. For example, during the commencement of the sixth year of testing at the FLTF, drainage was observed (during the unusually wet winter of 1992 to 1993) from several nonvegetated lysimeters that received supplemental precipitation.

The routine supplemental irrigation treatments, when combined with the unusually large amount of precipitation received during that winter, caused the storage capacity of the fine-soil reservoir to be exceeded and the 
nonvegetated lysimeters began draining. However, the lysimeters with vegetation did not drain, even though they received the same amount of moisture. Unless checked in some way, the percolating water that gets past the capillary barrier could potentially migrate through the lower layers of the barrier and into the waste zone below. As a means of restricting the infiltrating water from gaining access to the waste zone, a low-permeability layer(s) (such as asphalt or clay) is strategically placed below the capillary barrier to divert the water from the buried waste.

The low-permeability layers, in concert with (1) the barrier surface that has been engineered with a slight slope to maximize runoff while minimizing erosion, and (2) the capillary barrier, which blocks the downward movement of percolating water, is expected to perform in such a way that near-zero drainage rates through the barrier can be achieved.

Two types of asphalt have been used in tests being conducted by the BDP. Based on recommendations supported by laboratory test results, lysimeter studies at the STLF have used two asphalt formulations: (1) hot rubberized asphalt and (2) an admixture of cationic asphalt emulsion and concrete sand containing $24 \mathrm{wt} \%$ residual asphalt. These asphalt formulations have been very effective in limiting percolation (Freeman et al. 1989). A third type of asphalt, asphaltic concrete with $-8 \%$ asphalt, also is being evaluated for use in barrier designs. The advantage of this third asphalt formulation is its high mechanical strength.

Compacted clay layers will be used sparingly, if at all, in permanent isolation barriers at the Hanford Site. This reluctance to use compacted clay layers is caused primarily by the hot, arid climatic conditions at the Hanford Site. The construction of compacted clay layers requires relatively close control of moisture content and/or compactive energy imparted to the clay to achieve the desired degree of impermeability. The level of control required to achieve the desired low hydraulic conductivities may be difficult to realize and maintain during the Hanford Site's hot, dry summers and for the extremely large barriers planned for the Hanford Site's disposal needs. In addition, concerns have been raised regarding the potential for desiccation cracking of compacted clay layers in arid sites following construction.

Geosynthetic clay liners (GCLS) may provide an effective alternative to the compacted clay layers. GCLs are easy to install and, because they are placed in an unhydrated condition, the problems associated with drying and desiccation cracking during construction are minimized.

A particularly promising application of GCLs is their use in tandem with an asphalt layer to form a composite low-permeability layer. The composite layer concept has been shown to provide much lower permeabilities than one layer alone (Daniel and Trautwein 1991). One concept currently being considered is to place a GCL directly on top of an asphalt layer. Any cracks or holes that may develop (but are not expected) in the asphalt would be "plugged" by hydrated clay from the GCL above. Another composite layer concept currently being considered is to apply a layer(s) of hot rubberized asphalt directly on top of a layer(s) of asphaltic concrete.

The BDP plans to conduct literature reviews and consult with highway departments and asphalt institutes to gain important insights on asphalt 
studies already conducted. However, additional research and testing activities are necessary to verify the effectiveness of the various lowpermeability asphalt concepts proposed. Some of these research and testing needs are described in the following paragraphs. For example, the physical properties of the various types of asphalt being considered for use in permanent isolation barriers need to be understood. These physical properties include large-scale permeability and the stress-strain relationships associated with 3-dimensional deformation that may result because of subsidence events (see Task PHYS-2). The effects of noxious gas attack on the low-permeability asphalt layer also requires evaluation. This evaluation also will be performed in Task PHYS-2. Another area requiring further study pertains to the longevity of asphalt as a low-permeability component. The asphaltic layers need to be durable enough to provide the level of impermeability needed during the design life of the permanent isolation barriers. Asphalt longevity studies were initiated in 1992 as part of Task NAT-9.

The prototype barrier planned for construction in late FY 1993 to early Fy 1994 will provide an excellent opportunity to test the performance of the low-permeability asphalt concepts used in current designs. As discussed in Task WTR-2, a pan-type lysimeter (with a self-contained sump collector for water) will be placed below a portion of the asphalt layers in the prototype barrier. This lysimeter will collect any water that gets through the asphalt layers (although no drainage water is expected). Horizontal neutron probe access tubes, placed below the asphalt layers, also will enable the detection of any moisture that gets through the low-permeability component.

An asphalt test pad ( $18 \mathrm{~m}$ by $8.5 \mathrm{~m}$ ) will be constructed in conjunction with and adjacent to the prototype barrier. This test pad is designed such that the performance of the asphalt layers can be tested using sealed doublering infiltrometers (SDRIs) (or equivalent) and lysimeters. The SDRIs will be embedded into the surface of the asphalt layer while a $6.5-\mathrm{m}-\mathrm{by}-$ 6.5-m lysimeter will be constructed under the asphalt layers.

The pan lysimeter and neutron probe access tubes placed under the prototype barrier, and the test pad located adjacent to the prototype harrier, will provide an effective means of measuring the performance of the asphalt layers over a large area.

The costs associated with all asphalt testing are summarized in this section.

This task comprises the following activities:

- Assessing the need for impermeable layers to control noxious gas releases and to act as a diffusion barrier to minimize upward movement of diffusing species (in progress)

- Preparing a test plan for evaluating low-permeability components in protective barriers (in progress)

- Testing and evaluating various construction materials such as asphalts, clays, and solution grouts for applicability to needs (coordinate this task with WTR-1) (in progress) 
WHC-EP-0673

- Reporting results (progress to date has been reported).

(Please refer to references $13,20,23,24$, and 26 in Section 7.0.)

\subsubsection{Erosion/Deposition Control Tasks}

The objective of the erosion/deposition control development tasks is to demonstrate that protective barriers are capable of minimizing the effects of water and wind erosion of the surface cover, side slopes, and toe of a barrier under current, drier, or wetter climate scenarios. In addition, this task assesses the likelihood, magnitude, and effect of the deposition of wind-blown materials from surrounding areas onto the surface of the barrier.

The surface cover must be designed to prevent significant wind and water erosion from occurring following a range fire or a succession of dry years until natural revegetation of the barrier can take place. Gravel mulches are being considered for inclusion in the barrier design for this purpose. The barrier perimeter also must be capable of minimizing water (sheet or gully) and wind erosion.

The deposition of wind-blown materials could have a deleterious effect on the performance of a protective barrier. If relatively coarse-grained materials are deposited on the surface of the barrier, the moisture retention capabilities of the coarser materials may be significantly less than that of the fine soils used during the original construction of the barrier. The potential reduction in moisture-retention capability from deposition could adversely affect the establishment of desired species of vegetation and could reduce evaporation by allowing deeper penetration of moisture. This task addresses these issues.

Because the erosion-control development task group depends on future climate predictions, close coordination has been maintained with the long-term climate change effects task group (Section 4.2.11).

The erosion-control issue was discussed among the participants at the VE workshop convened in February 1993. The recommendation that resulted from the discussions was to discontinue all wind-tunnel studies and small-scale watererosion studies. It was also recommended that the effects of large-scale erosion phenomena be evaluated and documented on the prototype barrier planned for construction in FY 1993 to FY 1994 (see Section 4.2.8.3).

The rationale for these recommendations was based on the results of the erosion studies already conducted. Participants at the VE workshop felt that the studies that had been conducted to date were well done and demonstrated that the admix gravels were effective in minimizing erosion of the fine-soil cover. Consequently, the performance of any additional tests in the wind tunnel or on small-scale test plots was not considered necessary. Rather, it was recommended that the BDP's limited resources now be directed to evaluating and documenting the performance of the prototype barrier from an erosionresistance standpoint.

For completeness, the status of the tasks in the following sections of the Erosion/Deposition Control task group is provided. 
4.2.4.1 Gravel, Vegetation, and Soil Water Interactions (EROD-1). Mixing gravels into, or spreading gravels over the fine-soil layer of the barrier may become necessary to control erosion. Surface erosion could reduce the thickness of the fine-soil layer and thereby reduce its water retention capacity. A reduction in the amount of water that can be retained by the fine-soil layer of the barrier could increase the probability of drainage into the lower portions of the barrier. Wind-tunnel tests and field studies of runoff events (see tasks EROD-2 and EROD-3, respectively) have been conducted to determine the adequate amount of gravel and the best way to apply it (i.e., as an admix or as a surface mulch). Too much gravel has been demonstrated to reduce surface evaporation and plant transpiration and, thus, restrict the return of stored water to the atmosphere. Therefore, a poorly designed gravel mulch, just like the erosion it is intended to control, could increase the likelihood of drainage. Two studies (a field-plot experiment and a lysimeter experiment) have been designed to test the effects of gravel mulch on soil water storage, vegetation composition and abundance, evapotranspiration, and drainage.

The field plots were constructed in 1986 at McGee Ranch, the site selected as the fine soil borrow area (Figure 10). McGee Ranch is located on the west-central boundary of the Hanford Site. The experiment was designed to test the combined effects of gravel admix and enhanced precipitation on soil water storage and plant cover. In contrast with the lysimeter experiments discussed in Task WTR-3, the field plots, because of their location and greater size, retain a degree of edaphic nonuniformity, and the experimental design provides the means for isolating and testing the variation attributable to it.

Routine monitoring and data collection at the field plots was concluded in September 1990. The results of this task are interesting and are summarized by Cadwe 11 and other researchers, as follows (Cadwell et al. 1993), "Preliminary analysis showed that gravel admix surfaces perform well, with no appreciable impact on soil water balance and that the admix surfaces do not limit plant establishment or growth." The researchers also stated,

It is noteworthy that the final vegetation cover is approximately twice that of the first year (1987) and that there is no apparent difference in total cover among treatment combinations (gravel and precipitation). Note also that exposed surface gravel cover did increase on the non-vegetated plots from 1987 to 1992 in apparent response to the forces of erosion and/or the differential settling of the fine particles.

This task comprises the following activities:

- Modelling alternate gravel designs (completed)

- Preparing test plan (coordinate with EROD-2, EROD-3, WTR-3, NAT-2, and the CLIM task group) (completed)

- Constructing gravel admix field plots (completed)

- Conducting experiments and reporting results (completed). 


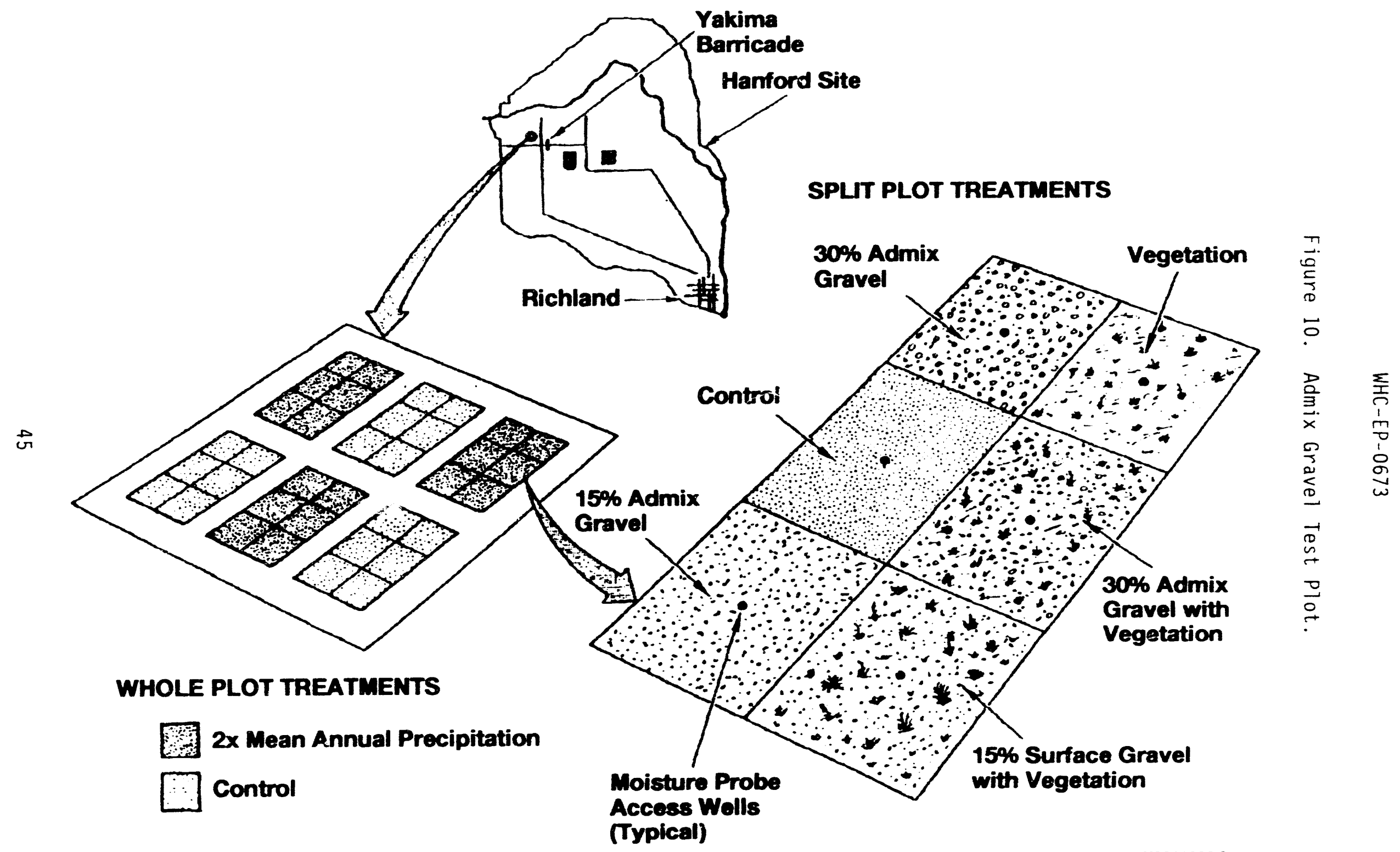


(Please refer to references 13,25 , and 39 in Section 7.0. Section 8.0 provides references to engineered drawings prepared to support construction of the Admix Gravel Test Plot.)

4.2.4.2 Wind-Tunnel Studies (EROD-2). Maintaining an intact, erosionresistant surface layer over waste sites during periods of extended dry finesoil reservoir of the permanent isolation barrier to the scouring effects of wind and sand storms. Wind-tunnel and field tests have been conducted or are planned to study the formation and function of natural surface armors by gravel during periods of simulated extreme climatic stress. Such surface armor has been shown in wind-tunnel tests to reduce erosion rates.

Specific objectives of wind, or eolian, erosion studies in support of natural-material protective barriers are (1) to contribute to the design of a surface layer that will protect the fine-soil reservoir during periods of extreme climatic stress, (2) to investigate the erosive mechanisms and impacts of wind and sand on soil and armored surfaces, (3) to develop a predictive model of erosion and deflation for the barrier surface, and (4) to contribute to the design and monitoring of prototype and actual waste site barriers. These objectives are being met by stucying the surface characteristics; climate and meteorological conditions; and normal and extreme, wind and sand erosive stresses present or possible in the field.

The stability of natural surfaces in an arid environment depends on the interaction of the surfaces with erosive stresses. Surfaces that are armored by crusts or gravel or protected by vegetation have greater resistance to eolian erosion. In addition, the formation of soil aggregates also aid surface stability. In contrast, the presence of sand-sized materials in the surface layer can act as an abrasive agent and reduce the resistance to eolian stresses. Mechanisms of eolian erosion include surface creep, saltation, and suspension. Surface creep is the wind-driven sliding and roling of sand and soil aggregates along the surface. Saltation is the transport mechanism of sand-sized particles and consists of vertical leaps followed by low-angle returns to the surface. Suspension is the long-distance transport of soil particles away from exposed surfaces. Saltation, and to a lesser extent creep, are often the primary causal mechanisms of soil erosion in arid lands; the kinetic energy of windborne or rolling grains is imparted to dry soil surfaces and causes suspension and surface deflation.

Wind-Tunnel Tests. The PNL Aerosol Wind Tunnel Research Facility (Figure 11) has been used to test candidate surfaces and armors under simulated worst-case eolian stress. The computer-automated wind-tunnel facility was selected for these tests to provide reproducible, cost-effective control of environmental conditions and eolian stresses. Controlled surface-shear stresses exceeding those expected during the estimated 1,000-year peak wind gust (about $43 \mathrm{~m} / \mathrm{s}$ or $96 \mathrm{mph}$ ) are achievable in the high-speed test section of the wind tunnel. Actual surface shear stresses are determined by measuring the characteristics of the air-flow boundary layer immediately over the test surface. The boundary layer is formed and stabilized using a length of non-eroding surface upwind of the exposed test surface. Calculations have shown the air velocity measured in the wind tunnel to provide a surface shear-stress equivalent to that provided by a wind speed about 1.5 times greater in the field. For example, a wind speed of $29 \mathrm{~m} / \mathrm{s}$ 
Figure 11. The PNL Aerosol Wind Tunnel Research Facility.

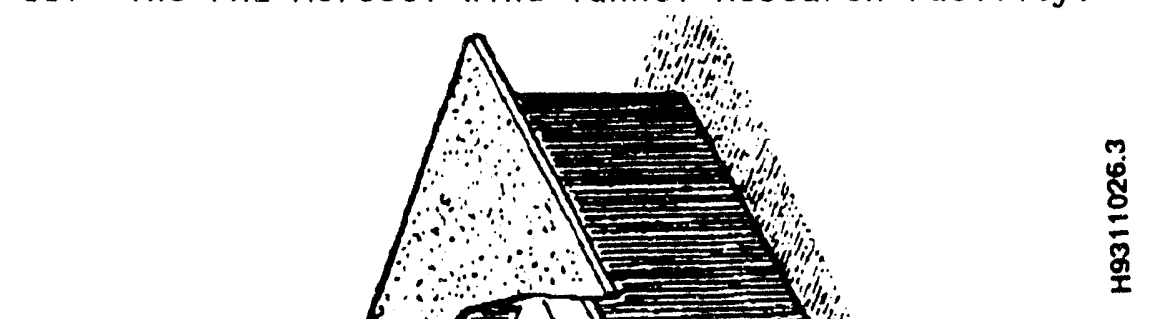


WHC-EP-0673

(65 mph) can be used to simulate the surface shear stresses present in the field during a wind gust of $43 \mathrm{~m} / \mathrm{s}(96 \mathrm{mph})$ measured $15 \mathrm{~m}$ above ground.

Test parameters that have been investigated in the wind tunnel include surface configurations and characteristics and the stresses caused by wind and saltating sand. Although only McGee Ranch soil has been used, a variety of admixtures using the soil have been prepared and tested. Admixture materials have included a wide range of sands and gravels. Gravel is a desired addition to the surface of the barrier as an engineered armoring agent. Very fine sand is present in McGee ranch soil and other sands may be transported from natural sources or construction sites and incorporated into the surface layer. Admixture characteristics that have been tested have included gravel size, size distribution, concentration, particle shape (rounded and irregular), and soil moisture content. Admixture configurations have included naturally weathered surfaces and surfaces prepared using layers of protective gravel armor. Wind stresses have been characterized by friction velocity and surface shear stress. Saltating sand stresses have been characterized by grain size and saltation rate.

Completed wind-tunnel test results based primarily on wind stresses have indicated that the optimum gravel armor for the fine-soil reservoir consists of a fine-grain pea gravel (Ligotke 1993). Nominal pea gravel characteristics provide a good approximation of the armor. Additional tests were performed in FY 1992 to investigate the impact of saltating sand stresses and the incorporation of sand of various sizes in the surface layer; trial tests were performed for a study of the stability of crusted surfaces and armors.

Although analyses of these data are preliminary, observations made during the tests indicated that a pea-gravel armor is sufficient to protect the surface even during extreme erosive conditions. In support of these tests, data on peak wind gusts at the Hanford Site (Stone et a1. 1983) were augmented and peak gust return periods were calculated. In addition, Hanford Site dune sand transport potentials were estimated (Glantz et al. 1990) and considered before performing sand saltation tests.

The following additional tests were planned for the future, but have been discontinued per the recommendations of the participants at the VE workshop convened in February 1993. These tests include the completion of measurements of the resistance of surfaces to saltation stresses; the testing of natural surface crusts (physical, chemical, and biological); and the study of the influerce of vegetation, plant root structures, and animal burrowing activity. other planned activities included completion of estimates of sand-grain saltation stresses during worst-case conditions, incorporation of a method for measuring the momentum profile of saltating sand grains, preparation of a predictive model of deflation and erosion based on wind-tunnel and field data, and validation of field sampling strategies.

Field Tests. Activities have been identified to support both prototype and actual natural-material protective barriers in the field. Also, field data may be obtained for comparison with wind-tunnel results. Using data obtained from the wind-tunnel tests and eolian erosion-monitoring activities at the prototype barrier and other sites, information for the validation or modification of the current armor design will be obtained. Such information also will provide information needed to identify any low-effort monitoring activities that may be useful at actual natural-material barrier sites. 
The composition of the fine-soil layer of the planned protctype barrier (see BAR-3) was based in part on the results of wind-tunnel tests. With a $15 \%$ admixture of pea gravel in the top $1 \mathrm{~m}$ of the layer, the worst-case surface deflation may be about $10 \mathrm{~cm}$. Objectives of the wind-erosion monitoring activities for the planned prototype barrier include quantifying surface deflation or inflation rates; characterizing the wind and saltating sand stresses impacting the barrier; and studying the impacts of a sand dune and a wildfire on the surface of the barrier.

The first monitoring objective will include characterizing the surface layer composition and morphology as it ages during natural and irrigated conditions. Expected results include evaluations of surface composition, uniformity, armor, and a comparison of surface deflation with that predicted using physical models in the wind tunnel. Expected results of the second objective include an evaluation of barrier shape on wind and saltating sand stresses, sand transport rates, and a comparison of field and wind-tunnel conditions. The third monitoring objective is proposed to be performed only after the primary water balance data has been collected--perhaps after 3 to 5 years. An induced sand dune will cause increased erosive stresses, displace vegetation, and alter water storage and transport characteristics in the finesoil reservoir. A simulated wildfire will remove protective vegetation and increase deflation potential. In addition to water-balance measurements, expected results include an evaluation of armor formation and function during worst-case erosion conditions.

The wind-erosion subtask includes the following activities:

- Identifying normal and maximum expected eolian erosive stresses at the Hanford Site, and to predict sand transport rates during normal and worst-case conditions (completed)

- Performing wind-tunnel tests to identify the characteristics of a gravel admixture best suited to protect the fine-soil reservoir from eolian erosion (completed)

- Performing wind-tunnel tests to provide deflation rates of bare soil and gravel-armored surfaces during simulated worst-case eolian erosive stresses caused by wind and saltating sand grains (partially completed but discontinued per recommendations made at the February 1993 VE workshop)

- Determining the potential for the formation of large-scale eolian structures such as sand dunes and blowouts, and assessing their impact on waste site barriers (scheduled to begin in FY 1993 but discontinued per recommendations made at the February 1993 VE workshop)

- Developing a predictive model of erosion and deflation for the barrier surface using both wind-tunnel and field data (scheduled to begin in FY 1993 but discontinued per recommendations made at the February 1993 VE workshop)

- Contributing to the design of a surface layer that will protect the fine-soil reservoir during periods of extreme climatic stress and 
performing long-term monitoring of a prototype natural-material protective barrier (partially completed, prototype monitoring to begin in FY 1994).

(Please refer to references $16,18,38$, and 63 in Section 7.0.)

4.2.4.3 Water Erosion Studies (EROD-3). The objective of the water erosion studies is to test the ability of the barrier fine-soil admix gravel surface to resist the erosional and destabilizing processes from high-intensity rainfall (Figure 7 ). The barrier design calls for the placement of McGee Ranch soil on the top surface as the first 1 ine of defense against the downward movement of water into the buried waste and to protect other underlying barrier layers. The soil layer is about $2.0 \mathrm{~m}$ thick and includes rock mulch and vegetation for increased stability. Through field tests of the McGee Ranch soil at the Hanford Site, the study has identified the dominant processes that contribute to erosion and failure of the soil cover. The effects of rock mulch (gravel admix) and vegetation cover have been included in the testing series. Some of the testing may include the effects of animal intrusion on erosion, and will be coordinated with other animal intrusion studies.

Barrier-Related Erosion Processes. The erosion of the barrier top surface soil is mostly the result of a combination of rainsplash and overland runoff from high-intensity rainfall events. Snowmelt has a smaller effect because of the absence of rainsplash and the longer length of time required for snowmelt to occur. The energy of raindrop impact loosens soil particles for transport downslope by overland flow, which removes soil from the barrier surface by sheet erosion and could lead to the eventual development of rills and small gullies. The establishment of vegetation has been demonstrated to greatly reduce the amount of erosion.

Experimental Field Testing. To meet the objectives of the BDP and provide barrier design criteria, a sequence of field tests have been conducted at the McGee Ranch site on the Hanford Reservation. The first set of tests used small plots of McGee Ranch soil $1 \mathrm{~m}^{2}$ in area. Both bare soil and soil with gravel admix were tested. Rainfall was applied using a rotating-boom rainfall simulator at various intensities for periods of 20 to 30 minutes. These small-scale tests served as scoping studies to obtain initial information on the behavior of McGee Ranch soil and to design tests on 1 arger plots $(3.1 \mathrm{~m}$ by $10.7 \mathrm{~m})$ for simulated storms of 30 to 60 minutes. The scoping tests also provided information on the performance of the rainfall simulator.

For the large-scale test plots, the rainfall simulator was used to apply water at various application rates representative of various rainfall intensities. Water and sediment samples, together with discharge measurements, were grabbed from a collector system at the downslope end of each plot. The water-sediment samples were analyzed in the laboratory to determine the amount of soil lost and, when possible, a particle-size distribution was determined by sieving and by hydrometer analysis. The percent of soil moisture, bulk density, and percent compaction of each soil plot was monitored before and after each test. The combined series of tests have provided data and information on the amount of erosion that can be expected from natural soil and soil with gravel admix (percentages by weight of soil) and the effects of vegetation on erosion rates. From the field test results, design criteria for the barrier top surface are being developed. 
This task comprises the following activities:

- Preparing a field test plan (completed)

- Designing and constructing small-scale test plots (completed)

- Conducting simulated rainfall tests on small plots (completed)

- Designing and constructing large plots (completed)

- Conducting simulated rainfall tests on large plots (in progress)

- Providing design input for the prototype barrier (completed)

- Conducting water erosion tests and observations on the prototype barrier

- Analyzing the data and preparing report (partially completed for tests conducted to date).

(Please refer to references 35,36 , and 78 in Section 7.0. )

\subsubsection{Physical Stability Tasks}

The purpose of performing physical stability testing is to demonstrate that the protective barrier can function as designed after potentially disruptive natural events that may be expected to occur during the design life of the barrier. Specifically, an assessment will be made of the likelihood, intensity, and consequence of earthquakes, the deposition of volcanic ash, tornados, other high-wind conditions, and high-intensity precipitation events.

In addition, the ability of the barrier to be used for the disposal of certain types of waste depends on the integrity and characteristics of the various waste forms. Of particular interest are waste sites where subsidence and the emanation of noxious gases may be a problem. In this task, the maximum allowable subsidence that a barrier can withstand and still remain functional will be determined. In addition, this task will assess the barrier's ability to mitigate potential problems associated with the emanation of noxious gases from the waste zone. The results of this task may be used to formulate barrier design standards and waste acceptance criteria.

Issues pertaining to physical stability were discussed extensively among the participants at the VE workshop convened in February 1993. Workshop attendees decided that the issue of physical stability requires significant attention. The following two sections have incorporated the recommendations made at the VE workshop.

4.2.5.1 Assessment of Potentially Disruptive Natural Events (PHYS-1). The purpose of this task is to assess which extreme, potentially disruptive natural events are likely to affect a protective barrier at the Hanford Site based on a probabilistic evaluation. Those disruptive events determined to have a reasonable probability of occurring during the design life of the barrier will be assessed to determine their consequences on the performance of 
the protective barrier. Specifically, an assessment of earthquakes; highintensity precipitation events; tornados and other high-wind conditions; the deposition of volcanic ash; and any other possible disruptive events that could act on the barrier will be made.

Participants at the VE workshop recommended that a literature review of the potentially disruptive natural events be conducted. Many studies and analyses already have been performed for this region that address potentially disruptive natural events in support of the design and construction of nuclear reactors and other nuclear facilities. This literature review is planned to be conducted in FY 1994.

Following the literature review and assessment of the types, probability, and severity of various potentially disruptive natural events acting on a barrier, predictions will be made of any adverse consequences that could result. In addition, recommendations for any changes to the barrier design (if needed) will be made to mitigate the problem. These recommendations then may be tested in the laboratory and/or the field to determine their effectiveness in maintaining barrier performance after a potentially disruptive natural event(s).

This task comprises the following activities:

- Performing a literature review/assessment of potentially disruptive natural events

- Preparing a laboratory/field test plan, as required

- Performing the required laboratory/field tests, as required

- Preparing design recommendations based on the results of this task.

4.2.5.2 Barrier Performance in Relation to Various Waste Form Characteristics PHYS-2). The performance of permanent isolation barriers may be adversely affected by the physical, chemical, and radiological characteristics of certain types of waste. In addition, the susceptibility of certain types of waste to biological attack or biodegradation also may have an impact on barrier performance. Of specific concern are the magnitude of subsidence events occurring below the barrier (size and rate of subsidence); and the volumes, concentrations, and types of noxious gases that could be generated by the waste. Participants at the VE workshop recommended that this task focus on the low-permeability asphalt layers because it is, in effect, the last line of defense against infiltrating water.

In this task, the maximum allowable subsidence that a barrier can withstand and still remain functional will be determined. Although the use of subsidence control measures (e.g., dynamic compaction and in situ grouting) is expected to significantly reduce the magnitude of subsidence experienced, for certain types of waste, subsidence events cannot be expected to be reduced to zero. Consequently, there is a need to determine the magnitude of subsidence that a barrier is capable of withstanding and still function as designed.

This task will be coordinated with Task WTR-4 in which a number of studies and tests on asphalt performance are being conducted and with 
Task RCRA-4, which describes how the asphalt studies fit into the approach to demonstrate RCRA equivalency. This task also will focus on the ability of asphalt to deform and remain functional following a subsidence event. The stress/strain relationships associated with 3-dimensional deformation of the asphalt layers will be studied. In addition, methods to enhance the tensile and shear strength of the asphalt layers will be tested and assessed. For example, does the incorporation of a woven fiberglass fabric or other highly durable and strong product into the asphalt layers increase the tensile and shear strength of the low-permeability layer?

This task also will assess the barrier's ability to mitigate potential problems associated with the emanation of noxious gases from the waste zone. Depending on the type of waste being disposed of, noxious gases from the wastes could be generated and subsequently diffuse from the waste zone to the accessible environment. Unless controlled in some way, the noxious gases could pose a potential threat to human health and the environment.

The potential for problems with noxious gases is not unique to the Hanford Site. As an example, uranium mill-tailings sites are often challenged with the emanation of elevated concentrations of radon gas. One such site is located in Grand Junction, Colorado.

Many years ago, scientists and engineers (several of whom are currently serving on the BDP) were requested to participate in finding a solution to the elevated radon gas concentrations at the Grand Junction uranium mill-tailings sites. Various barrier designs that used several different barrier construction materials were developed and tested. In general, the designs consisted of a multilayer barrier of compacted soils and gravels with a lowpermeability component (asphalt or clay) incorporated into the barrier profile. In 1979, full-scale protective barriers were constructed over the uranium mill-tailings sites (Baker et al. 1984).

Nearly 8 years after the protective barriers had been constructed, a post-mortem examination was performed on the performance of the Grand Junction protective barriers. The results of the post-mortem showed that the protective barriers that were constructed with low-permeability, asphaltic layers performed the best in inhibiting the diffusion of radon gas to the surface of the barrier. Control of radon exhalation was effective using lowpermeability asphalt because radon has a short half-life (less than 4 days). Restricting radon flux allows for radon decay. In addition, radon has a low partial pressure, so gas pressure build up did not occur; hence, the cover was not disrupted by excessive pressures. The results also suggested that asphaltic layers constructed in the field with conventional equipment can perform as designed for an extended period of time (Gee et al. 1989).

The BDP will use the experience and expertise gained at Grand Junction, Colorado, and el sewhere in the design of barriers that mitigate problems associated with the release of gaseous wastes. A test plan also is being developed to address the various technical issues associated with the emanation of noxious gases that were identified previously. Engineers and scientists will assess the barrier's ability to inhibit the diffusion of noxious gases to the accessible environment. In addition, concerns have been raised regarding the potential for gases to be trapped under various barrier layers-particularly the low-permeability components. These gases could 
potentially induce elevated pressures on the barrier components of concern. In addition, concerns have been raised regarding the accumulation of water vapor under the low-permeability components. Another concern requiring assessment is the potential harmful effects of organic vapors (solvents) on the low-permeability asphalt layers. This task also will address these issues.

The use of computer simulation models will be used as appropriate (1) to assess the barrier's ability to withstand subsidence events of various magnitudes, (2) to assess the barrier's ability to control the emanation of noxious gases, and (3) to assess the impact on barrier performance of gas accumulation under low-permeability components. Field and laboratory tests also will be performed to enhance understanding and corroborate the results of the computer simulation models (if used). The results of the tests will be used to formulate barrier design standards. To employ a permanent isolation barrier, end users would be required to provide waste forms that comply with the established barrier design standards for subsidence and noxious gas emanation.

The costs associated with all asphalt testing activities are summarized in Section 4.2.3.5.

This task comprises the following activities:

- Preparing a test plan (in progress)

- Running models and conducting the field and laboratory tests (in progress)

- Reporting results and establishing barrier design standards for subsidence and noxious gas emanation.

(Please refer to reference 20 in Section 7.0.)

\subsubsection{Human Interference Control Tasks}

The human interference control tasks were designed to develop markers capable of warning future generations of the dangers of disposed waste. The DOE fully intends to maintain active control of the Hanford Site (using fences, patrols, alarms, monitoring instruments, etc.) for the foreseeable future. However, if active control should ever cease, passive measures (i.e., those requiring no maintenance) may be needed to warn the inadvertent intruder of the potentially hazardous materials disposed of beneath the barrier. These passive measures may include recognizable warning markers, engineered features, and widely dispersed information (e.g., in U.S. Geological Survey maps, libraries, and other information repositories).

Passive measures will not provide absolute protection to every individual for all postulated events during the barrier's design life, nor will such measures prevent intentional intrusion. However, recognition of this limitation is consistent with the history of rulemaking for the disposal of radioactive waste. 
A preliminary human-intrusion deterrent concept for Hanford Site barriers was developed during the early 1980's. This concept included built-in redundancies: offsite records, surface markers, subsurface markers, and barrier designs. An approach for developing this concept to deter intrusion by humans was prepared. This approach involved (1) the definition and design of marker materials, configurations, and messages; (2) the testing of selected materials; and (3) the procurement and testing of marker prototypes.

At the VE workshop convened in February 1993, the human-intrusion issue was discussed among the workshop participants. The recommendation that resulted was to discontinue any additional human-intrusion studies. The rationale for this recommendation was that DOE has not yet decided on the approach that will be used to deter inadvertent human intrusion at the Hanford site. The concept proposed in the early 1980's represents just one approach and the effectiveness of some aspects of this approach has been questioned. For example, the use of the subsurface markers has been challenged repeatedly. Some individuals have viewed the subsurface markers as an attractive nuisance that could draw curious individuals to the protective barrier instead of deterring them.

Many opinions regarding barrier design exist, with regard to human intrusion. For example, two different side-slope designs are being considered by the BDP: a relatively gently sloping (10H:IV) clean-fill dike of pitrun gravels and a relatively steep (2H:IV) embankment of fractured basalt riprap. The clean-fill dike provides a gentle transition from the shoulder of the barrier to the surrounding environment. Essentially, the clean-fill dike concept blends the barrier into the topography of the surrounding landscape. Conversely, the steep, rocky side slope of the basalt riprap clearly delineates the boundaries of the surface barrier by providing a stark contrast with the surrounding environment.

Considering human intrusion, there are positives and negatives associated with using either side slope design. A clean-fill dike side slope is aesthetically appealing because it blends in with the surrounding landscape. However, if surface markers are lost for any reason, blending the waste sites in with the local topography might tend to hide the location of the waste sites, making it possible for someone to "stumble" inadvertently onto the sites. Barriers that employ the basalt riprap side slopes are obviously structures that have been engineered and constructed by humans. The basalt riprap sideslope designs make no attempt to blend the barrier in with the appearance of the surrounding landscape; consequently, these barriers are readily noticeable. There is some contention that the obvious barrier designs could become an attractive nuisance (similar to the subsurface markers) that draws curious individuals to the mounds. This certainly has been the experience with other (ancient) barrier systems that have been totally or partially breached (e.g., the Egyptian pyramids). Another potential problem is that the relatively flat surfaces of the barriers, which contain excellent fine soils, may attract future farmers to the barriers. In addition, curious individuals may think that valuables have been buried beneath the mounded soils and subsequently may want to excavate into it.

Warning marker designs other than those proposed at the Hanford Site have been developed. For example, the Sandia National Laboratory recently has assembled national experts in a workshop setting to develop, at least 
conceptualiy, various warning marker concepts for the Waste Isolation Pilot Plant (Guzowski et al. 1991; Hora et al. 1991; Ast et al. 1992; Givens et al. 1992). Many different concepts were considered, some quite different from the concepts proposed at the Hanford Site.

The warning marker issue is not one of which design/concept is "right" or "wrong." Rather, it appears that the critical concern is the assumption(s) upon which the warning marker designs/concepts are based. Without a clearly delineated set of assumptions and policies to guide the development of warning marker systems, the effort is unproductive at this time.

Any premature selection of a warning marker design before a humanintrusion policy decision also could be counterproductive. For example, participants at the VE workshop felt that proceeding forward with an "unofficial" marker system may be worse and more costly in the long term than purposely leaving out human-intrusion deterrent features at the current time. For instance, the prototype barrier to be constructed over the 216-B-57 Crib is intended to be the final remediation for that particular site--provided the barrier performs as designed. If subsurface markers were used in the prototype, they would have to be placed within the various layers of the barrier by the end of FY 1993 or the beginning of FY 1994 to meet schedule commitments. Because DOE probably will not have a human-intrusion policy in that time frame, the BDP would be uncertain with any decision to use the subsurface markers. If later the use of subsurface markers as a humanintrusion deterrent was not wanted or effective, the fate of the barrier over the 216-B-57 Crib would be in question. The multimillion-dollar barrier then might have to be removed or rebuilt. Because of these issues, the decision was made to leave subsurface markers out of the barrier over the 216-B-57 Crib.

Perhaps the worst possible scenario would be for every project at the Hanford Site, or across the DOE Complex, to decide independent of each other which human-intrusion deterrent designs/concepts would be used. This scenario could result in many different designs/concepts that make it difficult, if not impossible, to discern what is going on. The lack of consistency among warning marker schemes could exacerbate a situation that the warning markers were intended to ameliorate.

The VE workshop participants recommended that, until a DOE policy decision has been made, all activities designed to address the human-intrusion problem be discontinued. However, when a human-intrusion policy has been made and a warning marker approach selected, it should be uniformly and consistently applied across the Hanford Site -- and probably across the entire DOE Complex.

The status of the following tasks is provided for completeness.

4.2.6.1 Surface-Marker Development and Testing (HUM-1). The surface-marker development task involves the design, procurement, and field testing of monolithic stone surface markers. Field monitoring will involve the determination of erosion rates, the examination for lichen damage, and the observation of foundation performance and stone damage. Emplacement procedures also will be tested. 
This task comprises the following activities:

- Defining alternative marker concepts (completed)

- Assessing the natural and archaeological analogs (completed)

- Selecting the configuration and materials (completed)

- Prezaring the drawings (completed)

- Procuring a prototype marker (discontinued per recommendations made at the February 1993 VE workshop)

- Monitoring the marker in the field (discontinued per recommendations made at the February 1993 VE workshop)

- Reporting the results (discontinued per recommendations made at the February 1993 VE workshop).

(Please refer to references $1,2,5$, and 7 in Section 7.0. Section 8.0 provides references to engineered drawings prepared to support surface-marker development and testing.)

4.2.6.2 Subsurface-Marker Development and Testing (HUM-2). The subsurfacemarker development task involves the design, procurement, and testing (both laboratory and field) of alternative subsurface-marker materials and configurations. The laboratory testing involved the exposure of a marker prototype to much more severe physical, thermal, and chemical conditions than would be encountered in the soil. Such tests enabled comparisons and choices to be made among marker types. Markers also will be tested for their ability to withstand placement in the barrier during construction.

This task comprises the following activities:

- Defining alternative marker concepts (completed)

- Assessing the archaeological analogs (completed)

- Selecting the configurations and materials (completed)

- Preparing the drawings and specifications (completed)

- Preparing the test plan (completed)

- Procuring and testing the prototypes (completed)

- Conducting the construction emplacement tests (discontinued per recommendations made at the February 1993 VE workshop)

- Reporting the results (discontinued per recommendations made at the February 1993 VE workshop). 
(Please refer to references 1, 2, 5, and 7 in Section 7.0. Section 8.0 provides references to engineered drawings prepared to support subsurfacemarker development and testing.)

\subsubsection{Message Development and Record Requirements (HUM-3). This task} involves the selection and preparation of messages to be placed on surface and subsurface markers, including language selection and content, pictogram design, and symbol selection and design. Offsite record-keeping requirements are also defined in this task, based on a study of regulatory requirements.

This task comprises the following activities:

- Assessing and defining the messages required (completed)

- Selecting the languages and symbols (partially completed but discontinued per recommendations made at the February 1993 VE workshop)

- Designing the pictograms (completed)

- Identifying the record-keeping requirements (partially completed but discontinued per recommendations made at the February 1993 VE workshop).

(Please refer to references $1,2,5$, and 7 in Section 7.0.)

4.2.6.4 Marker Placement Activities (HUM-4). The marker placement activities involve a determination of surface-marker placement locations and intervals, based on actual Hanford Site topography and vegetative cover considerations. Field surveys will be conducted to locate marker placement points that offer the best visibility while optimizing placement intervals and costs. The objective is to establish a marker perimeter $(6.4 \times 12.9 \mathrm{~km})$ around the 200 Areas at the Hanford Site. Markers al so will be placed at the corners of each barrier mound (disposal block) and at any other locations necessary to clearly delineate areas where wastes have been disposed of. Maps will be prepared to guide marker placement.

This task comprises the following activities:

- Performing a field survey for surface-marker placement (discontinued per recommendations made at the February 1993 VE workshop)

- Preparing the placement maps (discontinued per recommendations made at the February 1993 VE workshop).

(Please refer to references 1,2, 5, and 7 in Section 7.0.)

\subsubsection{Barrier Construction Materials Procurement Tasks}

A variety of barrier construction materials has been or will be needed to conduct barrier development tasks as well as to support the construction of the prototype barrier planned for late FY 1993 to early FY 1994. Some of the materials which have been or will be needed are basalt riprap $-25.4 \mathrm{~cm}$ blasted 
basalt, coarse pitrun gravel, crushed and screened gravels, fine and medium sands, and fine soils.

The primary objective of this task has been to conduct all of the activities required to obtain the materials necessary to support the BDP's testing and monitoring activities. These activities have included the identification and characterization of candidate borrow pits and quarries. In addition, the supporting documentation required to excavate barrier construction materials has been prepared (e.g., National Environmental Policy Act documentation; excavation permits; threatened, endangered, and sensitive plant and animal species surveys; cultural resource reviews; and site evaluation reports).

One of the key objectives of the BDP has been to conduct its tests and experiments on those materials that would be used in the construction of large-scale barriers over actual waste sites. It would be unproductive and wasteful to perform tests and experiments on exotic materials that would either be cost prohibitive, ineffective, or not exist in sufficient quantities to support the Hanford Site's cleanup objectives. For many of the barrier construction materials identified previously, the quantity and quality of materials needed to support Hanford Site objectives is not considered to be a problem. Many of these materials are known to exist in large quantities on the Hanford Site. However, some materials, sucr as fine soil, do cause concern.

Fine soils that possess suitable moisture-retention characteristics are critical for the long-term barrier to function as designed during its intended design life. The fine soils at McGee Ranch are the best fine soils for longterm protective barriers found to date on the Hanford Site. The quantity of fine soils available at the McGee Ranch site is not known. Only a relatively small portion of McGee Ranch has been characterized. These preliminary characterization activities have demonstrated that there exists enough fine soil to support the testing and monitoring objectives of the BDP as well as the construction of a limited quantity of large-scale barriers to support Hanford Site remediation objectives. However, it is not known if the quantity of fine soils exists in large enough volumes to support all of the planned remediation activities that would use permanent isolation surface barriers. As a result, the McGee Ranch site may (or may not) be a limited resource.

The current scope of the BDP does not include performing additional characterization activities to confirm the quantity of materials (such as fine soil and basalt riprap) available for the construction of permanent isolation surface barriers or to identify new sources of materials. However, this additional characterization effort is critical and needs to be performed by end users and programs wanting to use permanent isolation surface barriers to remediate waste sites. This point was recognized and noted at the VE workshop convened in February 1993. Some programs already have initiated these additional characterization activities. However, the entire characterization effort needs to be well coordinated among all programs and an analysis needs to be performed to determine if the current level of effort is sufficient.

Other issues regarding barrier construction materials that are beyond the scope of the BDP also need to be addressed. For example, how will the barrier construction materials be transported from the borrow pits or quarries to the 
waste sites where the barrier will be constructed? Will trucks, trains, or conveyors be used? Will the current transportation infrastructure (i.e., roadways, railroad grades, or conveyor systems) need to be improved or engineered to handle the loads and volume of traffic required to support the construction of protective barriers? If needed, can modifications to the infrastructure be planned, procured, and installed in a timely manner to support environmental restoration and waste management activities? Members of the BDP have been struggling with these issues for years and would be a valuable resource to management in solving these and other similar types of problems.

The following tasks and activities are needed to support the acquisition or procurement of materials to conduct barrier development tasks as well as to construct the prototype barrier planned for late FY 1993 to early FY 1994.

- Determination of the types and quantities of materials required to perform the barrier development tasks and to construct the prototype barrier (completed)

- Preparation of the site evaluation reports as required for borrow pit and quarry sites (completed)

- Completion of the required environmental studies and documentation for the anticipated borrow pit and quarry sites (completed)

- Performance of the threatened, endangered, and sensitive plant and animal species surveys for the anticipated borrow pit and quarry sites (completed)

- Performance the Cultural Resource Review for the anticipated borrow pit and quarry sites (completed)

- Obtaining of the necessary excavation permits (completed)

- Resolution of issues related to opening a basalt quarry on the Hanford Site and conducting drilling and blasting operations (e.g., obtaining permits for using explosives on the Hanford Site and resolving safety and security issues related to blasting operations) (in progress for the prototype barrier).

(Please refer to references 4,10 , and 67 in Section 7.0.)

\subsubsection{Prototype Barrier Designs and Testing Tasks}

Periodically during the life of the BDP, full-scale prototypes of the latest barrier designs will be constructed in the field and tested. This approach enables engineers and scientists to momentarily "freeze" evolving barrier design(s) and obtain hands-on experience in constructing protective barriers. Constructability issues that were not readily apparent on the engineering drawings may be more easily detectable in the field. Another valuable benefit of this approach is that the construction of prototype barriers forces all of the various components of the barrier to be brought together into an integrated system. This integration is particularly 
important because some of the components of the protective barrier are required to be developed independently of other barrier components. This task identifies existing prototype barriers that already have been constructed as well as the prototype barrier planned for construction over the 216-B-57 Crib within the 200-BP-1 operable unit in late FY 1993 to early FY 1994.

\subsubsection{Protective Barrier Test Facility (BAR-1). The Protective Barrier} Test Facility (PBTF) originally was established in the early 1980 's to demonstrate the construction of full-scale (in the vertical dimension) barrier plots and to monitor their performance in the field. During a period of several years, five relatively small barrier prototypes were constructed at the PBTF. Two of the five barrier plots were variations of a multilayer barrier design concept. The other three barrier plots included a mounded rock; mounded soil; and a low-permeability, off-flow barrier plot. The installation of these prototypes illustrated that protective barriers can be constructed using conventional highway construction and earth-moving equipment.

During the first years of the facility's existence, the PBTF was monitored to determine the performance of the barriers from a hydrogeologic standpoint and the resistance of the barrier plots to biointrusion and erosion. Other uses for the PBTF were planned to be identified and considered during FY 1988. However, early in FY 1988, the BDP was informed that plans were being developed to construct a new waste management facility, the Hanford Central Waste Complex (HCWC), on a 100-acre parcel of 1 and in the 200 West Area of the Hanford Site. The site plans for the HCWC illustrated that the PBTF was located in the southeast corner of the proposed 100-acre parcel. Because of space limitations and other constraints, relocation of the HCWC to a site where the PBTF would not be impacted was not feasible. Consequently, the BDP was obliged to vacate the PBTF. Engineers and scientists from the BDP were allowed to salvage any equipment, data, or information that could be gleaned from the affected barrier plots before they were excessed.

(Please refer to references 1 and 2 in Section 7.0. Section 8.0 provides references to engineered drawings prepared to support construction of the PBTF.)

4.2.8.2 Field Observations of Grand Junction, Colorado Barriers (BAR-2). In 1979, barriers were constructed over uranium mill-tailing sites in Grand Junction, Colorado (Baker et al. 1984). One of the types of barriers used for mill-tailing sites consisted of a multilayer configuration with a lowpermeability, asphaltic layer placed low in the barrier profile (immediately above the uranium tailings). Because these barriers had been in place for approximately 8 years, an analys is of barrier performance in relation to asphalt durability, water infiltration, and plant and animal intrusion during this time frame was considered to be an activity that could provide valuable insights into barrier performance. The analysis of the Grand Junction barriers took place between June $8-19,1987$, and the results are summarized in Gee et al. (1989).

This task comprised the following activities:

- Performing sampling activities ard make other field observations as required (completed) 
WHC-EP-0673

- Performing laboratory analyses of samples collected (completed)

- Reporting results and making design recommendations (completed).

(Please refer to reference 20 in Section 7.0.)

4.2.8.3 Design, Construction, and Testing of Prototype Barriers (BAR-3). The data and insights gained from conducting barrier development tasks have enabled the BDP to progress to the point where the design, construction, and testing of a full-scale prototype is vital to continued barrier development. Although the results of development and testing efforts conducted heretofore are not final and additional work needs to be performed, enough information and data exist to allow the design, construction, and testing of a prototype barrier.

A full-scale prototype permanent isolation surface barrier will enable engineers and scientists to gain insights and experience with issues regarding barrier design, construction, and performance that have not been possible with the individual tests and experiments conducted to date in the program. For example, the prototype barrier will enable an assessment to be made of the quantity and fate of water that accumulates at the side slope and toe of the barrier. Does the water affect barrier stability and/or migrate laterally under the barrier toward the location where wastes are buried? Does the accumulation of water at the toe of the barrier enhance the growth of vegetation which in turn transpires much of the water back to the atmosphere? The prototype barrier will be of sufficient scale to enable the collection of quantitative data that can be used to address these and other issues. This information would have been very difficult, if not impossible to obtain without the prototype barrier.

The design, construction, and testing of a prototype barrier at this stage of the BDP is an important activity. The current program has been in existence since FY 1986. During this time, the emphas is of the program's efforts has been on the development and testing of various barrier components that are based on preliminary barrier conceptual designs. For the most part, these development and testing efforts have been performed either in the laboratory or on relatively small-scale field plots. Although not completely resolved, issues pertaining to protective barrier performance with respect to water infiltration; biointrusion; erosion and deposition; physical stability; and climate change are being addressed. Natural analog studies of various barrier components also have been conducted and computer simulation models have been used to predict the performance of preliminary barrier conceptual designs.

The design of a prototype barrier will enable engineers and scientists to use the data and insights collected to date from BDP field and laboratory tests. Also, a prototype barrier will enable barrier development team members to obtain experience in designing and constructing protective barriers.

Once constructed, the prototype barrier will be tested and monitored to evaluate its performance over a range of conditions representative of those expected to be experienced during the design life of a permanent isolation barrier. Many tests and experiments are planned to be conducted on the prototype barrier to assess its performance in relation to water infiltration, 
biointrusion, erosion, and physical stability. Because only a finite amount of time exists to test a prototype barrier that is intended to function for a minimum of 1,000 years, the testing program has been designed to "stress" the prototype so that barrier performance can be determined within a reasonable time frame. In addition, the prototype barrier will enable the performance of various aspects of the barrier to be evaluated.

The design, construction, and testing of a prototype barrier also will be a critical activity in demonstrating RCRA equivalency (see Section 4.2.13).

This task comprises the following activities:

- Gathering all of the relevant information that will be used to design and construct the prototype barrier (completed)

- Designing the prototype barrier (completed)

- Constructing the prototype barrier and installing testing and monitoring instrumentation (to be initiated in late FY 1993 to early FY 1994)

- Testing and monitoring the performance of the prototype barrier (to be conducted for a minimum of 3 years following construction)

- Analyzing the data and reporting the results

- Using the data and results acquired from the design, construction, and monitoring of the prototype barrier as input for directing the efforts of the BDP and for the final barrier design(s).

(Please refer to references 69 and 70,79 and 80 in Section 7.0 .

Section 8.0 provides references to engineered drawings prepared to support the construction of the prototype barrier.)

\subsubsection{Model Applications and Testing Tasks}

Performance assessments of waste management systems using protective barriers are required to demonstrate that the barriers provide adequate protection of the waste forms from the environment. To support these performance assessments, computer simulation models are being developed to evaluate the performance of protective barriers for a minimum of 1,000 years. The models simulate the movement of water through various barrier configurations, the unsaturated zone under the barrier, and the unconfined aquifer. By aitering various barrier parameters (e.g., soil-layer thickness, soil properties, the presence or absence of gravel mulches, the presence or absence of vegetation, and the amount of precipitation), the relative performance of a variety of barrier designs over a range of conditions can be evaluated (Fayer et al. 1985; Fayer 1987).

This task group uses computer models to help design barrier development. tests and experiments and to prepare preliminary design specifications for barrier components (Figure 12). In addition, this task group uses laboratory and field data generated by the BDP to verify the models and enhance their validity. 

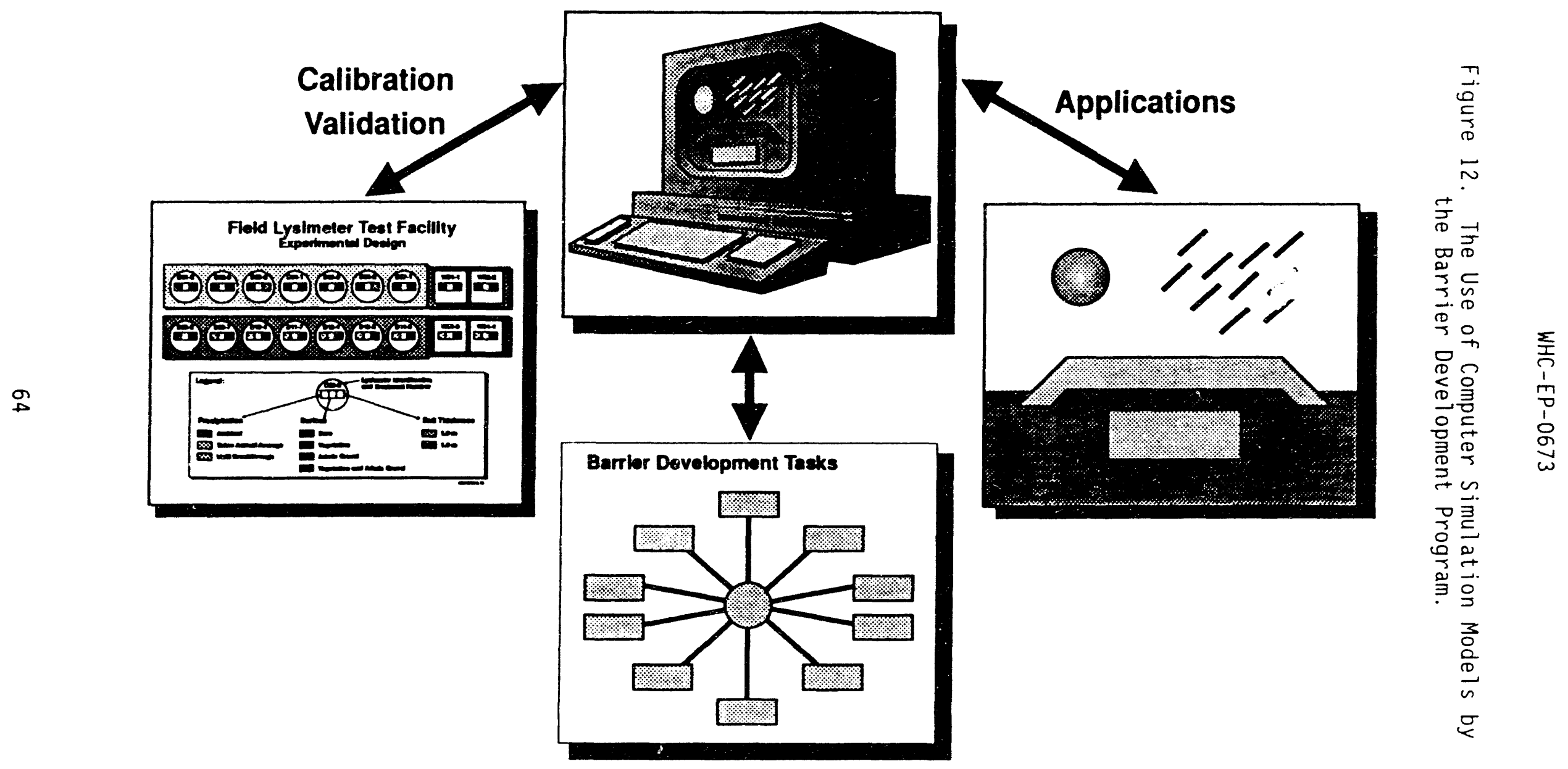

H9008010.27A b/w 
4.2.9.1 Application of Computer Models (MOD-1). While being developed and refined, computer models have been used to perform sensitivity analyses for insights into the design, testing, and performance of various barrier systems and components. The use of models in this manner is not considered a substitute for data collection (see task MOD-2). Rather, the early use of models provides a defensible basis for improving conceptual barrier designs and for collection of data. For example, the surface of the fine-soil layer of the barrier may need to be armored with a gravel mulch to limit the adverse effects of wind erosion. If too much gravel is used, plant transpiration and surface evaporation could be significantly reduced, thereby increasing the potential for water drainage through the barrier. Conversely, if too little gravel is used, the ability of the gravel mulch to reduce wind and water erosion may be severely limited.

Computer simulation models have been used to test the relative sensitivity of barrier performance to the amount of gravel mixed into or spread onto the fine-soil surface and allow for an estimate of the optimum amount of gravel. Furthermore, the range over which the simulations predict the barrier to perform best can be tested in the field. The use of models in this manner helps to focus field tests and experiments and provide insights into modifying and improving conceptual barrier designs.

This task comprises the following activities:

- Coordinating with personnel in other model development projects to ensure access to the most appropriate computer programs (completed)

- Preparing the data necessary to perform computer simulations (completed)

- Using the results of the simulations to help design tests and experiments and to improve the conceptual barrier designs (in progress).

(Please refer to references $3,9,27,29,33,46,56,58,59,60,64$, and 68 in Section 7.0.)

4.2.9.2 Model Testing (MOD-2). Computer simulations are being used by the BDP to assess the long-term performance of protective barriers. Before using the models to evaluate the performance of protective barriers, the models must be verified and tested for validity. Verification will be performed to demonstrate that correct solutions are produced by the encoded mathematical models within the defined limits for each parameter employed. Validation testing of the computer programs also will be performed to demonstrate that the encoded mathematical model produces a valid solution to the physical system being simulated.

Barrier performance, in terms of water infiltration cuntrol, is highly dependent on plant transpiration rates. Field tests have been and/or are being performed to collect data on the transpiration rates of $p$ lant communities expected to inhabit protective barriers. Some of this work may be accomplished at the FLTF (discussed in more detail in task WTR-2). Other approaches to collecting transpiration data include the use of gas-exchange chambers and field-plot measurement techniques. The gas-exchange studies will 
provide supportive data for the development of evapotranspiration models. These evapotranspiration models will be used in conjunction with the water infiltration models being developed to predict the movement of water through the barrier. This task also will be coordinated with the activities planned for task NAT-6, microrelief effects.

In addition to the evapotranspiration studies, the BDP will generate other data and information that will be used to test the validity of the models. Many of the field and laboratory tests and experiments presented in this document are designed to quantitatively evaluate the performance of protective barriers. The data collected from these field and laboratory tests will be provided to the individuals responsible for this task (MOD-2). The field and laboratory data will be compared with the prediction of the computer simulation models. Modification and refinements of the models will be made as needed, to provide the required degree of correlation with the data. Whenever appropriate, statistical methods will be used to analyze errors associated with the simulations.

This task comprises the following activities:

- Determining the required degree of correlation between the computer simulation models and the field and laboratory data (in progress)

- Comparing the model predictions with the data from the field and laboratory tests (in progress)

- Improving the conceptual models and computer programs as required (in progress).

(Please refer to references $3,9,27,29,33,46,56,58,59,60,64$, and 68 in Section 7.0.)

\subsubsection{Natural Analog Study Tasks}

Insights into the effects of environmental processes on protective barriers in the future can be gained from the study of past environmental processes that have acted on analogs of barrier components. For example, an analysis of the stratigraphy of soils that have been deposited on the Hanford Site may be indicative of the long-term physical stability of rock and soil barrier layers. Secondary mineralization in layered sediments also may be indicative of patterns of soil water movement over past millennia. Desert pavements and other surface rock formations may provide analogs for developing erosion-control practices and for measuring the effects of such practices on soil-water balance. The ability of plants to re-establish themselves after perturbations such as range fires can be predicted from studies of plant community dynamics on the soils that will be used for barrier construction. The potential for biointrusion of layered barriers can be judged from measurements of plant root and animal burrow distribution in analogous layered sediments. The long-term performance of barrier designs or components can be understood by studying ancient synthetic mounds and materials such as asphalt. Furthermore, the effects of future shifts in climate can be deduced by comparing the above factors at separate locations that exhibit spatial variability in climate. 
The objective of this task group has been to identify and provide a quantitative assessment of analogs of long-term barrier performance. The use of natural analogs was discussed by participants at the VE workshop convened in February 1993. The recommendation that resulted from the discussions was to discontinue all analog studies with the exception of the asphalt analogs study. Also, several preliminary reports that were written on analog studies conducted early in the BDP were to be completed, publicly released, and published.

The rationale for this recommendation was that the asphalt analog work may be needed to build a defensible case for the use of asphalt in permanent isolation barriers. The longevity of asphalt and its ability to perform as a low-permeability component for at least 1,000 years are key technical issues that have been raised. By studying asphalt artifacts that have existed for hundreds to thousands of years, insights into the design and durability of low-permeability asphalt layers may be obtained.

Most of the other natural analog activities either already have been completed or have been discontinued. For those few analog activities in which there still remained some work to be performed, VE workshop participants recommended that these activities be discontinued. There seemed to be little value added by continuing these tasks and the potential benefits did not seem to justify the anticipated costs. For those discontinued tasks in which some analog work was performed, a final report will be prepared to document any results found or conclusions drawn. The status of the following tasks is provided for completeness.

4.2.10.1 Barrier Analog Identification (NAT-1). A regional survey was conducted to locate and describe geologic outcrops and ecological settings that may be analogous either to components of proposed protective barrier systems or to measures of barrier performance. Gravel pits and other exposed cross sections of unconsolidated Hanford formation sediments were of principle interest. Sites visited during the initial reconnaissance were ranked and a few were selected for more detailed descriptions. The results of this work led to the following conclusions.

- It is highly unlikely that sediment profiles analogous to graded multilayer barrier designs, and particularly finding matching profiles in different climatic regions, will be found.

- Geologic and ecological settings do exist that can be analyzed as analogs of the long-term performance of barrier components. These analyses became the focus of subsequent tasks.

The following activities were included within this task and have all been completed:

- Conducting barrier analog reconnaissance (completed)

- Selecting sites for detailed characterization (completed)

- Evaluating the analog approach to barrier performance assessment (completed) 
- Reporting results (a final document will be prepared to document the findings of this task).

4.2.10.2 Armored-Surface Analog Field Studies (NAT-2). Incorporation of gravel into the surface of the protective barrier topsoil layer is a design feature intended to mimic conditions that lead to the formation of desert pavements. Desert pavements form on soils dispersed with stones. Over time, with wind deflation, runoff, and/or upward migration caused by freeze-thaw action, the stones become concentrated in the surface layer, forming a stone armor, which protects the underlying soil from further erosion.

In addition to desert pavements, bergmounds are another type of armored surface analog found on the Hanford Site. Bergmounds are geologic formations (mounds) believed to have resulted from the deposition of iceberg debris during catastrophic floods that occurred at the end of the Pleistocene glaciation about 13,000 years ago. The bergmounds are topographically higher than the surrounding environment. Hypotheses suggest that the gravel armoring on the surface of the bergmound, which covers fine soils similar to those that will be used in the barriers, may have enabled it to be more erosion resistant than other surface soils in the area.

Incorporation of gravel into the barrier topsoil may influence soil moisture-retention characteristics and the type and productivity of vegetation. The addition of gravel also may increase infiltration rates, roduce evaporation, yield fewer grasses and more shrubs and forbs, and possibly increase drainage. The objective of this task is to compare soil moisture and vegetation on gravel-armored soils with that on similar unarmored soils. A field evaluation of the armored-surface analogs also may provide important information on expected barrier performance over millennia.

This task comprises the following activities:

- Selecting armor analog sites (completed)

- Preparing field study plans (completed)

- Conducting field studies (completed)

- Assessing data and report. [The initial results of this task did not provide the expected information and the task was abandoned. However, a final report (Chamness 1993) has been prepared to document the findings of this task--per the recommendation of the participants of a VE workshop convened in February 1993].

(Please refer to reference 74 in Section 7.0.)

4.2.10.3 Blowout Field Studies (NAT-3). Blowouts have been observed to occur on disturbed sandy soils that are not stabilized with vegetation. Blowouts are circular or semicircular depressions that result from wind erosion. Up to 6 in. $(15 \mathrm{~cm})$ of erosion caused by blowouts could occur on a soil surface in a single season. A field investigation of blowouts at the Hanford Site was considered to be needed so that an understanding of the conditions that cause the phenomenon could be obtained. With this information, the barrier design could be adequately assessed and, if necessary, modified to prevent blowouts 
from occurring on the barrier cover. The objective of this task was to develop and use a model of eolian processes to better understand the erosive forces on long-term barrier stability.

In addition to erosion-related blowout problems, blowouts that occur on sandy soils immediately surrounding the barriers may create deposition-related problems on the barrier surface. The deposition-related activities of this task will be closely coordinated with the activities planned for task EROD-2.

This task comprises the following activities:

- Preparing a field test plan (completed)

- Coordinating the activities of this task with task EROD-2 (completed)

- Conducting field studies (discontinued per recommendations made at the February 1993 VE workshop)

- Developing a predictive model (discontinued per recommendations made at the February 1993 VE workshop)

- Assessing blowout prevention measures and reporting. (The initial results of this task did not provide the expected information and the task was abandoned. However, a final document will be prepared to document the findings of this task.)

(Please refer to reference 43 in Section 7.0.)

4.2.10.4 Pedogenic Indicators of Soil Water Movement (NAT-4). The distribution of carbonates in layered Hanford formation sediments may be indicative of long-term patterns of soil-water movement. If not of lithogenic origin, zones of carbonate accumulation in these sediments are probably the result of carbonate dissolution, bicarbonate translocation, and the reprecipitation of carbonates as moisture is removed from the system.

A subcontract was prepared and administered to assess carbonates in selected Hanford formation sediment profiles as indicators of past soil-water movement. This information was useful in providing insights into the ability of protective barriers to control water infiltration to the waste zone during long periods of time.

This task comprised the following activities:

- Preparing and administering the subcontract (completed)

- Characterizing carbonate distribution in selected sediment profiles (completed)

- Establishing the probable origin of zones of carbonate accumulation in these profiles (completed)

- Modelling the causal factors of carbonate accumulation (completed) 
- Evaluating water movement within layered sediments and report (completed).

(Please refer to reference 40 in Section 7.0.)

4.2.10.5 Sediment Stratigraphy and Geofilters (MAT-5). The long-term performance of protective barriers will depend, in part, on the prevention of fines in the topsoil layer from filtering into the interstitial spaces of the underlying coarse rock layer. Current barrier designs include, for this purpose, a graded sequence of coarse-to-fine gravel and sand layers between the rock and topsoil layers. This task was identified to evaluate the longterm structural integrity of such a layering sequence.

Many Hanford formation profiles consist of a lower horizon of cobbles and gravels in a coarse sand matrix that is mantled with an horizon of eolian silty sand. A protective barrier of similar design, in contrast to the graded layer design, may be more structurally stable.

The objectives of this task are to characterize the stratigraphy and effects of geofilters in selected Hanford formation deposits and to assess the size and stability of these graded-layer sequences in comparison with the bimodal layer deposits.

This task comprises the following activities:

- Preparing a field study plan (completed)

- Selecting sediment profiles for study (completed)

- Characterizing the structure of geofilters (completed)

- Contrasting the causality of graded and bimodal layering (completed)

- Contrasting the stability of graded and bimodal layering (completed)

- Reporting (a final report has been prepared to document the findings of this task--per the recommendation of the participants of a VE workshop convened in February 1993).

(Please refer to reference 73 in Section 7.0.)

4.2.10.6 Microrelief Effects (NAT-6). Lateral uniformity in barrier materials has been assumed in the modeling of soil water movement and in the designing of lysimeter studies to test model results. Therefore, it may be difficult to project these results over large areas where the soil surface may not be as regular as the modeling scenarios and lysimeter studies have assumed.

Surface soil irregularities caused by localized deposition and deflation or subsidence must be accounted for. A hummocky microrelief is common on Hanford Site uplands, particularly where sagebrush (Artemisia tridentata) and spiny hopsage (Grayia spinosa) co-dominate the shrub layer. The hummocks appear to be caused by localized deflation and redeposition within the dense canopies of these shrubs. This redistribution of soil may create 
heterogeneity in physical and chemical soil properties as well as in the microtopography. The objective of this task is to measure the effects of localized topographic heterogeneity on soil moisture.

This task comprises the following activities:

- Preparing a field study plan (coordinate with tasks MOD-2 and NAT-7) (completed)

- Selecting study areas (completed)

- Measuring spatial variability in microtopography and soil properties (completed)

- Analyzing the effects of localized topographic heterogeneity on the soil moisture regime and reporting results (completed).

(Please refer to references 27 and 33 in Section 7.0.)

4.2.10.7 Plant Community Dynamics (NAT-7). Temporal changes in the plant community inhabiting a barrier surface (plant succession) may be accompanied by changes in evapotranspiration, the potential for erosion, elemental cycling, and microorganism populations as well as in the potential for biointrusion. Although taking repeated measurements in permanent plots established on a barrier surface may be the only unequivocal way to document plant succession and its consequences, the necessary length of such a study would far exceed the scheduled completion of the BDP. As an alternative, the effects of plant succession can be studied as a consequence if proximal sites are found that are analogous to disparate stages of change. Changes in a plant community following a pulse type of disturbance, such as fire, or that resulting from a change in climate can be inferred using this approach.

The objective of this task is to locate plant communities that represent different stages of recovery (seral stages) from fire and/or cultivation, and to compare water infiltration, plant water extraction, microorganism populations, and nutrient cycling. The establishment of study sites at different elevations will incorporate climatic variability into the analyses. Coordination of this task with ongoing research on the Arid Land Ecology (ALE) Reserve will be pursued.

This task comprises the following activities:

- Preparing a field study plan (completed)

- Locating representative plant communities (this task was discontinued per recommendations made by participants at the VE workshop convened in February 1993)

- Measuring plant abundance and species composition (this task was discontinued per recommendations made by participants at the VE workshop convened in February 1993) 
- Comparing water infiltration and extraction characteristics (this task was discontinued per recommendations made by participants at a VE workshop convened in February 1993)

- Measuring the impacts on soil microorganism populations and nutrient cycling (this task was discontinued per recommendations made by participants at a VE workshop convened in February 1993).

(Please refer to reference 45 in Section 7.0.)

4.2.10.8. Ancient Mounds (NAT-8). Closure caps for waste disposal facilities are typically designed as layered earthen structures, the composition of which is intended to prevent the infiltration of water and the intrusion of the public into waste forms for many centuries. Archaeological mounds hundreds to thousands of years old that are closely analogous to closure caps in form, construction details, and intent can be studied to obtain an understanding of design performance, both in terms of structural integrity and hydrology.

The objective of this task is to research extant archaeological literature on ancient burial and temple mounds and extract information on design and structural integrity. This information will be analyzed to ascertain relationships between these two parameters. A selected set of archaeological mounds in both moist and arid parts of the United States will be selected then for water balance study.

This task comprises the following activities:

- Assembling archaeological literature on mounded structures and extracting information relevant to durability and design (completed)

- Analyzing data on durability and designing and preparing a report of findings (completed)

- Selecting a set of three to four mounds for water balance study (initiated but discontinued per recommendations made by participants at a VE workshop convened in February 1993)

- Conducting a water balance study (this task was discontinued per recommendations made by participants at the VE workshop convened in February 1993)

- Analyzing and reporting results (a preliminary report was prepared; however, this task was discontinued per recommendations made by participants at the VE workshop convened in February 1993).

(Please refer to reference 54 in Section 7.0.)

4.2.10.9 Asphalt Analogs (NAT-9). Asphalt is a planned component of permanent isolation surface barriers. The ability of asphalt to perform as dasigned for 1,000 years or more is not known. Asphalt on the land surface is subject to rapid aging from exposure to oxygen and ultraviolet radiation. However, buried asphalt, which will not be subjected to ultraviolet radiation, should perform much better. Data on the magnitude of the improvement is not currently available and, therefore, must be estimated by laboratory 
experiments and analyses of asphalt analogs. This task is designed to investigate the effects of aging on buried asphalt by studying the effect of intentional long-term burial on rates of oxidation and volatile loss.

Asphalt artifacts from human graves have been obtained from museum collections in areas where asphalt occurs naturally. Samples of naturally occurring asphait then will be obtained from the suspected sources of the artifacts. The artifacts will be age dated by radiocarbon analysis of associated organic materials. Elemental analyses will confirm the relationship between naturally occurring "fresh" asphalts and the artifacts. Chemical analyses will be performed to assess the effects of time on asphalt in the buried environment. The result will be an aging trajectory for one or more asphalt types that will be used to calibrate an artificial aging process. Artificially aged asphalt will be used in experiments of another task to ascertain the effects of the observed changes on asphalt's physical and hydrological properties (refer to PHYS-2).

This task is being coordinated with Tasks WTR-4, PHYS-2, 3AR-3, and RCRA-4. The costs associated with all asphalt testing activities are summarized in Section 4.2.3.5.

This task comprises the following activities:

- Locating museum collections and natural seeps (completed for one locality)

- Obtaining archaeological samples and seep asphalts (completed for one locality)

- Determining ages of artifacts by radiocarbon dating of associated materials (initiated)

- Conducting elemental and chemical analyses (initiated)

- Analyzing and reporting on results.

\subsubsection{Long-Term Climate Change Effects Assessment}

Changes in climate will have an all-pervading influence on protective barrier performance. Soil-water movement will be sensitive to changes in precipitation, temperature, and the water extraction characteristics of plants growing on the barrier. Biointrusion analyses must account for climateinduced changes in plant root distribution and animal burrowing. These factors, plus shifts in the wind regime, may impact surface stability. Until recently, the possible 1,000-year variations in the climate and ecology of the Pasco Basin have been largely unknown. The objective of these tasks is to obtain probabilistic projections of long-term variability in the Pasco Basin climate that can be input to analyses of water balance, biointrusion, and erosion of protective barriers.

At the VE workshop convened in February 1993, climate change and its impact on barrier performance was discussed. The recommendation from the discussions was to discontinue any additional climate studies supported by the 
BDP at the end of FY 1993. The remaining climate studies still should be performed, but the VE workshop recommended that they should be funded by larger programs with a Sitewide scope. Also, a document should be prepared and published in FY 1994 that summarizes the climate-change assessment work that has been conducted to date and states (with supporting evidence) the climate change effects position taken by the BDP.

The rationale for the recommendations made by the VE workshop participants is summarized below. The lead scientist for the climate studies felt that the work that has been conducted to date will enable a defensible case to be made that future climate changes over the next 1,000+ years will not exceed $3 X$ (three times the average annual precipitation). This level of information should suffice for the BDP. However, it was acknowledged by the VE workshop participants that the remainder of the tasks identified in the climate study plan (Petersen et al. 1993) should be conducted. Climate change is an extremely important consideration that must be taken into account for any long-term remediation or waste management activity conducted at the Hanford Site. The climate study plan was carefully prepared and peer reviewed by offsite technical experts to provide the climate information needed to support the clean-up objectives of the Hanford jite. However, the BDP should not be required to bear the entire burden of funding an important activity that would benefit many different programs across the entire Hanford Site. Consequently, the VE workshop participants recommended that the BDF fund only those climate tasks that will provide thein with the information they need. The results of these tasks will be summarized in a document to be prepared during FY 1994. The remaining climate study plan :asks needed by other Sitewide programs should be funded by those programs.

For comple $e^{+}$ the Long-Term C the status of the tasks in the following sections of hange Effects Assessment Task group is provided.

4.2.11.1 Evalual iimate Informational Needs (CLIM-1). The objectives of this task are to identify specific parameters of long-term climate that will be required for water infiltration, erosion, and biointrusion analyses; to evaluate the adequacy of existing information; and to determine an approach for acquiring any needed information.

Previously, much of the climate-related information needed by the BDP was planned to be obtained by tying into the multimillion dollai climate prograin funded by the Basalt Waste Isolation Project (BWIP). The BWIP climate program would generate much of the same information needed by the BDP. By tying into the BWIP climate effort, the BDP would have been able to acquire needed climate-related information without having to incur the significant costs associated with generating the data. The BDP would have funded and performed any additional climate work that was needed and was not planned to be conducted by the BWIP.

A decision was made to discontinue investigating the Hanford Site as a possible location for a commercial nuclear waste repository. As a result of this decision, the BWIP was no longer funded. The impact that this decision had on the climate-related needs of the BDP was significant. Cursory estimates suggested that millions of dollars would have to be expended by the BDP to obtain the same relevant information that was to be acquired at no cost 
from the BWIP. These additional costs were not anticipated and, if incurred, would have had a severe impact on the BDP's budget.

The decision to discontinue funding the BWIP forced the BDP to reevaluate its strategy for obtaining needed climate information. So, a set of study plans was drafted that incorporated the applicable BWIP tasks. These plans were critiqued, in a workshop setting, by an external panel of regulators and technical peers. The comments received from the peer reviewers were used to aid barrier development team members in finalizing the climate study plan that met the technical needs of the BDP and was commensurate with anticipated budget levels. The modular climate study plan was designed to provide an overall research strategy that would be flexible enough to accommodate future funding uncertainties or could be used for other applications that might have need for climate information.

This task comprises the following activities:

- Identifying the key climate parameters for input to barrier performance analyses (completed)

- Evaluating the adequacy of existing data (completed)

- Preparing a long-term climate change assessment study plan based on existing, applicable BWIP study plans (completed)

- Having an offsite peer review of the long-term climate change assessment study plan (completed)

- Finalizing the climate study plan (completed).

(Please refer to references $17,21,28,43,53,57,66$ and 71 in Section 7.0.)

4.2.11.2 Predict Local Climate and Vegetation Changes (CLIM-2). Different types of models will be employed to predict variability in the climate and vegetation of the Pasco Basin over the next 1,000+ years. Statistical models called transfer functions will be used to reconstruct past climates from geologic and paleobiotic indicators such as glacier fluctuations, fossil pollen records, and tree rings. A local climate forecast model will be developed and calibrated with this information. The relationships between local "limate variables and regional controlling factors, such as atmospheric and oceanic circulation patterns, also must be modeled and infut to the local climate forecasts. Future variability in the vegetation and wind regime of the Pasco Basin will be estimated in addition to variability in precipitation and temperature. This information will be input to water infiltration, biointrusion, and erosion control tasks.

This task comprises the following activities:

- Executing the climate study plan (in progress)

- Reconstructing the local paleoclimate (in progress)

- Developing and calibrating the local climate forecast models 
- Predicting changes in precipitation and temperature (in progress)

- Predicting changes in the wind regime

- Predicting climate-induced changes in vegetation

- Reporting the results of this task for use by tasks dependent on the data (completed for work performed to date).

Many of the activities identified in this task have been initiated. However, based on the recommendations made by participants at the VE workshop convened in February 1993, the BDP will discontinue funding these activities after FY 1993. Based on this same recommendation, other programs requiring climate information to support the remediation and management of wastes at the Hanford site will fund the remailling tasks identified in the climate study plan.

(Please refer to references $17,21,28,43,53,57,66$ and 71 in Section 7.0.)

\subsubsection{Interface with Regulatory Agencies}

The need to interface and interact with regulatory agencies is recognized as an important part of the process to foster regulatory agency understanding of technology development initiatives which, in the case of the BDP, are intended for consideration in arriving at a record of decision regarding the final closure of waste disposal sites at the Hanford Site. The actual regulations that will govern the closure of waste disposal sites will be determined through the implementation of the Tri-Party Agreement (Ecology et al. 1990) process as applicable or relevant and appropriate requirements (ARAR) for final site closure are identified and negotiated. This section is not intended to be an exhaustive discussion of regulations and their applicability to the closure of waste disposal sites. The mechanisms used to enhance communications between the regulatory agencies and the developers of protective barrier technology will be addressed.

4.2.12.1 Background. The Hanford Federal Facility Agreement and Consent Order (Ecology et al. 1990) was signed in May of 1989. This document, commonily referred to as the Tri-Party Agreement, is a legally enforceable agreement between DOE, EPA, and Washington State Department of Ecology (Ecology). The Tri-Party Agreement establishes the framework for cleanup of the Hanford Site by 2018 in accordance with the provisions of RCRA and CERCLA. The Tri-Party Agreement addresses the actions necessary to achieve full RCRA compliance, including closure of inactive RCRA treatment, storage, or disposal (TSD) facilities. The Tri-Party Agreement also addresses the cleanup of inactive waste disposal sites as remedial actions under RCRA or CERCLA corrective action authority.

In general, waste disposal site closure at the Hanford Site possibly could be conducted (1) under RCRA transportation, storage, and disposal regulations and Washington Administrative Code requirements, (2) as remediation projects under CERCLA and/or Section 3004(u) of RCRA, or (3) under newly promulgated legislation and regulations that do not currently exist, but 
could result from attempts to reconcile inconsistencies between various federal and state regulations. Any closure option must also comply with applicable Atomic Energy Act of 1954 (AEA) requirements and DOE orders concerning the management of radioactive materials and wastes.

Closure of some RCRA TSD facilities in full compliance with federal and state regulations, and DOE orders may not be feasible because of unacceptable risks posed by the nature of the waste form, uncertainty in the structural integrity of waste disposal structures, radiation exposure and other concerns. In these instances, the Tri-Party Agreement contains sufficient flexibility to negotiate alterations to the agreement to arrive at mutually agreeable solutions for cost-effective and safe site closure.

4.2.12.2 Site Closure Under Current Regulations. The final closure of waste disposal sites will be conducted in accordance with numerous federal, state, and local regulations. As indicated previously, the actual governing regulations will become part of the regulatory process in which ARARs are identiried and negotiated under the RCRA and CERCLA processes.

The radioactive and mixed waste nature of most of the wastes at the Hanford Site poses a somewhat challenging and complex situation concerning final waste disposal in full compliance with applicable site closure regulations. With regard to the radioactive materials present in the wastes, the management, treatment, storage, and disposal of radioactive wastes are governed by the AEA, Nuclear Regulatory Commission, and DOE orders. The hazardous waste constituents, however, are governed by federal and state regulations (e.g., RCRA, CERCLA, TSCA, HSWA, etc.).

The RCRA and AEA were written with provisions for reconciling differences when the requirements of RCRA were in conflict with the AEA requirements. For example, under Section 1006(a) of RCRA, the federal and state requirements for the removal of mixed waste and residues are applicable to the closure of waste disposal sites only to the extent that they are consistent with the requirements of the AEA.

Proper closure of waste disposal sites is imperative to ensuring adequate protection of human health and the environment. In general, protective barrier systems must effectively control the creation and migration of leachate, which could adversely affect groundwater quality. Other concerns include biointrusion ( $p l a n t s$ and animals) that could result in the secondary spread of contamination away from its place of disposal. The regulatory requirements for protective barrier systems can vary widely depending upon the nature of the wastes and the regulatory agency having purview over final site closure operations.

4.2.12.3 RCRA/CERCLA Covers. Subparts $G, K$, and $N$ of the RCRA Subtitle $C$ regulations provide the basic requirements for many of the cover systems being designed today for application to hazardous waste landfill closures. The EPA recommended protective barrier design consists of a vegetated topsoil layer that overlies a drainage layer and a low hydraulic conductivity geomembrane/ soil layer. This design is commonly known as the "RCRA Clay Cap" and is intended for a minimum 30-year postclosure care period after the closure of hazardous waste landfill sites. 
The RCRA Subtitle D regulations provide guidance on the design of cover systems for nonhazardous waste landfills. Subtitle D cover designs are mostly a function of the performance of a bottom liner system and incorporate an overall liquids-management strategy to avoid the disposal of free liquids.

The final design for protective barriers must consider the site geohydrology, climatic conditions, nature of the wastes, and other sitespecific conditions. So, the RCRA Clay Cap design is provided by the EPA as a minimum recommended design. The EPA encourages the development of alternate designs provided that RCRA Clay Cap equivalency or better performance can be demonstrated. Problems experienced with the desiccation and cracking of clays under arid site conditions is one of several reasons why the Hanford Site protective barrier is being researched and developed as a viable alternative to the RCRA Clay Cap.

The Superfund Amendments and Reauthorization Act of 1986 (SARA) adopts and expands a provision in the 1985 National Contingency Plan requiring that remedial actions attain ARARs at a minimum. The RCRA Subtitle $C$ requirements for TSDs frequently become ARARs for CERCLA actions because RCRA typically regulates the same or similar wastes as those found at many CERCLA sites (with the exception of radioactive materials). Therefore, RCRA cover systems and closure requirements are oftentimes applied in the closure of CERCLA sites. When RCRA closure requirements are determined to be applicable, the regulations allow two types of closure:

- Clean Closure--All waste residues and contaminated system components are removed and managed as hazardous waste or are decontaminated before the site management is completed. This includes contaminated subsoils, structures, and equipment that has been contaminated by the waste leachate.

- Landfill closure--The waste disposal site is capped with a final protective barrier that is designed and constructed to provide longterm water infiltration control, minimize maintenance, promote surface drainage, minimize erosion, minimize biointrusion, protect against subsidence, and have an hydraulic conductivity less than or equal to any bottom liner system or natural subsoils.

Clean closure is typically referred to as the "eatable solid, drinkable leachate" standard in which there is unrestricted access to the site following closure. Clean closure also assumes that no future maintenance will be required. Landfill closure, on the other hand, assumes that postclosure care and maintenance will be conducted for at least 30 years following closure. Postclosure care typically involves maintenance of the final protective barrier system, operation and maintenance of leachate removal systems (for disposal cells equipped with liners and leachate collection systems), and maintenance of groundwater monitoring systems.

Even though RCRA closure requirements may be determined not to be applicable, they may be considered relevant and appropriate. This can provide more flexibility in final closure system designs. As relevant and appropriate requirements are defined, hybrid closure approaches may be developed. Hybrid closure combines desirable elements of clean closure, landfill closure, and 
other pertinent closure schemes into an optimized design that adequately protects human health and the environment.

4.2.12.4 Low-Level Radioactive Waste Covers. Most of the Hanford Site's waste disposal sites contain varying quantities of low-level radioactive wastes (LLW). The regulations governing the disposal of $L L W$ include, but are not limited to, 10 CFR Part 61, 40 CFR Part 192, and 40 CFR Part 193.

By regulation, LLW disposal sites are required to demonstrate long-term stability typically on the order of 300 to 500 years (10 CFR Part 61.44). Regulations governing the disposal of LLW from uranium mill-tailing remedial action programs require the stability of waste disposal sites for periods up to 1,000 years (40 CFR Part 192.02). The 1,000-year control period is also typical of the requirements of the remanded 40 CFR 193 regulations governing the disposal of LLW.

In developing these regulations, the EPA sought closure system designs that rely on passive control systems rather than active control systems. Active control systems typically require a commitment to long-term maintenance and possibly land-use restrictions. Design features such as thick soil covers, belowgrade disposal, and high-quality rock covers for erosion protection are suggested. The emphas is in the federal regulations governing LLW is on protection of human health and the environment from radiological and nonradiological hazards associated with radioactive materials. In general, protective barrier systems must satisfy long-term stability and environmental protection standards, which include water infiltration control, wind and water erosion control, subsidence control, radioactivity dose rate control, biointrusion control, freeze/thaw control, and long-term stability without active riaintenance.

4.2.12.5 Regulatory Interactions. The need to interface/interact with the regulators on protective barrier technology is of critical importance to provide assurances that alternative barrier designs will meet regulatory expectations, satisfy identified ARARs, and meet RCRA equivalency requirements (see Section 4.2.13). This is especially true at the Hanford Site because one of the objectives of the BDP is to provide a defensible alternative to the commonly used "RCRA Clay Cap." The Hanford Site's barrier development efforts are directed at demonstrating cover systems that will meet or exceed RCRA requirements and be capable of providing final waste disposal in arid to semiarid environments for more than 1,000 years without maintenance.

The Hanford Site protective barrier has become a prominent feature in Sitewide plans for waste management and environmental restoration at the Hanford site. This reinforces the need for regulatory involvement to foster early understanding of and concurrence with the focus of protective-barrier research, development, and demonstration efforts.

The current regulatory interfaces are depicted in Figure 13. From a technology development perspective, the stakeholders in protective barrier technology at the Hanford Site fall into three broad categories. These categories include Waste Management (EM-30), Environmental Restoration (ER) (EM-40), and the Office of Technology Development (EM-50). Waste Management is responsibie for ongoing site operations that include the treatment, storage, and disposal of wastes. As such, Waste Management operations 


\section{USTID}

Connection

(EM-50)

- USTID closure TSG

- Other ID/IP closure TSGs

- Technical seminars

- EPAWDOE membership on BTAB

\section{WM}

Connection (EM-30)

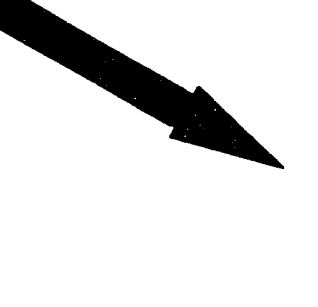

\section{ER Connection (EM-40)}

- Permit applications

- Unit manager briefings

- Closure plans

- Special topic group

- Technology milestones in TPA

- Records of decision 
typically fall within the jurisdiction of RCRA regulations. Consequently, Waste Management has prepared permit applications and closure plans for active TSDs that indicate the ultimate use of the Hanford Site protective barrier in support of final site closure activities under RCRA. These documents are reviewed and approved by the EPA and Ecology.

Environmental Restoration is responsible for the characterization, remediation, and final closure of the Hanford Site's inactive waste disposal sites. In general, ER activities typically fall within the jurisdiction of CERCLA regulations. There are many initiatives underway to enhance regulatory interaction and involvement in protective barrier development efforts. First, there are periodic technical briefings presented at the monthly Unit Managers Meetings in which DOE, ECology, EPA, WHC, and others gather to discuss and exchange information pertinent to the characterization, remediation, and final closure of the Hanford Site's waste disposal sites. Second, a "Special Topic" group was formed with the regulators to provide more visibility to the progress being made at the Hanford Site in protective barrier research and development. Finally, a series of meetings have been conducted with the regulators to discuss the construction and testing/monitoring of the first protective barrier prototype design over an actual waste site (216-B-57 Crib in the 200-BP-1 operable unit) in support of in-field treatability studies and possibly an early record of decision on final site closure.

The Office of Technology Development (OTD) is responsible for the research, development, demonstration, testing, and evaluation (RDDT\&E) of innovative technologies for waste site characterization, remediation, and final closure. Until recently, the development and demonstration of the Hanford Site's protective barrier system fell within the purview of the OTD. The ER Program now has taken responsibility for fully funding the BDP to completion. However, the BDP still has ties to OTD because several members of the barrier development team serve on OTD-sponsored Technical Support Groups (TSG). The TSGs represent broad areas of expertise (e.g., retrieval, pretreatment, closure, etc.). The TSGs also provide technical review of research and development proposals and make recommendations on worthy technology development initiatives. The Site Closure TSG for the Underground Storage Tank Integrated Demonstration has representatives from the EPA and Ecology to provide regulatory insight and perspective. Also, independent third-party peer reviews of the BDP and prototype barrier design have been conducted. Several of the peer review team members are active, at a national level, in promulgating site closure regulations for the EPA and other regulatory agencies.

\subsubsection{Resource Conservation and Recovery Act Equivalency}

One of the major findings that resulted from the VE workshop convened in February 1993 was the need to demonstrate "RCRA equivalency." This is necessary because the Hanford Site barrier does not look like the conventional barrier designs provided in EPA guidance documents. In addition, no one has ever constructed a Hanford Site barrier. Consequently, no applicable construction $Q A$ or quality control (QC) procedures currently exist that are readily adaptable. The appropriate $Q A / Q C$ procedures that are relevant to various performance objectives must be developed. Because the regulatory agencies will need to endorse the use of the Hanford Site barrier for the 
remediation of waste sites, data will need to be generated that provide convincing evidence that the Hanford Site barrier is as good as or better than "equivalent" conventiona? caps. Close interactions with the regulatory community will be needed to define RCRA equivalency (see Section 4.2.12). The close interactions also will help to ensure that BDP tasks and prototype barrier design and testing activities adequately address RCRA equivalency objectives.

The objective of this task group is to coordinate the generation of data that will provide the convincing evidence of the Hanford Site barrier's ability to meet and exceed RCRA requirements.

4.2.13.1 Preparation of a RCRA Equivalency Report (RCRA-1). During the VE workshop, it was recommended that a RCRA equivalency expert, preferably with experience building cover systems in the state of Washington, be contracted to address the RCRA equivalency issues for the Hanford Site barrier. During FY 1993, DOE, Richland Operations Office (RL), through its General Support Services Contractor, contracted Dr. Ronald J. Tanenbaum of Dames and Moore (San Diego office) to prepare a RCRA equivalency report. This report was intended to provide an analysis between the standard RCRA cover and the Hanford Site barrier prototype scheduled for construction in late 1993 to early 1994 over the 216-B-57 Crib in the 200-BP-1 operable unit. The report would address the specific RCRA equivalency issues that pertain to the Hanford Site barrier prototype at the 216-B-57 Crib location as well as some general considerations for RCRA equivalency at any site where the use of a Hanford Site barrier may be considered.

This task comprises the following activity:

- Preparing a RCRA equivalency report for the prototype Hanford barrier (completed).

\subsubsection{Construction and Testing of a Prototype Barrier (RCRA-2).} A discussion was provided for task BAR-3 regarding the design, construction, and testing of a prototype barrier. This task describes the needed interaction of the barrier development team with the regulatory agencies to ensure that the testing of the prototype barrier meets the regulators' expectations for addressing RCRA equivalency issues. It has been the desire of the BDP to involve the regulatory agencies in the barrier development process. A more general discussion of the BDPs interface with the regulatory agencies is provided in Section 4.2.12.

A common practice for owners of RCRA hazardous waste landfills and many municipal solid waste landfills is to construct a test pad to demonstrate and verify that barrier performance objectives can be met. The prototype Hanford Site barrier with its associated testing and monitoring facilities is intended to serve as a test pad for demonstrating the barrier's ability to meet established performance objectives.

To ensure that stakeholders in the barrier development effort (especially the regulatory community) have input to the design, construction, and testing of the prototype barrier, regular meetings, tours, presentations, etc., have been convened to address the interests and needs of all parties. Based on the input of the various stakeholders, two documents have been prepared to support 
the testing and monitoring of the prototype barrier. One of these documents is a treatability test plan. The treatability test plan is intended to be relatively general in scope and provides the general methodology or approach for conducting a treatability study on the prototype barrier. This document is necessary to support the remediation of the 216-B-57 Crib within the 200-BP-1 operable unit. The writing of the treatability test plan was followed by the preparation of a more comprehensive and technically-oriented testing and monitoring plan. Both of these documents have been cleared for public release and published (see the list below).

Another important aspect of this task is the involvement of independent external technical experts. These experts provide technical oversight to the entire BDP as well as review specific information and documentation pertaining to the prototype barrier project. Numerous technical peer reviews have been conducted throughout the life of the barrier development effort. As mentioned previously, a comprehensive review of the prototype barrier was conducted by five of the nation's leading barrier experts in 1991 (Wing 1992). In addition, Dr. David Daniel has been contracted to participate in a VE workshop, to provide technical oversight, and to review various prototype barrier documents including design media, construction specifications, the testing and monitoring plan, and the construction quality assurance plan.

This task comprises the following activities:

- Conducting regular meetings, tours, presentations, etc., that involve all stakeholders (ongoing)

- Preparing a prototype barrier treatability test plan (completed, DOE-RL 1993)

- Preparing a prototype barrier testing and monitoring plan (completed, Gee 1993)

- Establishing contracts with technical experts to provide technical oversight and to conduct reviews of project documentation (ongoing).

(Please refer to references 61,69 , and 70 in Section 7.0.)

4.2.13.3 Preparation of a Construction Quality Assurance Plan (RCRA-3). A hanford Site barrier has never before been constructed. The prototype barrier scheduled for construction during the latter part of 1993 and early part of 1994 will provide the first opportunity to construct a large-scale permanent isolation surface barrier. A full-scale prototype barrier will enable engineers and scientists to gain insights and experience with issues regarding barrier design, construction, and performance that have not been possible with the individual tests and experiments that have been conducted to date in the program. An important activity that supports the prototype barrier effort is the preparation of a construction quality assurance (CQA) plan.

Experience with past constiuction projects has demonstrated that poor construction has been a much more common problem than poor design. Because the Hanford Site barrier is different than any other type of cover, no QA/QC procedures exist that can be readily adapted. Consequently, the development 
of appropriate $Q A / Q C$ tests and procedures that are relevant to various performance objectives for the Hanford Site barrier is needed.

This task comprises the following activities:

- Preparing a CQA plan for the prototype barrier that contains appropriate $Q A / Q C$ tests and procedures relevant to various performance objectives for the Hanford Site barrier (a CQA plan for the prototype barrier has been prepared)

- Making modifications to the CQA plan basEd on lessons learned after the construction of the prototype barrier

- Using the modified prototype barrier CQA plan as a model in the preparation of CQA plans for future barrier construction projects.

(Please refer to reference 81 in section 7.0. )

4.2.13.4 RCRA Equivalency of Low-Permeability Asphalt Layers (RCRA-4). Asphalt testing activities being conducted in the BDP are described in tasks WTR-4, PHYS-2, BAR-3, RCRA-4, and NAT-9. No additional asphalt studies are planned to be performed as part of this task. However, any discussion of RCRA equivalency would not be complete without including information on the importance of the asphalt layers in the current Hanford Site barrier design. Consequently, for completeness, this section describes how the asphalt studies fit into the approach to demonstrate RCRA equivalency.

As mentioned previously, the basic premise of the capillary barrier concept is that most of the meteoric water that infiltrates the barrier surface can be returned to the atmosphere by surface evaporation and plant transpiration. The capillary barrier portion of the permanent isolation surface barrier is expected to be the real "workhorse" most of the time in ridding the barrier of excess moisture. However, for periods of unusually heavy, intense, and/or prolonged precipitation, the water-holding capacity of the fine soils may be exceeded, thereby allowing water to break through the capillary barrier before it can be recycled back to the atmosphere. Unless checked in some way, the water would be free to migrate down through the barrier and into the waste zone below. As a means of restricting the percolating water from gaining access to the waste zone, a low-permeability component is placed strategically within the barrier profile below the capillary barrier to divert percolating water away from the buried waste. This diversion barrier is constructed of a material(s) with low permeability such as a composite asphalt layer.

Although the composite asphalt layer is not the only mechanism available in the Hanford Site barrier for managing percolating water, its function is similar to that of the composite geomembrane/compacted clay liner found in caps for virtually all modern hazardous waste landfills and many municipal solid waste landfills. Because the composite asphalt layer could become challenged by infiltrating water during the design life of the permanent isolation barrier, data on its performance is needed. These data will be generated in tasks WTR-4, PHYS-2, BAR-3, RCRA-4, and NAT-9 and reported in pubilished status reports and other documents. These asphalt performance data will be an important part of the information assembled to demonstrate RCRA 
equivalency of the Hanford Site barrier to a conventional RCRA Clay Cap. The costs associated with all asphalt testing activities are summarized in Section 4.2 .3 .5 .

This task comprises the following activity:

- Coordinating with the regulatory agencies on requirements for RCRA equivalency with regard to the composite asphalt layer (in progress).

4.2.13.5 Barrier Comparisons at the H1ll Air Force Base (RCRA-5). In this task, engineers and scientists on the BDP at the Hanford Site will collaborate with colleagues from LANL, who are working on barrier-related activities at Hill AFB in Ogden, Utah. The LANL scientists and engineers have constructed a large lysimeter facility that enables a comparison to be made of the performance of four different barrier designs: a RCRA Clay Cap, two LANLdesigned multilayer barriers, and a monolithic soil cover. In this task, a Hanford Site barrier will be constructed at the facility and its performance will be compared with the other barrier designs. This test will provide a good opportunity to understand how the Hanford Site barrier performs in a wetter climate compared to other barrier designs, including a RCRA Clay Cap. $H i 11$ AFB receives about three times the average annual precipitation ( $3 X$ ) that the Hanford Site receives. Much of Hill AFB's precipitation is in the form of snow as well. Because current preliminary projections suggest that Hanford's future climate should not exceed $3 X$ precipitation during the next $1,000 \%$ years, the tests at Hill AFB should present a worst-case condition for Hanford Site barriers.

This task comprises the following activisies:

- Preparing a test plan for the barrier comparisons to be conducted at Hill AFB in Ogden, Utah (in progress)

- Constructing the Hanford Site barrier at Hill AFB (planned for FY 1994)

- Monitoring the performance of the Hanford Site barrier at Hill AFB per the test plan

- Evaluating the data generated at Hill AFB and reporting.

\subsubsection{Technology Integration and Transfer}

The activities within this task are intended to transfer permanent isolation surface barrier technology to end users. Technology integration and transfer will be accomplished by performing activities such as making presentations, conducting workshops, and convening special topics and regular working-group meetings with end users. In addition, presentations will be made at national and international conferences and symposia. Documents produced as a result of barrier development activities will continue to be cleared for public release, published, and disseminated to interested individuals and organizations both onsite and offsite. 
WHC-EP-0673

4.2.14.1 Barrier Development Program Documentation (TECH-1). Progress leading to a final barrier design will be documented. The documentation will include the results of all barrier development, research, demonstration, and testing activities conducted throughout the life of the BDP. This information will provide a technically sound foundation on which final designs can be based. In addition, current plans include videotaping the design, construction, and testing/monitoring of the prototype barrier. The videotape will be a valuable resource for final barrier design efforts. Furthermore, documentation assembled and activities conducted as part of the prototype barrier project will serve as an excellent resource for developing design media for a final barrier design at the conclusion of all development activities.

This task will support the editing and information release requirements for publishing BDP documents.

4.2.14.2 Consultation on Special Barrier-Related Topics (TECH-2). Members of the BDP are also expected to be needed as consultants to end users regarding special topics related to barrier design and construction. Members of the BDP have become acquainted with various issues pertaining to barrier design and construction. These issues may not be commonly known or understood by those who are not as intimately familiar with the barrier program.

From a design perspective, a systems engineering or holistic approach should be employed when permanent isolation barriers are used for environmental restoration activities or for various types of waste disposal facilities. For example, because water running on and off the barrier may be concentrated in a relatively localized area at the side slope and toe, the amount of water available for recharge at the periphery of the barrier may be significantly higher than at other locations of the barrier that receive only ambient precipitation. So, the barrier must be designed such that the accumulation of water under the side slope and at the toe is not allowed to travel indiscriminately via overland or subsurface flow into adjacent waste sites, which would adversely affect their performance. This design consideration would likely affect the operations of existing waste sites as well as the layout of new disposal facilities where permanent isolation barriers are planned to be employed.

Another design consideration requiring a systems engineering or holistic approach pertains to the interface of individual barriers covering adjacent waste disposal sites. Many of the waste sites on the Hanford Site are located in relatively close proximity to one another. If barriers are constructed one at a time, there exists a high degree of probability that the footprint of one barrier may encroach onto another adjacent waste disposal site. A systems engineering or holistic approach would require that analyses be performed to determine the best manner in which to remediate a group of waste sites. For example, constructing one relatively large barrier over a group of adjacent waste sites may be preferable to constructing a barrier over each individual waste site.

In addition to the examples cited previously, long-term monitcring issues also should be considered early in the design phase. To monitor barrier performance, instruments and transducers, or access for the instruments and transducers, may need to be included within or below the barrier. Some of the 
approaches for monitoring the barrier may not lend themselves to retrofitting after barrier construction. Consequently, the entire scope of barrier design, construction, testing, and monitoring should be considered first.

other similar types of design issues should be factored into activities that support the environmental restoration, management, and disposal of wastes at the Hanford Site. Members of the BDP could provide valuable insights into these design issues.

In addition to design issues, construction issues exist as well. As mentioned in Section 4.2.7, the procurement of barrier construction materials to support environmental restoration activities at the Hanford Site probably will require extensive advanced planning and coordination. Some fundamental questions, such as the following, require well-reasoned responses.

- Do barrier construction materials of suitable quality exist in adequate quantities to support the Hanford Site's environmental restoration plans?

- Are additional characterization activities needed to finalize the quantity estimates of barrier construction materials or to identify new sources of materials?

- Has the appropriate documentation been completed to support excavation of barrier construction materials?

- How will the barrier construction materials be transported from the borrow pit or quarry to the waste site where the barrier is being constructed?

- Will the current transportation infrastructure need to be improved or engineered to handle the loads and volume of traffic required to support the construction of protective barriers? If needed, can modifications to the infrastructure be planned, procured, and installed in a timely manner to support environmental restoration activities?

Members of the BDP have given considerable thought to these issues and would be a valuable resource to managenent in addressing these and other similar types of problems.

4.2.14.3 Technology Transfer (TECH-3). In conjunction with the technology integration activities noted above, the permanent isolation barrier technology will be transferred to other sites and organizations as well. Permanent isolation barrier technology is of particular interest to other DOE sites located in arid climates. Collaborative efforts already have been fostered with engineers and scientists from other field offices who are either working on or have intersst in barrier-related issues. Workshops have been convened, special topics meetings have been organized, and papers have been presented at DOE-sponsored symposia and technology exchanges. One of the recommendations proposed at the February 1993 VE workshop was for the Hanford Site to convene an annual workshop during which progress on barrier development at the Hanford Site and elsewhere is shared with all interested parties. In addition, 
highlights documents are prepared and disseminated to individuals and organizations interested in the barrier technology.

In addition to the activities noted above, an international conference on barrier technology is planned to be convened in Richland, Washington, in November 1994. The objective of this conference is to bring together individuals from around the world who are working on surface-barriers and other in situ remediation technologies. The conference is envisioned 10 include several days of presentations and a tour of the barrier field test sites, including the prototype barrier constructed during 1993 to 1994. A proceedings document of the presented papers is planned to be compiled and published.

This task comprises the following activities:

- Publishing barrier-related documents (more than 80 BDP publications have been cleared for public release [see Sections 7.0 and 8.0 for a complete listing of these documents])

- Consulting on special barrier-related topics at the Hanford Site and el sewhere (ongoing)

- Participating in and/or giving presentations at numerous technical conferences, symposia, and workshops; such as the following:

- Lectures on barrier design and performance in China

- Members of the BDP chair or are members of national TSGS

- Papers presented at National Technology Information Exchange Workshops sponsored by DOE-Headquarters

- Paper presented and session chaired at the In Situ Waste Stabilization and Remediation Workshop, sponsored by DOESavannah River and the Westinghouse Savannah River Company

- Discussions with barrier researchers at the University of Hamburg and visits to the Georgswerder Landfill Cover Test Site, Francop Sludge Disposal Site in Hamburg, Germany

- Paper presented at the GEO CONFINE 93 International Symposium, Geology and Confinement of Toxic Wastes, Montpellier, France

- Discussions with the French Commissariat à l'Energie Atomique, Centre d'Etude Nucléaires in Saclay, France.

(Please refer to references $5,6,7,14,15,28,30,41,42,48,49,50$, $51,52,60,62,65$, and 75 in Section 7.0.) 


\subsubsection{Final Design Tasks}

The completion of all of the preceding development tasks identified in this document will enable a final design(s) of a permanent isolation surface barrier to be made. Issues pertaining to barrier performance with respect to biointrusion, water infiltration, erosion, and physical stability will have been resolved. The studies of natural analogs of barrier components and structures will have been completed and applicable input will have been made available for the final design step. Prototype barriers also will have been constructed and tested, and insights into the design and construction of permanent isolation surface barriers will have been gained. The final barrier design(s) will be documented and drawings will be prepared within this task.

At this point in the development of permanent isolation surface barriers, simulation models to predict water infiltration will have been extensively tested and compared to field data. These models can then be used with confidence in performing the confirmatory testing of the final design of the barrier and in making a definitive statement about its performance.

Supporting documentation in the form of published reports, videotapes, models, presentations, graphics, engineered drawings, barrier design standards, design guides, specifications, files, bibliographies, etc., will have been prepared for transfer to end users of permanent isolation surface barrier technology.

This task comprises the following activities:

- Assembling all relevant data from preceding tasks (in progress)

- Preparing final design(s) of permanent isolation surface barriers

- Preparing documentation and drawings of final designs.

\subsection{INTERRELATIONSHIP AND LOGIC AMONG TASKS}

By performing the tasks discussed in this document, a great amount of data will be generated. Many of the tasks identified in this plan are interrelated, and the data or results of one test may be required as input for another test. As a result, during test plan preparation, care has been and will continue to be taken to ensure that the results of specific tests are in a usable form and completed at the proper time to be of greatest value to subsequent, dependent tests. This advance planning will promote continuity of efforts and will maximize the usefulness of test results during interim design steps.

A records management system is being developed to archive information and data generated by the BDP. The system is envisioned to consist of an electronic data base and a repository for document archival. The system is expected to be operational by the end of FY 1994. 
WHC-EP-0673

\subsection{TASK COST SUMMARY}

Table 1 provides the cost estimate for all remaining barrier development work to be performed, organized according to major task group and fiscal year. Table 2 provides the cost estimate for all remaining barrier development work to be performed broken out by cost element. All costs associated with asphalt testing are summarized in the Water Infiltration Control task group (WTR-4 task). More detailed cost estimates for each individual task are provided in Appendix A. Costs aro in FY 1994 programmatic dollars. The cost estimates provided in this document represent the funding levels required to finish the various activities and do not include the costs expended to date.

WHC-EP-0673

38. Ligotke, M. W., and D. C. Klopfer, 1990, Soil Erosion Rates from Mixed Soil and Gravel Surfaces in a Wind Tunnel, PNL-7435, Pacific Northwest Laboratory, Richland, Washington. 
Table 1. Cost Estimate Summary for Major Task Groups by Fiscal Year. (Dollars in Thousands)

\begin{tabular}{|l|r|r|r|r|r|r|}
\hline \multicolumn{1}{|c|}{ Task } & \multicolumn{1}{|c|}{ FY 94} & \multicolumn{1}{|c|}{ FY 95} & FY 96 & FY 97 & \multicolumn{1}{|c|}{ FY 98} & Total \\
\hline Project Management Tasks (MGT) & 584.2 & 518.8 & 542.2 & 542.2 & 542.2 & $2,729.7$ \\
\hline Biointrusion Control Tasks (BI0) & 149.2 & 0.0 & 0.0 & 0.0 & 0.0 & 149.2 \\
\hline $\begin{array}{l}\text { Water Infiltration Control Tasks } \\
\text { (WTR) }\end{array}$ & 701.1 & 455.2 & 449.7 & 584.8 & 0.0 & $2,190.8$ \\
\hline $\begin{array}{l}\text { Erosion/Deposition Control Tasks } \\
\text { (EROD) }\end{array}$ & 0.0 & 0.0 & 0.0 & 0.0 & 0.0 & 0.0 \\
\hline Physical Stability Tasks (PHYS) & 552.7 & 307.8 & 160.4 & 160.4 & 0.0 & $1,181.4$ \\
\hline $\begin{array}{l}\text { Human Interference Control Tasks } \\
\text { (HUM) }\end{array}$ & 0.0 & 0.0 & 0.0 & 0.0 & 0.0 & 0.0 \\
\hline $\begin{array}{l}\text { Barrier Materials Procurement Tasks } \\
\text { (MATLS) }\end{array}$ & 0.0 & 0.0 & 0.0 & 0.0 & 0.0 & 0.0 \\
\hline $\begin{array}{l}\text { Prototype Designs and Testing Tasks } \\
\text { (BAR) }\end{array}$ & $1,061.9$ & $1,292.9$ & $1,273.8$ & $1,296.9$ & 0.0 & $4,925.5$ \\
\hline $\begin{array}{l}\text { Model Applications and Testing Tasks } \\
\text { (MOD) }\end{array}$ & 236.9 & 232.0 & 232.0 & 232.0 & 0.0 & 932.9 \\
\hline Natural Analog Study Tasks (NAT) & 53.4 & 184.5 & 129.9 & 129.9 & 0.0 & 497.7 \\
\hline $\begin{array}{l}\text { Climate Change Effects Assessment } \\
\text { (CLIM) }\end{array}$ & 155.1 & 0.0 & 0.0 & 0.0 & 0.0 & 155.1 \\
\hline $\begin{array}{l}\text { Interface with Regulatory Agencies } \\
\text { (REG) }\end{array}$ & 23.9 & 23.9 & 23.9 & 23.9 & 23.9 & 119.4 \\
\hline RCRA Equivalency (RCRA) & 396.9 & 207.0 & 207.0 & 207.0 & 0.0 & $1,017.8$ \\
\hline $\begin{array}{l}\text { Technology Integration and Transfer } \\
\text { (TECH) }\end{array}$ & 289.8 & 277.7 & 241.6 & 241.6 & 229.4 & $1,280.1$ \\
\hline Final Barrier Design (DES) & 0.0 & 0.0 & 0.0 & 0.0 & 592.9 & 592.9 \\
\hline Total & $4,205.2$ & $3,499.8$ & $3,260.5$ & $3,418.6$ & $1,388.5$ & $15,772.5$ \\
\hline
\end{tabular}




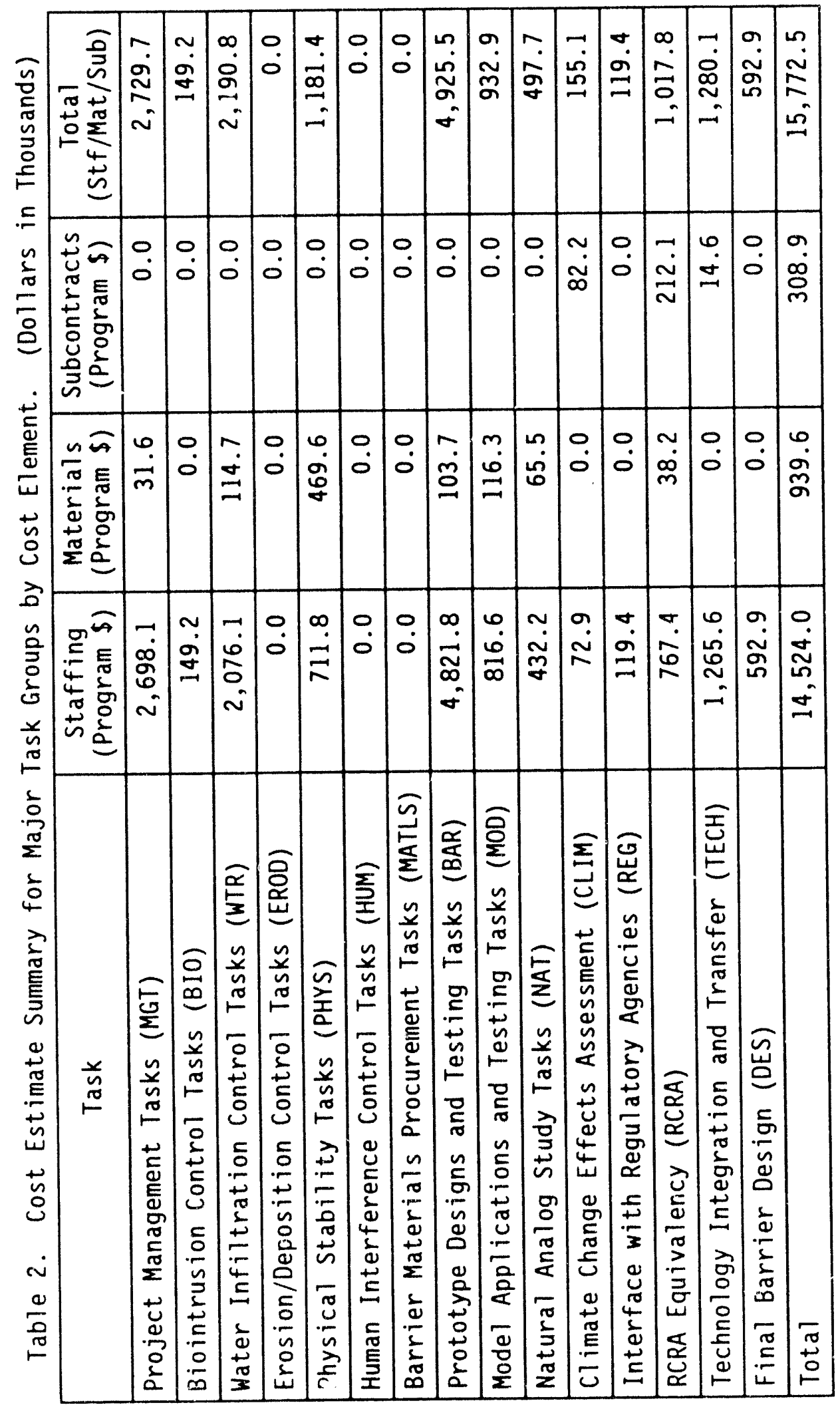


WHC-EP-0673

\subsection{TASK MASTER SCHEDULE}

The Barrier Development Program Master Schedule (Figure 14) illustrates the time required to accomplish each of the major task groups. The Barrier Development Program Schedule (by task) (Figure 15 [a-e]) illustrates the time required to accomplish each of the tasks and activities within each of the task groups. The schedules illustrate that a minimum of 5 years of continuous, uninterrupted effort beginning in October 1993 is required to provide a permanent isolation surface barrier for waste disposal applicacions. Year-to-year budget guidance and program priorities will require modificaicions to this "ideal" schedule.

74. Chamness, M. A., 1993, An Investigation of Bergmounds and Analogs to Erosion Control Factors on Protective Barriers, PNL-8841, Pacific. Northwest Laboratory, Richland, Washington. 
Figure 15b. Barrier Development Program Schedule (by Task).

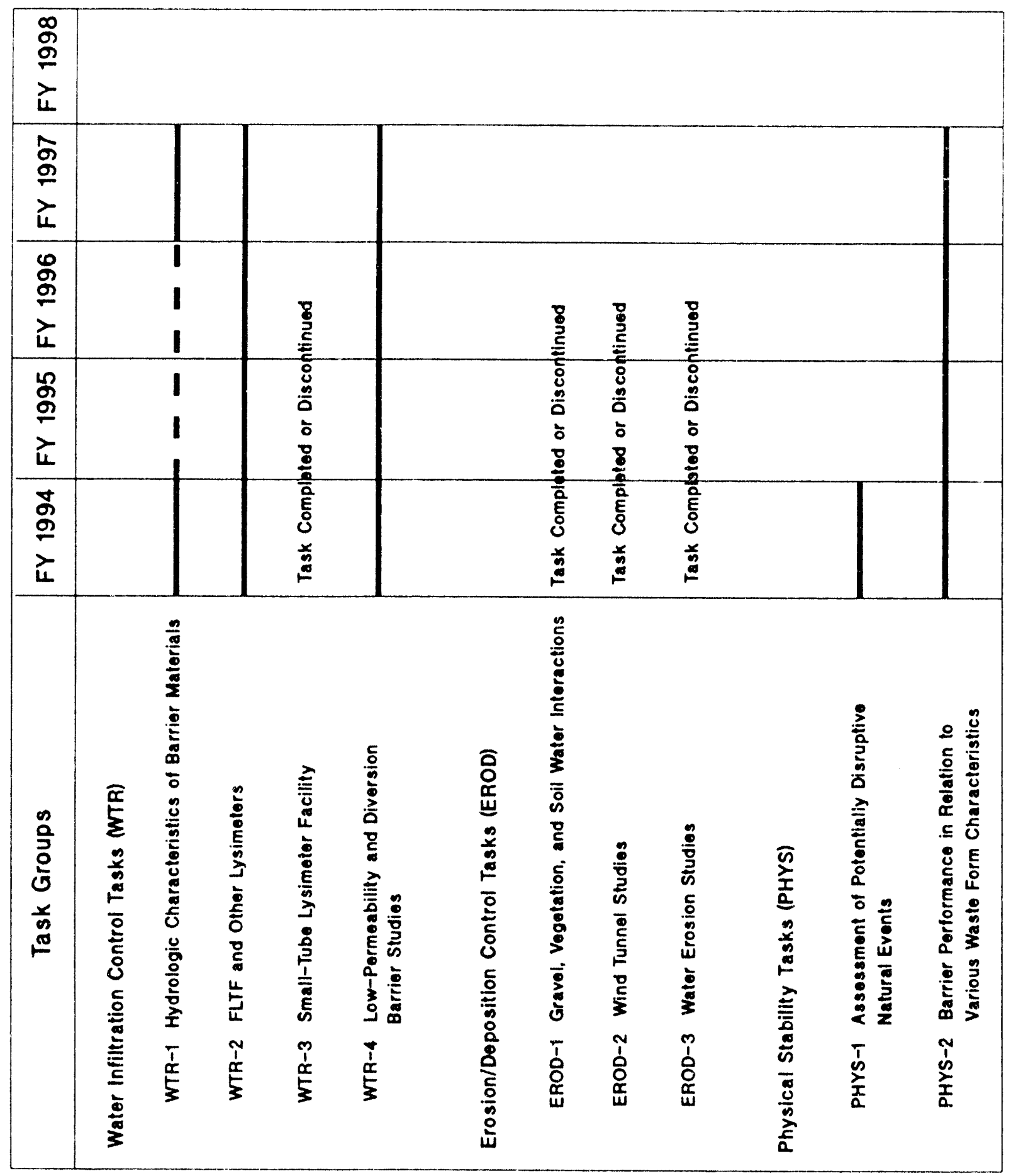

WHC-EP-0673

H-6-1655, Rev. 0, Structural Crib Plan and Crib Installation Field Lysimeter Boxes, Sh. 1

H-6-1656, Rev. 0, Structural Inner Box Assembly Field Lysimeter - Boxes, Sh. 1 


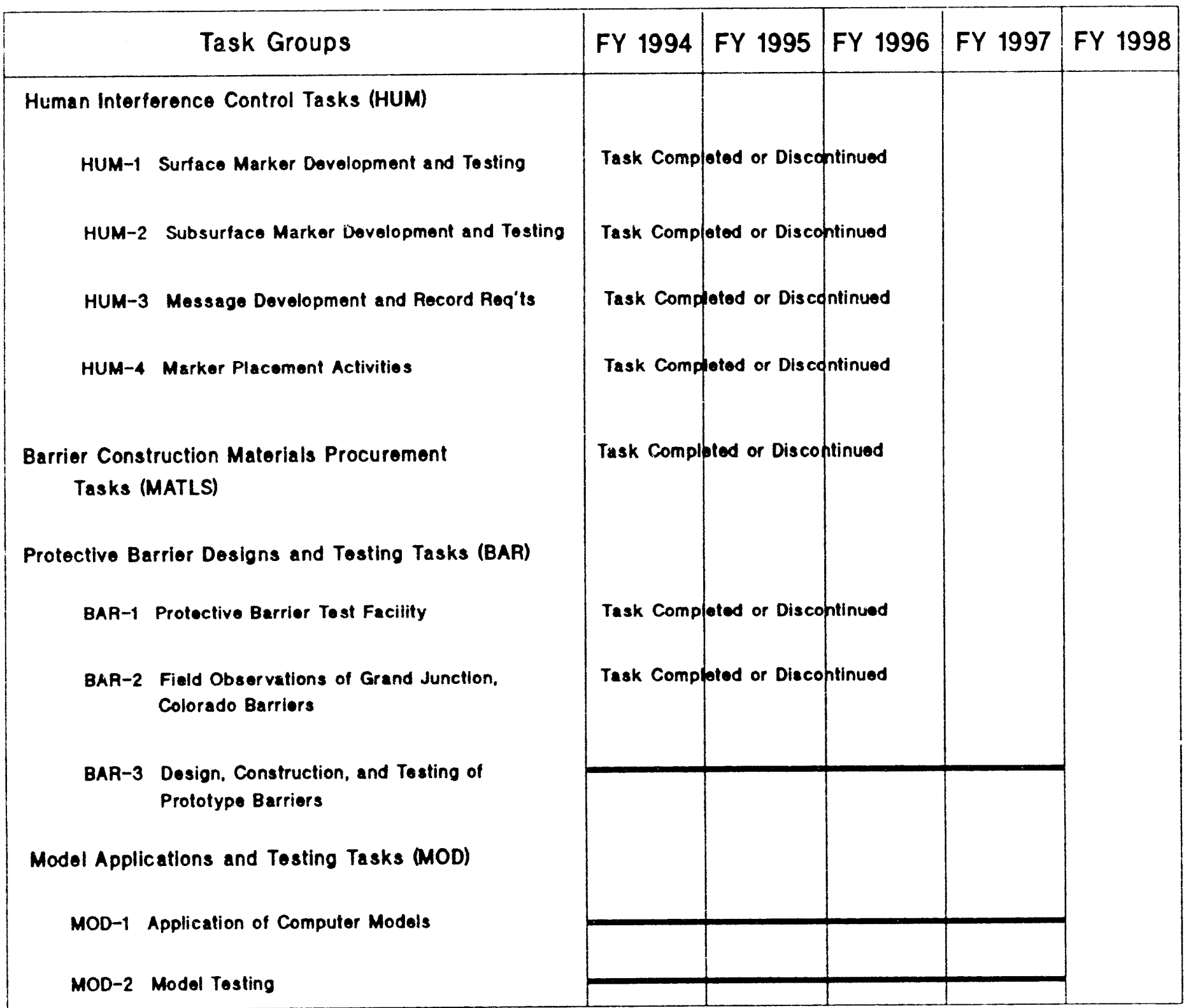




\begin{tabular}{|c|c|c|c|c|c|}
\hline Task Groups & FY 1994 & FY 1995 & FY 1996 & FY 1997 & FY 1998 \\
\hline \multicolumn{6}{|l|}{ Natural Analog Study Tasks (NAT) } \\
\hline NAT-1 Barrier Analog Identification & Task Comple & ted or Discon & inued & & \\
\hline NAT-2 Armored-Surface Analog Field Studies & Task Comple & ted or Discon & inued & & \\
\hline \multicolumn{6}{|l|}{ NAT-3 Blowout Field Studies } \\
\hline NAT-4 Podogenic Indicators of Soil Water Movement & Task Comple & fod or Discon & inued & & \\
\hline NAT-5 Sediment Stratigraphy and Geofilters & Task Comple & fed or Discor & tinued & & \\
\hline NAT-6 Microreliof Effects & Task Comple & ted or Discon & inued & & \\
\hline NAT-7 Plant Community Dynamics & Task Comple & ted or Discon & inued & & \\
\hline NAT-8 Ancient Mounds & Task Compl & ted or Discor & finued & & \\
\hline \multicolumn{6}{|l|}{ NAT-9 Asphall Analogs } \\
\hline \multicolumn{6}{|l|}{ Long-Term Climate Change Effects Assessment (CLIM) } \\
\hline CLIM-1 Evaluate Climate Informational Needs & Task Comple & ted or Discor & inued & & \\
\hline CLIM-2 Prodict Local Climate and Vegotation Changes & & & & & \\
\hline
\end{tabular}




\begin{tabular}{|c|c|c|c|c|c|c|}
\hline & Task Groups & FY 1994 & FY 1995 & FY 1996 & FY 1997 & FY 1998 \\
\hline \multicolumn{7}{|c|}{ Interface with Regulatory Agencies (REG) } \\
\hline \multicolumn{7}{|c|}{ RCRA Equivalency (RCRN } \\
\hline RCRA-1 & Proparation of A RCRA Equivalency Report & Task Compl & pled or Discon & tinued & & \\
\hline \multirow{2}{*}{ RCRA-2 } & Construction and Testing of a Prototype & & & & & \\
\hline & Barrier & & & & & \\
\hline RCRA-3 & $\begin{array}{l}\text { Preparation of A Construction Quality } \\
\text { Assurance Plan }\end{array}$ & Task Compl & pled or Discon & tinued & & \\
\hline PCRA-4 & $\begin{array}{l}\text { RCRA Equivalency of Low-Pormeabllity } \\
\text { Asphalt Layors }\end{array}$ & & & & & \\
\hline RCRA-5 & $\begin{array}{l}\text { Barrier Comparisons at the Hill } \\
\text { Air Force Base }\end{array}$ & & & & & \\
\hline \multicolumn{7}{|c|}{ Technology Integration and Transfer (TECH) } \\
\hline \multicolumn{7}{|c|}{ TECH-1 Barrier Development Program Documentation } \\
\hline \multirow{2}{*}{ TECH-2 } & Consultation on Special Barrier-Reiated & & & & & \\
\hline & Topics & & & & & \\
\hline $\mathrm{TECH}-3$ & Technology Transfor & & & & & \\
\hline Final Design & Tasks (DES) & -1 & - & - & & \\
\hline
\end{tabular}


WHC-EP-0673

This page intentionally left blank. 
WHC-EP-0673

\subsection{PUBLISHED PERMANENT ISOLATION BARRIER DOCUMENTS}

1. Phillips, S. J., M. R. Adams, T. W. Gilbert, C. C. Meinhardt, R. M. Mitchell, and W. J. Waugh, 1985, Engineered Barrier Test Facility Status Report: 1984, RHO-WM-SR-3P, Rockwell Hanford Operations, Richland, Washingtor.

2. Phillips, S. J., T. W. Gilbert, and M. R. Adams, 1985, Preliminary Engineering Specifications for a Test Demonstration Multilayer Protective Barrier Cover System, RHO-WM-EV-8 P, Rockwell Hanford Operations, Richland, Washington.

3. Fayer, M. J., W. Conbere, P. R. Heller, and G. W. Gee, 1985, Model Assessment of Protective Barrier Designs, PNL-5604, Pacific Northwest Laboratory, Richland, Washington.

4. Myers, D. R., 1985, Disposal Materials Study, RHO-WP-EV-12P, Rockwell Hanford Operations, Richland, Washington.

5. Adams, M. R., and M. F. Kaplan, 1986, "Marker Development for Hanford Waste Site Disposal," Waste Management '86, (Vol. 1), pp. 425-431, R. G. Post (ed.), University of Arizona, College of Engineering and Mines, Tucson, Arizona.

6. Phillips, S. J., and J. N. Hartley, 1986, "Protective Barrier Systems for Final Disposal of Hanford Waste Sites," Waste Management '86, (Vol. 1), pp. 433-437, R. G. Post (ed.), University of Arizona, College of Engineering and Mines, Tucson, Arizona.

7. Kaplan, M. F., and M. R. Adams, 1986, "Using the Past to Protect the Future: Marking Nuclear Waste Disposal Sites," Archeology, 39(5):51-54.

8. Adams, M. R., and N. R. Wing, 1986, Protective Barrier and Warning Marker System Development Plan, RHO-RE-PL-35 P, Rockwell Hanford Operations, Richland, Washington.

9. Fayer, M. J., 1987, Model Assessment of Protective Barrier Designs: Part II, PNL-6297, Pacific Northwest Laboratory, Richland, Washington.

10. Last, G. V., M. A. Glennon, M. A. Young, and G. W. Gee, 1987, Protective Barrier Materials Analysis: Fine Soil Site Characterization, PNL-6314, Pacific Northwest Laboratory, Richland, Washington.

11. Gee, G. W., 1987, "Preliminary Analysis of the Performance of the Protective Barrier and Marker System," Final Environmental Impact Statement, Disposal of Hanford Defense High-Level, Transuranic and Tank Wastes, Appendix M, DOE/EIS-0113, U.S. Department of Energy, Richland Operations Office, Richland, Washington.

12. Kirkham, R. R., G.W. Gee, and J. L. Downs, 1987, Field Lysimeter Test Facility for Protecilive Barriers: Experimental Plan, PNL-6351, Pacific Northwest Laboratory, Richland, Washington. 
13. Waugh, W. J., and S. 0. Link, 1988, Barrier Erosion Control Test Plan: Gravel Mulch, Vegetation, and Soil Water Interactions, WHC-EP-0067, Westinghouse Hanford Company, Richland, Washington.

14. Wing, N. R., M. D. Campbe11, J. L. Downs, G. W. Gee, R. R. Kirkham, and S. J. Phillips, 1988, "Protective Barrier Development: The Field Lysimeter Test Facility," Proceedings of the International Topical Meeting on Nuclear and Hazardous Waste Management Spectrum '88, pp. 196-198, American Nuclear Society, Inc., La Grange Park, I11 inois, WHC-SA-0203-FP, Westinghouse Hanford Company, Richland, Washington.

15. Phillips, S. J., M. S. Ruben, and R. R. Kirkham, 1988, "Engineered Surface Barriers for Waste Disposal Sites: Lysimeter Facility Design and Construction," DOE Model Conference Proceedings, pp. 1229-1238, CONF-881054, U.S. Department of Energy, Washington, D.C.

16. Ligotke, M. W., 1988, Soil Erosion Rates from Mixed Soil and Gravel Surfaces in a Wind Tunnel: A Preliminary Report, PNL-6677, Pacific Northwest Laboratory, Richland, Washington.

17. Waugh, W. J., and M. G. Foley, 1988, Protective Barrier Climate-Change Impacts: Technical Workshop Findings and Recommendations, PNL-6615, Pacific Northwest Laboratory, Richland, Washington.

18. Ligotke, M. W., 1989, Surface Stability Test Plan for Protective Barriers, PNL-6722, Pacific Northwest Laboratory, Richland, Washington.

19. Gee, G. W., R. R. Kirkham, J. L. Downs, and M. D. Campbel1, 1989, The Field Lysimeter Test Facility (FLTF) at the Hanford Site: Installation and Initial Tests, PNL-6810, Pacific Northwest Laboratory, Richland, Washington.

20. Gee, G. W., M. D. Campbel1, H. D. Freeman, and J. F. Cline, 1989, Assessment of Cover Systems at the Grand Junction, Colorado Uranium Mill Tailings Pile: 1987 Field Measurements, PNL-6762, Pacific Northwest Laboratory, Richland, Washington.

21. Petersen, K. L., 1989, The Long-Term Climate Change Assessment Task of the Hanford Site, Washington, Protective Barrier Development Program, WHC-SA-0537-FP, Westinghouse Hanford Company, Richland, Washington.

22. Cadwel1, L. L., E. L. Eberhardt, and M. A. Simmons, 1989, Animal Intrusion Studies for Protective Barriers: Status Report for FY 1988, PNL-6869, Pacific Northwest Laboratory, Richland, Washington.

23. Freeman, H. D., G.W. Gee, and J. F. Relyea, 1989, Field Study Plan for Alternate Barriers, PNL-6840, Pacific Northwest Laboratory, Richland, Washington.

24. Freeman, H. D., and G. W. Gee, 1989, Hanford Protective Barriers Program Asphalt Barrier Studies - FY 1988, PNL-6874, Pacific Northwest Laboratory, Richland, Washington. 
25. Waugh, W. J., 1989, Gravel Admix, Vegetation and Soil Water Interactions in Protective Barriers: Experimental Design, Construction and Initial Conditions, PNL-6616, Pacific Northwest Laboratory, Richland, Washington.

26. Freeman, H. D., and G.W. Gee., 1989, Hanford Protective Barriers Program: Status of Asphalt Barrier Study - FY 1989, PNL-7153, Pacific Northwest Laboratory, Richland, Washington.

27. Link, S. 0., and W. J. Waugh, 1989, Evapotranspiration Studies for Protective Barriers: Experimental Plans, PNL-6899, Pacific Northwest Laboratory, Richland, Washington.

28. Petersen, K. L., 1990, "The Long-Term Climate Change Assessment Task of the Protective Barrier Development Program for Low-Level Waste Site Remediation at the Hanford Site, Washington," High Level Radioactive Waste Management, Vol 2, pp. 1235-1239, Proceeding of an International Topical Meeting, American Nuclear Society, La Grange, Park, 117 inois, WHC-SA-0808-FP, Westinghouse Hanford Company, Richland, Washington.

29. Fayer, M. J., 1990, Test Plan for Hydrologic Modeling of Protective Barriers, PNL-7152, Pacific Northwest Laboratory, Richland, Washington.

30. Wing, N. R., and G. W. Gee (eds.), 1990, Hanford Site Protective Barrier Development Program: Fiscal Year 1989 Highlights, WHC-EP-0318, Westinghouse Hanford Company, Richland, Washington.

31. Campbe11, M. D., G. W. Gee, M. J. Kanyid, and M. L. Rockhold, 1990, Field Lysimeter Test Facility: Second Year (FY 1989) Test Results, PNL-7209, Pacific Northwest Laboratory, Richland, Washington.

32. Landeen, D. S., L. L. Cadwe11, L. E. Eberhardt, R. E. Fitzner, and M. A. Simmons, 1990, Animal Intrusion Field Test Plan, WHC-EP-0253, Westinghouse Hanford Company, Richland, Washington.

33. Link, S. 0., M. E. Thiede, R. D. Evans, J. L. Downs, and W. J. Waugh, 1990, Evapotranspiration Studies for Protective Barriers: FY 1988 Status Report, PNL-6985, Pacific Northwest Laboratory, Richland, Washington.

34. Relyea, J. F., M. R. Sackschewsky, W. J. Waugh, 1989, Small-Tube Lysimeter Facility Status Report for Fiscal Year 1989, WHC-EP-0297, Westinghouse Hanford Company, Richland, Washington.

35. Walters, W. H., K. A. Hoover, and L. L. Cadwell, 1990, Project Test Plan for Runoff and Erosion on Fine-Soil Barrier Surfaces and Rock-Covered Side Slopes, PNL-6791, Pacific Northwest Laboratory, Richland, Washington.

36. Hoover, K. A., L. L. Cadwell, and W. H. Walters, 1990, Hanford Protective Barriers Program: Water Erosion Studies - FY 1989, PNL-7214, PacifiC Northwest Laboratory, Richland, Washington.

37. Landeen, D. S., 1990, Animal Intrusion Status Report for Fiscal Year 1989, WHC-EP-0299, Westinghouse Hanford Company, Richland, Washington. 
WHC-EP-0673

38. Ligotke, M. W., and D. C. Klopfer, 1990, Soil Erosion Rates from Mixed Soil and Gravel Surfaces in a Wind Tunnel, PNL-7435, Pacific Northwest Laboratory, Richland, Washington.

39. Waugh, W. J., M. E. Thiede, C. J. Kemp, L. L. Cadwell, and S. O. Link, 1990, Field Study of Gravel Admix, Vegetation, and Soil Water

Interactions: Protective Barrier Program Status Report - FY 1989, PNL7440, Pacific Northwest Laboratory, Richland, Washington.

40. Hunter, C. R., A. J. Busacca, and W. J. Waugh, 1990, A Feasibility Study of Modeling Pedogenic Carbonates in Soils and Sediments at the U.S. Department of Energy's Hanford Site, PNL-7413, Pacific Northwest Laboratory, Richland, Washington.

41. Wing, N. R., and G.W. Gee, 1990, "Protective Barrier Development: Overview, " Proceedings of the Twenty-Eighth Hanford Symposium on Health and the Environment, Environmental Monitoring, Restoration, and Assessment: What Have We Learned?, pp. 147-151, R. H. Gray (ed.), Pacific Northwest Laboratory, Richland, Washington, WHC-SA-0619 FP, Westinghouse Hanford Company, Richland, Washington.

42. Wing, N. R., and G. W. Gee, 1990, "Protective Barrier Development: Overview, "Proceedings of the International ropical Meeting on Nuclear and Hazardous Waste Management Spectrum '90, pp. 335-337, American Nuclear Society, Inc., La Grange Park, Ill inois; WHC-SA-0985-VA, Westinghouse Hanford Company, Richland, Washington.

43. Glantz, C. S., M. N. Schwartz, K. W. Burk, R. B. Kaspar, M. W. Ligotke, and D. J. Perrault, 1990, Climatological Summary of Wind and Temperature Data for the Hanford Meteorology Monitoring Network, PNL-7471, Pacific Northwest Laboratory, Richland, Washington.

44. Campbe11, M. D., and G. W. Gee, 1990, Field Lysimeter Test Facility: Protective Barrier Test Results (FY 1990, The Third Year), PNL-7558, Pacific Northwest Laboratory, Richland, Washington.

45. Sackschewsky, M. R., J. C. Chatters, S. 0. Link, and C. A. Brandt, 1991, Protective Barrier Program: Test Plan for Plant Community Dynamics, WHC-EP-0380, Westinghouse Hanford Company, Richland, Washington.

46. Nichols, W. E., 1991, Comparative Simulations of a Two-Layer Landfill Barrier Using the Help Version 2.0 and UNSAT-H Version 2.0 Computer Codes, PNL-7583, Pacific Northwest Laboratory, Richland, Washington.

47. Landeen, D. S., 1991, Animal Intrusion Status Report for Fiscal Year 1990, WHC-EP-0398, Westinghouse Hanford Company, Richland, Washington.

48. Campbell, M. D., G. W. Gee, R. R. Kirkham, S. J. Phillips, N. R. Wing, 1991, "Water Balance Lysimetry at A Nuclear Waste Site," Proceedings of the International Symposium on Lysimetry, pp. 125-134, R. G. Allen (ed.), American Soc. Civil Engr., New York, New York.

49. Kirkham, R. R., M. L. Rockhold, G. W. Gee, M. J. Fayer, M. D. Campbell, and L. J. Fritschen, 1991, "Lysimeters: Data Acquisition and Analysis," 
Proceedings of the International Symposium on Lysimetry, pp. 362-370, R. G. Allen (ed.), American Soc. Civil Engr., New York, New York.

50. Phillips, S. J., J. F. Relyea, C. J. Kemp, N. R. Wing, M, D, Campbell, G. W. Gee, M. J. Graham, R. R. Kirkham, M. S. Rubin, 1991, "Development of Hanford Site Lysimeter Facilities," Proceedings of the International Symposium on lysimetry, pp. 19-27, R. G. Allen (ed.), American Soc. Civil Engr., New York, New York.

51. Waugh, W. J., M. E. Thiede, L. L. Cadwe11, G. W. Gee, H. D. Freeman, M. R. Sackschewsky. J. F. Relyea, 199i, "Small Lysimeters for Documenting Arid Site Water Balance," Proceedings of the International Symposium on Lysimetry, pp. 151-159, R. G. Allen (ed.), American Soc. Civil Engr., New York, New York.

52. Cadwe11, L. L. (ed.), 1991, Hanford Site Protective Barrier Development Program: Fiscal Year 1990 Highlights, PNL-7831, Pacific Northwest Laboratory, Richland, Washington.

53. Petersen, K. L., 1991, Modern and Pleistocene Climatic Patterns in the West, WHC-EP-0523, Westinghouse Hanford Company, Richland, Washington.

54. Chatters, J. C., and H. A. Gard, 1991, Archaeological Mounds as Analogs of Engineered Covers for Waste Disposal Sites Literature Review and Progress Report, PNL-7718, Pacific Northwest Laboratory, Richland, Washington.

55. Sackschewsky, M. R., C. J. Kemp, L. L. Cadwell, M. E. Thiede, and W. J. Waugh, 1991, Status Report for the Small-Tube Lysimeter Facility Fiscal Year 1990, WHC-EP-0381, Westinghouse Hanford Company, Richland, Washington.

56. Fayer, M. J., M. L. Rockhold, and D. J. Holford, 1992, Model Assessment of Protective Barriers: Part III Status of FY 1990 Work, PNL-7975, Pacific Northwest Laboratory, Richland, Washington.

57. Petersen, K. L., 1992, A Warm and Wet Little Climatic Optimum and a Cold and Dry Little Ice Age in the Southern Rocky Mountains, U.S.A., WHC-SA-1382-FP, West inghouse Hanford Company, Richland, Washington.

58. Link, S. 0., J. L. Downs, M. E. Thiede, D. J. Lettau, T. R. Twadde11, and R. A. Black, 1992, Evapotranspiration Studies for Protective Barriers: FY 1990 Status Report, PNL-8032, Pacific Northwest Laboratory, Richland, Washington.

59. Link, S. 0., M. E. Thiede, J. L. Downs, D. J. Lettau, and W. J. Waugh, 1992, Evapotranspiration Studies for Protective Barriers: FY 1989 Status Report, PNL-8033, Pacific Northwest Laboratory, Richland, Washington.

60. Fayer, M. J., M. L. Rockhold, and M. D. Campbell, 1992, "Hydrologic Modeling of Protective Barriers: Comparison of Field Data and Simulation Results," Soil Science Society of America Journal, Volume 56, No. 3, May-June 1992, pp. 690-700, Madison, Wisconsin. 
WHC-EP-0673

61. Wing, N. R., 1992, A Peer Review of the Hanford Site Permanent Isolation Surface Barrier Development Program, WHC-MR-0392, Westinghouse Hanford Company, Richland, Washington.

62. Gee, G. W., M. J. Fayer, M. L. Rockhold, and M. D. Campbell, 1992, "Variations in Recharge at the Hanford Site," Northwest Science, Vol. 66, No. 4,1992 , pp. 237-250.

63. Ligotke, M. W., 1993, Soil Erosion Rates Caused by Wind and Saltating Sand Stresses in a Wind Tunne7, PNL-8478, Pacific Northwest Laboratory, Richland, Washington.

64. Fayer, M. J., 1993, Model Assessment of Protective Barriers: Part IV, Status of FY 1992 Work, PNL-8498, Pacific Northwest Laboratory, Richland, Washington.

65. Wing, N. R., and G. W. Gee, 1993, The Development of Permanent I solation Surface Barriers: Hanford Site, Richland, Washington, U.S.A. WHC-SA-1799-FP, Westinghouse Hanford Company, Richland, Washington.

66. Petersen, K. L., J. C. Chatters, and W. J. Waugh, 1993 , Long-Term Climate Change Assessment Study Plan for the Hanford Site Permanent Isolation Barrier Development Program, WHC-EP-0569, Revision 1, Westinghouse Hanford Company, Richland, Washington.

67. Wing, N. R., 1993, The Results of Laboratory Tests to Determine the Physical Properties of Various Barrier Construction Materials, WHC-SD-ER-DP-006, Westinghouse Hanford Company, Richland, Washington.

68. Link, S. O., R. N. Kickert, M. J. Fayer, and G. W. Gee, 1993 , A Comparison of Simulation Models for Predicting Soil Water Dynamics in Bare and Vegetated Lysimeters, PNL-8675, Pacific Northwest Laboratory, Richl and, Washington.

69. Gee, G. W., L. L. Cadwe11, H. D. Freeman, M. W. Ligotke, S. O. Link, R. A. Romine, and W. H. Walters, Jr., 1993, Testing and Monitoring Plan for the Permanent Isolation Surface Barrier Prototype, PNL-8391, Pacific Northwest Laboratory, Richland, Washington.

70. DOE-RL, 1993, Treatability Test Plan for the 200-BP-1 Prototype Surface Barrier, DOE/RL-93-27, Rev. O, U.S. Department of Energy, Richland Operations Office, Richland, Washington.

71. Petersen, K. L., and J. C. Chatters, 1993, Long-Term Climate Change Assessment Task for the Hanford Site Permanent Isolation Barrier Development Program: Status through FY 1992, WHC-EP-0644, Westinghouse Hanford Company, Richland, Washington.

72. Sackschewsky, M. R., C. J. Kemp, and L. L. Cadwe11, 1993, Status Report for the Small-Tube Lysimeter Facility Fiscal Year 1992, WHC-EP-0597, Westinghouse Hanford Company, Richland, Washington.

73. Bjornstad, B. N., and S. S. Tee1, 1993, Natural Analog Study of Engineered Protective Barriers at the Hanford Site, PNL-8840. Pacific Northwest Laboratory, Richland, Washington. 
WHC-EP-0673

74. Chamness, M. A., 1993, An Investigation of Bergmounds and Analogs to Erosion Control Factors on Protective Barriers, PNL-8841, Pacific Northwest Laboratory, Richland, Washington.

75. Cadwe11, L. L., S. 0. Link, and G. W. Gee, 1993, Hanford Site Permanent Isolation Surface Barrier Development Program: Fiscal Year 1992 and 1003 Highlights, PNL-8741, Pacific Northwest Laboratory, Richland, Washington.

76. Wing, N. R., 1993, Permanent Isolation Surface Barrier: Functional Performance, WHC-EP-0650, Westinghouse Hanford Company, Richland, Washington.

77. Gee, G. W., D. G. Felmy, J. C. Ritter, M. D. Caripbell, J. L. Downs, M. J. Fayer, R. R. Kirkham, and S. 0. Link, 1993, Field Lysimeter Test Facility Status Report IV: FY 1993, PNL-8911, Pacific Northwest Laboratory, Richland, Washington.

78. Gilmore, B. G. and W. H. Walters, 1993, Water Erosion Field Tests for Hanford Protective Barriers: FY 1992 Status Report, PNL-8949, Pacific Northwest Laboratory, Richland, Washington.

79. Fort, D. L. and B. R. Fillion, 1993, Construction Specification, Prototype Surface Barrier at 200-BP-1 Operable Unit, Sitework Construction Services, W-263-C1, Rev. 0, Kaiser Engineers Hanford Company, Richland, Washington.

80. Fort, D. L., S. D. Consort, B. R. Fillion, L. A. Gaddis, and R. G. Hollenbeck, 1993, Construction Specification for Prototype Surface Barrier at 200-BP-1 Operable Unit, W-263-C2, Rev. 0, Kaiser Engineers Hanford Company, Richland, Washington.

81. Gaddis, L. A., 1993, Construction Quality Assurance Plan, Prototype Surface Barrier, Project $W-263$, Kaiser Engineers Hanford Company, Richland, Washington.

82. DOE-RL, 1993b, Report on Value Engineering Study of Permanent Isolation Surface Barrier and Warning Marker System Development Plan at the Hanford Site, DOE/RL/12074--8, Rev. 0, U.S. Department of Energy, Richland Operations office, Richland, Washington. 
WHC-EP-0673

This page intentionally left blank.

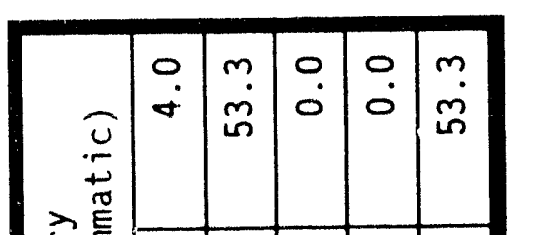


WHC-EP-0673

\subsection{DRAWINGS PRODUCED BY THE BARRIER DEVELOPMENT PROGRAM}

\section{MARKERS}

SK-2-23649, Rev. 0, Reference Subsurface Marker Prototypes, Sh. 1

SK-2-23650, Rev. 0, Reference Surface Marker Prototype, Sh. $1 \& 2$

\section{PPOTECTIVE BARRIER TEST FACILITY}

H-2-93048, Rev. 1, Site Closure Methods Development, Sh. 1

H-2-94869, Rev. 0, Engineered Barrier Test Facility, Sh. 1

H-2-95425, Rev. 0, Engineered Barrier Test Columns and Support, Sh. 1

\section{FIELD LYSIMETER TEST FACILITY}

H-6-5324, Rev. 0, Drawing List and Specifications, Sh. $1 \& 2$

H-6-5325, Rev. 0, Civil Site Plan, Sh. I

H-6-5326, Rev. 0, Structural Foundation / Floor Plan and Details, Sh. I

H-6-5327, Rev. 0, Structural Roof Plan and Details, Sh. 1

H-6-5328, Rev. 0, Structural Miscellaneous Details, Sh. $1 \& 2$

H-6-5329, Rev. 0, Structural Outer Tank, Sh. 1

H-6-5330, Rev. 0, Structural Inner Tank, Sh. I

H-6-5331, Rev. 0, Structural Round Tank, Sh. 1

H-6-5332, Rev. 0, Structural Miscellaneous Steel, Sh. 1 \& 2

H-6-5333, Rev. 0, HVAC / Electrical Plan and Details, Sh. 1

\section{SMALL-TUBE LYSIMETER FACILITY}

H-6-1654, Rev. 0, Civil / Structural Plan and Details Field Lysimeter Tubes, Sh. 1

H-6-954, Rev. 0, Gantry Crane Footing, Sh. 1

H-6-955, Rev. 0, Tube Rack, Sh. I

ANIMAL INTRUSION LYSIMETER FACILITY 
WHC-EP-0673

H-6-1655, Rev. 0, Structural Crib Plan and Crib Installation Field Lysimeter Boxes, Sh. 1

H-6-1656, Rev. 0, Structural Inner Box Assembly Field Lysimeter - Boxes, Sh. 1

H-6-1657, Rev. 0, Structural Spreader Beam Assembly Field Lysimeter - Boxes, Sh. 1

H-6-1659, Rev. 0, Structural Crib Plan and Section Field Lysimeter - Drain Boxes, Sh. i

H-6-1660, Rev. 0, Structural Box Assembly Field Lysimeter - Drain Boxes, Sh. 1

H-6-1661, Rev. 0, Structural Box Section and Details Field ysimeter - Drain Boxes, Sh. 1

\section{ADMIX GRAVEL TEST PLOT}

H-6-5323, Rev. 0, Civil Gravel Plots, Sh. 1

\section{PROTOTYPE SURFACE BARRIER}

H-2-817484, Rev. 0, Drawing List, Sh. 1

H-2-817485, Rev. 0, Site Prep Plan, Sh. 1

H-2-817486, Rev. 0, Civil Profile - Raw Water, Sh. 1

H-2-817487, Rev. 0, Civil Profile \& Details - Raw Water, Sh. 1

H-2-817488, Rev. 0, Civil Plan, Section \& Detail - Water Collection System, Sh. 1 of 2

H-2-817488, Rev. 0, Civil Plan, Section \& Detail - Water Volume System,

Sh. 2 of 2

H-2-817489, Rev. 0, Civil Plan, Section \& Detail - Asphaltic Layer, Sh. 1 of 2

H-2-817489, Rev. 0, Civil Plan, Section \& Detail - Asphaltic Layer Drainage, Sh. 2 of 2

H-2-817490, Rev. 0, Civil Plans - Drainage \& Basalt Layers, Sh. 1

H-2-817491, Rev. 0, Civil Plan - Filter \& Clean Fill Layers, Sh. I

H-2-817492, Rev. 0, Civil Plans - Lower \& Upper Silt Layers, Sh. 1

H-2-817492, Rev. 0, Civil Plans - Lower \& Upper Silt Layers, Sh. I

H-2-817493, Rev. 0, Civil Final Plan - Roads, Barricades, Signs, Sh. 1 of 2

H-2-817493, Rev. 0, Civil Final Plan-Roads, Barricades, Signs, Sh. 2 of 2 
WHC-EP-0673

H-2-817494, Rev. 0, Civil Sections \& Details - Barrier Cross Section, Signs, Sh. 1

H-2-817495, Rev. 0, Civil Plan \& Details - Asphalt Test Pad, Lysimeter, Sh. 1 H-2-817495, Rev. 0, Civil Plan \& Details - Asphalt Test Pad, Lysimeter, Sh. 1 H-2-817496, Rev. 0, Civil Details - Road, Signs \& Access Tubes, Sh. 1 
WHC-EP-0673

This page intentionally left blank. 
WHC-EP-0673

\subsection{REFERENCES}

Adams, M. R., and M. F. Kaplan, 1986, "Marker Development ior Hanford Waste Site Disposal," Waste Management '86, (Vol. 1), pp. 425-431, R. G. Post (ed.), University of Arizona, College of Engineering and Mines, Tucson, Arizona.

Ast, D. G., M. Bril1, W. Goodenough, M. Kaplan, f. Newmeyer, and W. Sullivan, 1992, Marking the Waste Isolation Pilot Plant for 10,000 Years: A Report Prepared for the US Department of Energy, Material Science Department, Cornell University, Ithaca, New York.

Baker, E. G., J. N. Hartley, H. D. Freeman, T. E. Gates, D. A. Nelson, and R. L. Dunning, 1984, Asphalt Emulsion Radon Barrier Systems for Uranium Mill Tailings - An Overview of the Technology, PNL-4840, Pacific Northwest Laboratory, Richland, Washington.

Bennett, R. D., 1991, Recommendations to the NRC for Soil Cover Systems Over Uranium Mill Tailings and Low-Level Radioactive Wastes, NUREG/CR-5432, Volume 1, U. S. Army Engineer Waterways Experiment Station.

Cadiel1, L. L., E. L. Eberhardt, and M. A. Simmons, 1989, Animal Intrusion Studies for Protective Barriers: Status Report for FY 1988, PNL-6869, Pacific Northwest Laboratory, Richland, Washington.

Cadwel1, L. L., S. D. Link, and G. W. Gee, 1993, Hanford Site Permanent Isolation Surface Barrier Development: Fiscal Year 1992 and 1993 Highlights, PNL-841, Pacific Northwest Laboratory, Richland, Washington.

Campbe11, M. D., G. W. Gee, M. J. Kanyid, and M. L. Rockhold, 1990, Field Lysimeter Test Facility: Second Year (FY 1989) Test Results, PNL-7209, Pacific Northwest Laboratory, Richland, Washington.

Chamness, M. A., 1993, An Investigation of Bergmounds and Analogs to Erosion Control Factors on Protective Barriers, PNL-8341, Pacific Northwest Laboratory, Richland, Washington.

Daniel, D. E., and S. Trautwein, 1991, Clay Liners and Covers for Waste Disposal Facilities, Short Course, University of Texas at Austin, College of Engineering, Austin, Texas.

DOE, 1987, "Preliminary Analysis of the Performance of the Protective Barrier and Marker System," Final Environmental Impact Statement, Disposal of Hanford Defense High-Level, Transuranic and Tank Wastes, Appendix M, DOE/EIS-0113, U.S. Department of Energy, Richland Operations Office, Richland, Washington.

DOE-RL, 1987, Interim Hanford Waste Management Plan, U.S. Department of Energy, Richland Operations Office, Richland, Washington. 
DOE-RL, 1988, Final Environmental Impact Statement for the Disposal of Hanford Defense High-Level, Transuranic, and Tank Wastes, DOE/EIS-0113, U.S. Department of Energy, Richland Operations Office, Richland, Washington.

DOE-RL, 1989, Low-Level Burial Grounds Dangerous Waste Permit Appiication, DOE/RL 88-20, U.S. Department of Energy, Richland Operations Office, Richland, Washington.

DOE-RL, 1993a, Report on Value Engineering Study of Permanent Isolation Surface Barrier and Warning Marker System Development Plan at the Hanford Site, DOE/RL/12074--8, Rev. 0, U.S. Department of Energy, Richland Operations office, Richland, Washington.

DOE-RL, 1993b, Treatability Test Plan for the 200-BP-1 Prototype Surface Barrier, DOE/RL93-27, Rev. 0, U.S. Department of Energy, Richland Field office, Richland, Washington.

EPA, 1982, RCRA (Resource Conservation and Recovery Act) Guidance Document: Landfill Design, Liner Systems and Final Cover, PB87-157657, U.S. Environmental Protection Agency, National Technical Information Service, Springfield, Virginia.

EPA, 1988, Guidance for Conducting Remedial Investigations and Feasibility Studies Under CERCLA, EPA/540/G-89/004, OSWER Directive 9355.3-01, U.S. Environmental Protection Agency, Office of Emergency and Remedial Response, Washington, D.C.

EPA, 1990, Seminars--Design and Construction of RCRA/CERCLA Final Covers, Center for Environmental Research Information 90-55, U.S. Environmental Protection Agency, Office of Research and Development, Washington, D.C.

EPA, 1991, Design and Construction of RCRA/CERCLA Final Covers, EPA/625/4-91/025, U.S. Environmental Protection Agency, Office of Research and Development, Washington, D.C.

EPA, DOE, and Ecology 1989, Proposed Action Plan for Implementation of the Hanford Federal Facility Agreement and Consent Order between the U.S. Environmental Protection Agency, the U.S. Department of Energy, and the State of Washington Department of Ecology, February 27, 1989

U.S. Environmental Protection Agency, U.S. Department of Energy, and the State of Washington Department of Ecology, Washington, D.C.

Fayer, M. J., W. Conbere, P. R. Heller, and G. W. Gee, 1985, Model Assessment of Protective Barrier Designs, PNL-5604, Pacific Northwest Laboratory, Richland, Washington.

Fayer, M. J., 1987, Model Assessment of Protective Barrier Designs: Part II, PNL-6297, Pacific Northwest Laboratory, Richland, Washington.

Freeman, H. D., G. W. Gee, and J. F. Relyea, 1989, Field Study Plan for Alternate Barriers, PNL-6840, Pacific Northwest Laboratory, Richland, Washington. 
Gano, K. A. and J. B. States, 1982, Habitat Requirements and Burrowing Depths of Rodents in Relation to Shallow Waste Burial Sites, PNL-4140, Pacific Northwest Laboratory, Richland, Washington.

Givens, D. B. (editor), V. R. Baker, F. D. Drake, B. R. Finney, D. B. Givens. J. Lomberg, L.E. Narens, and W. S. Williams, 1992, Team B Report -- The Development of Markers to Deter Inadvertent Human Intrusions in to the Waste Isolation Pilot Plant (WIPP): Final Report for Sandia National Laboratories, American Anthropological Association, Washington, D.C.

Hora, S. C., D. von Winterfeldt, and K. M. Trauth, 1991, Expert Judgment on Inadvertent Human Intrusion into the Waste Isolation Pilot Plant, SAND90-3063, Sandia National Laboratory, Albuquerque, New Mexico.

Glantz, C. S., M. N. Schwartz, K. W. Burk, R. B. Kaspar, M. W. Ligotke, and D. J. Perrault, 1990, Climatological Summary of Wind and Temperature Data for the Hanford Meteorology Monitoring Network, PNL-7471, Pacific Northwest Laboratory, Richland, Washington.

Gee, G. W., M. D. Campbel1, J. F. Cline, and H. D. Freeman, 1989, Assessment of Cover Systems at the Grand Junction, Colorado, Uranium Mill Tailings Pile: 1987 Field Measurements, PNL-6762, Pacific Northwest Laboratory, Richiand, Washington.

Gee, G. W., L. L. Cadwe11, H. D. Freeman, M. W. Ligotke, S. O. Link, R. A. Romine, and W. H. Walters, Jr., 1993, Testing and Monitoring Plan for the Permanent I solation Surface Barrier Prototype, PNL-8391, Pacific Northwest Laboratory, Richland, Washington.

Hoover, K. A., L. L. Cadwe 11, and W. H. Walters, 1990, Hanford Protective Barriers Program: Water Erosion Studies - FY 1989, PNL-7214, Pacific Northwest Laboratory, Richland, Washington.

Kaplan, M. F., and M. R. Adams, 1986, "Using the Past to Protect the Future: Marking Nuclear Waste Disposal Sites," Archeology, 39(5):51-54.

Landeen, D. S., L. L. Cadwe 11, L. E. Eberhardt, R. E. Fitzner, and M. A. Simmons, 1990, Animal Intrusion Field Test Plan, WHC-EP-0253, Westinghouse Hanford Company, Richland, Washington.

Landeen, D. S., 1990, Animal Intrusion Status Report for Fiscal Year 1989, WHC-EP-0299, Westinghouse Hanford Company, Richland, Washington.

Landeen, D. S., 1991, Animal Intrusion Status Report for Fiscal Year 1990, WHC-EP-0398, Westinghouse Hanford Company, Richland, Washington.

Last, G. V., M. A. Glennon, M. A. Young, and G. W. Gee, 1987, Protective Barrier Materials Analysis: Fine Soil Site Characterization, PNL-6314, Pacific Northwest Laboratory, Richland, Washington.

Ligotke, M. W., 1988, Soil Erosion Rates from Mixed Soil and Gravel Surfaces in a Wind Tunnel: A Preliminary Report, PNL-6677, Pacific Northwest Laboratory, Richland, Washington. 
Ligotke, M. W., 1989, Surface Stability Test Plan for Protective Barriers, PNL-6722, Pacific Northwest Laboratory, Richland, Washington.

Ligotke, M. W., 1993, Soil Erosion Rates Caused by Wind and Saltating Sand Stresses in a Wind Tunnel, PNL-8478, Pacific Northwest Laboratory, Richland, Washington.

Ligotke, M. W., and D. C. Klopfer, 1990, Soil Erosion Rates from Mixed Soil and Gravel Surfaces in a Wind Tunnel, PNL-7435, Pacific Northwest Laboratory, Richland, Washington.

Petersen, K. L., J. C. Chatters, and W. J. Waugh, 1993, Long-Term Climate Change Assessment Study Plan for the Hanford Site Permanent Isolation Barrier Development Program, WHC-EP-0569, Revision 1, Westinghouse Hanford Company, Richland, Washington.

Phillips, S. J., M. R. Adams, T. W. Gilbert, C. C. Meinhardt, R. M. Mitchell, and W. J. Waugh, 1985, Engineered Barrier Test Facility Status Report: 1984, RHO-WM-SR-3P, Rockwell Hanford Operations, Richland, Washington.

Relyea, J. F., M. R. Sackschewsky, W. J. Waugh, 1989, Small-Tube Lysimeter Facility Status Report for Fiscal Year 1989, WHC-EP-0297, Westinghouse Hanford Company, Richland, Washington.

Stone, W. A., J. M. Thorp, 0. P. Gifford, and D. J. Hoitink, 1983, Climatological Summary for the Hanford Area, PNL-4622k, Pacific Northwest Laboratory, Richland, Washington.

U.S. Federal Register, Disposal of Hanford Defense High-Level, Transuranic, and Tank Wastes, Hanford Site, Richland, Washington; Record of Decision (ROD), 53-FR-12449, April 14, 1988.

Walters, W. H., K. A. Hoover, and L. L. Cadwell, 1990, Project Test Plan for Runoff and Erosion on Fine-Soil Barrier Surfaces and Rock-Covered Side Slopes, PNL-6791, Pacific Northwest Laboratory, Richland, Washington.

Waugh, W. J., 1989, Gravel Admix, Vegetation and Soil Water Interactions in Protective Barriers: Experimental Design, Construction and Initial Conditions, PNL-6616, Pacific Northwest Laboratory, Richland, Washington.

Wing, N. R., 1993, Permanent Isolation Surface Barrier: Functional Performance, WHC-EP-0650, Westinghouse Hanford Company, Richland, Washington.

Wing, N. R., and G. W. Gee (eds.), 1990, Hanford Site Protective Barrier Development Program: Fiscal Year 1989 Highlights, WHC-EP-0318, Westinghouse Hanford Company, Richland, Washington. 
Table 1. Barrier Development Program Cost \& Schedule Estimates.

Estimates Based on the Results of the Value Engineering Study.

All estimates are in fiscal year 1994 dollars.

It is assumed PNL is funded via the FIN Plan.

(sheet 1 of 37 )

\begin{tabular}{|c|c|c|c|c|c|c|c|c|}
\hline MGT-1 Project Coordination & FY 94 & FY 95 & FY 96 & FY 97 & FY 98 & Total & \multicolumn{2}{|c|}{$\begin{array}{c}\text { Summary } \\
\text { (\$K-Programmatic) }\end{array}$} \\
\hline Staffing Exempt (PNL) (WM) & 2.0 & 2.0 & 2.0 & 2.0 & 2.0 & 10.0 & Workermonths & 103.8 \\
\hline Staffing Exempt (PNL) (\$K-P) & 43.0 & 43.0 & 43.0 & 43.0 & 43.0 & 214.8 & $\begin{array}{l}\text { Staffing } \\
\text { (WHC/PNL) }\end{array}$ & $1,328.8$ \\
\hline Staffing Exempt (PNL) (WM) & 2.0 & 3.0 & 3.0 & 3.0 & 3.0 & 14.0 & $\begin{array}{l}\text { Staffing } \\
\text { (IRM) }\end{array}$ & 125.5 \\
\hline Staffing Exempt (PNL) (\$K-P) & 33.3 & 49.9 & 49.9 & 49.9 & 49.9 & 233.0 & $\begin{array}{l}\text { Staffing } \\
\text { (KEH) }\end{array}$ & 65.6 \\
\hline Staffing Exempt (PNL/QA) (WM) & 2.6 & 3.0 & 3.0 & 3.0 & 3.0 & 14.6 & Materials & 31.4 \\
\hline Staffing Exempt (PNL) (\$K-P) & 33.8 & 39.0 & 39.0 & 39.0 & 39.0 & 189.9 & Subcontracts & 0.0 \\
\hline $\begin{array}{l}\text { Staffing Nonexempt (PNL/Secretary) } \\
\text { (WM) }\end{array}$ & 3.8 & 4.0 & 4.0 & 4.0 & 4.0 & 19.8 & Total & $1,551.3$ \\
\hline Staffing Nonexempt (PNL) (\$K-P) & 51.5 & 55.0 & 55.0 & 55.0 & 55.0 & 271.4 & & \\
\hline Staffing Exempt (WHC/25320) (WM) & 3.4 & 3.0 & 3.0 & 3.0 & 3.0 & 15.4 & & \\
\hline Staffing Exempt (WHC/25320) (\$K-P) & 40.7 & 35.9 & 35.9 & 35.9 & 35.9 & 184.3 & & \\
\hline Staffing Exempt (WHC/38620) (WM) & 2.0 & 2.0 & 2.0 & 2.0 & 2.0 & 10.0 & & \\
\hline Staffing Exempt (WHC/38620) (\$K-P) & 23.9 & 23.9 & 23.9 & 23.9 & 23.9 & 119.7 & & \\
\hline Staffing Nonexempt (WHC/25320) (WM) & 4.0 & 4.0 & 4.0 & 4.0 & 4.0 & 20.0 & & \\
\hline $\begin{array}{l}\text { Staffing Nonexempt (WHC/25320) } \\
(\$ K-P)\end{array}$ & 23.1 & 23.1 & 23.1 & 23.1 & 23.1 & 115.7 & & \\
\hline Staffing Exempt (KEH) (WM) & 1.0 & 1.0 & 1.0 & 1.0 & 1.0 & 5.0 & & \\
\hline Staffing Exempt (KEH) (\$K-P) & 13.1 & 13.1 & 13.1 & 13.1 & 13.1 & 65.6 & & \\
\hline IRM Support (\$K-Direct) & 20.0 & 20.0 & 20.0 & 20.0 & 20.0 & 100.0 & & \\
\hline
\end{tabular}


Table 1. Barrier Development Program Cost \& Schedule Estimates.

(sheet 2 of 37)

\begin{tabular}{|c|c|c|c|c|c|c|}
\hline IRM Support (\$K-Programmatic) & 25.1 & 25.1 & 25.1 & 25.1 & 25.1 & 125.5 \\
\hline Travel (\$K-Direct) & 5.0 & 5.0 & 5.0 & 5.0 & 5.0 & 25.0 \\
\hline Travel (SK-P) & 6.3 & 6.3 & 6.3 & 6.3 & 6.3 & 31.4 \\
\hline Subcontracts (SK-Direct) & 0.0 & 0.0 & 0.0 & 0.0 & 0.0 & 0.0 \\
\hline Subcontracts (SK-P) & 0.0 & 0.0 & 0.0 & 0.0 & 0.0 & 0.0 \\
\hline Total (\$K-P) & 293.9 & 314.3 & 314.3 & 314.3 & 314.3 & $1,551.3$ \\
\hline Total (WM) & 20.8 & 22.0 & 22.0 & 22.0 & 22.0 & 108.8 \\
\hline WHC & 94.1 & 89.3 & 89.3 & 89.3 & 89.3 & 451.2 \\
\hline PNL & 161.6 & 186.9 & 186.9 & 186.9 & 186.9 & 909.0 \\
\hline IRM & 25.1 & 25.1 & 25.1 & 25.1 & 25.1 & 125.5 \\
\hline KEH & 13.1 & 13.1 & 13.1 & 13.1 & 13.1 & 65.6 \\
\hline Total & 293.9 & 314.3 & 314.3 & 314.3 & 314.3 & $1,551.3$ \\
\hline
\end{tabular}


Table 1. Barrier Development Program Cost \& Schedule Estimates. (sheet 3 of 37 )

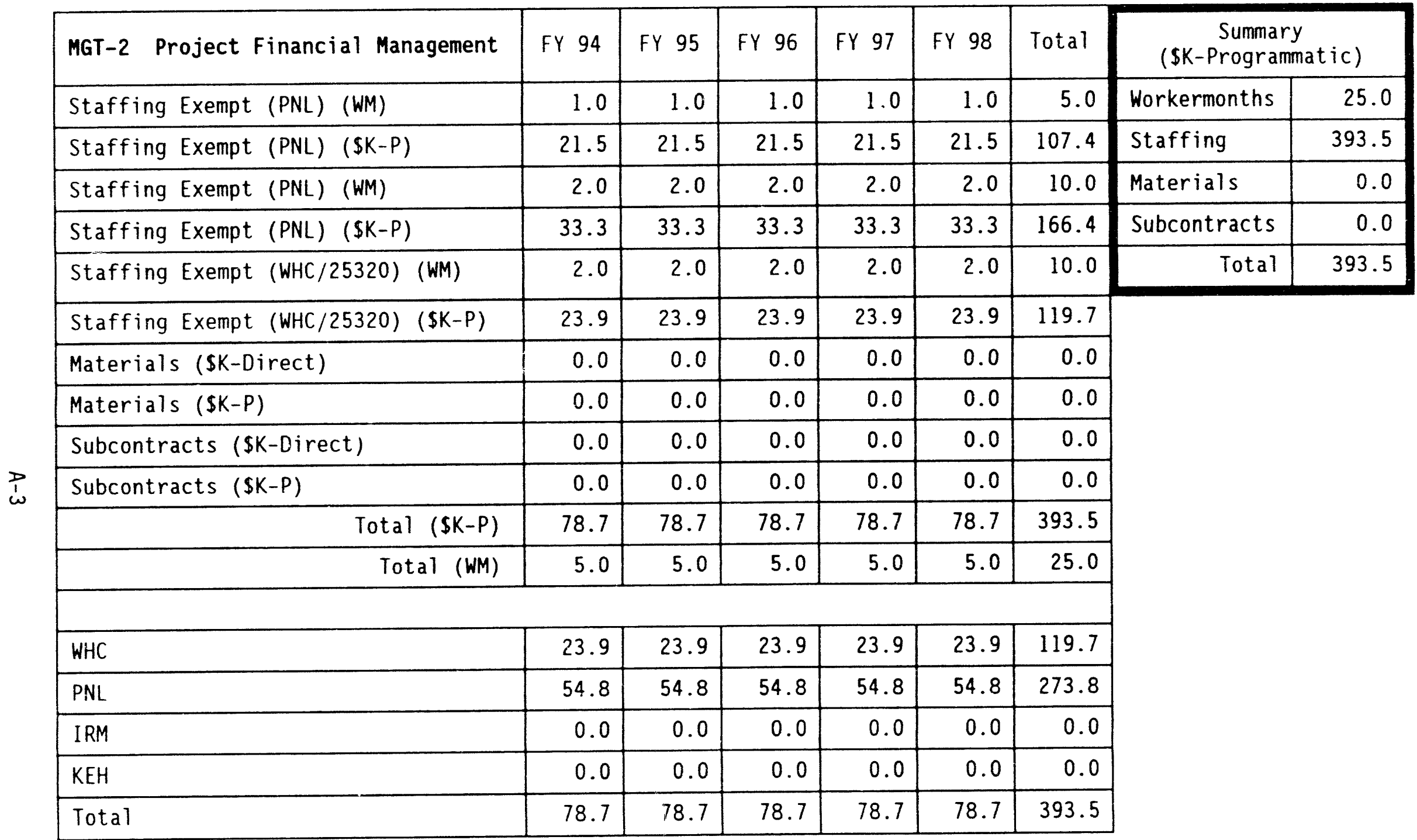


Table 1. Barrier Development Program Cost \& Schedule Estimates. (sheet 4 of 37 )

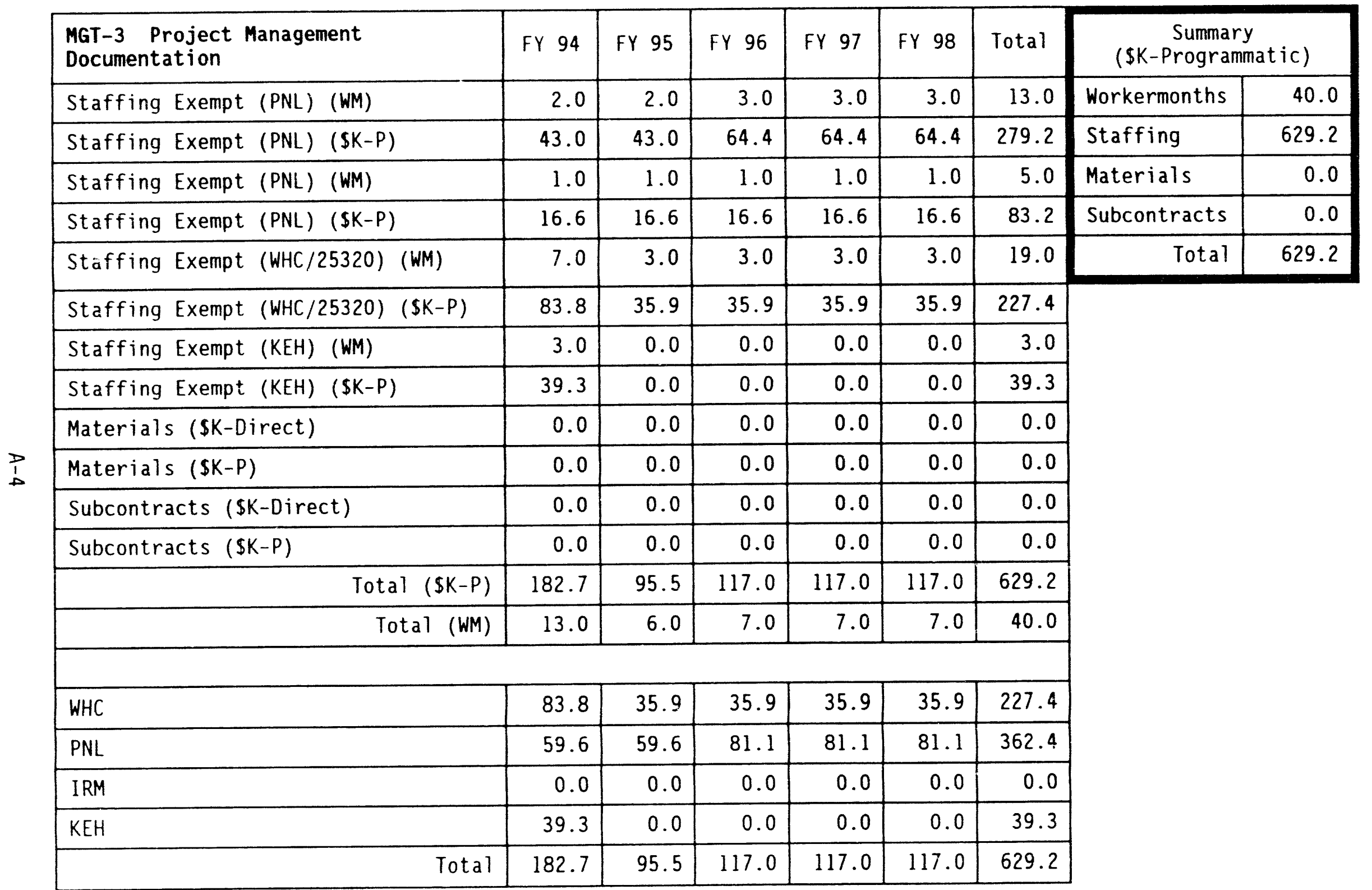


Table 1. Barrier Development Program Cost \& Schedule Estimates. (sheet 5 of 37 )

\begin{tabular}{|c|c|c|c|c|c|c|c|c|}
\hline $\begin{array}{l}\text { BI0 Documentation of Animal } \\
\text { Intrusion Studies }\end{array}$ & FY 94 & FY 95 & FY 96 & FY 97 & FY 98 & Total & \multicolumn{2}{|c|}{$\begin{array}{c}\text { Summary } \\
\text { (\$K-Programmatic) }\end{array}$} \\
\hline Staffing Exempt (PNL) (WM) & 3.0 & 0.0 & 0.0 & 0.0 & 0.0 & 3.0 & Workermonths & 6.0 \\
\hline Staffing Exempt (PNL) ( $(S K-P)$ & 51.7 & 0.0 & 0.0 & 0.0 & 0.0 & 51.7 & Staffing & 87.6 \\
\hline Staffing Exempt (WHC/25320) (WM) & 3.0 & 0.0 & 0.0 & 0.0 & 0.0 & 3.0 & Materials & 0.0 \\
\hline Staffing Exempt (WHC/25320) (\$K-P) & 35.9 & 0.0 & 0.0 & 0.0 & 0.0 & 35.9 & Subcontracts & 0.0 \\
\hline Materials (\$K-Direct) & 0.0 & 0.0 & 0.0 & 0.0 & 0.0 & 0.0 & Total & 87.6 \\
\hline Materials (SK-P) & 0.0 & 0.0 & 0.0 & 0.0 & 0.0 & 0.0 & & \\
\hline Subcontracts (\$K-Direct) & 0.0 & 0.0 & 0.0 & 0.0 & 0.0 & 0.0 & & \\
\hline Subcontracts (\$K-P) & 0.0 & 0.0 & 0.0 & 0.0 & 0.0 & 0.0 & & \\
\hline Total (SK-P) & 87.6 & 0.0 & 0.0 & 0.0 & 0.0 & 87.6 & & \\
\hline Total (WM) & 6.0 & 0.0 & 0.0 & 0.0 & 0.0 & 6.0 & & \\
\hline WHC & 35.9 & 0.0 & 0.0 & 0.0 & 0.0 & 35.9 & & \\
\hline PNL & 51.7 & 0.0 & 0.0 & 0.0 & 0.0 & 51.7 & & \\
\hline IRM & 0.0 & 0.0 & 0.0 & 0.0 & 0.0 & 0.0 & & \\
\hline KEH & 0.0 & 0.0 & 0.0 & 0.0 & 0.0 & 0.0 & & \\
\hline Total & 87.6 & 0.0 & 0.0 & 0.0 & 0.0 & 87.6 & & \\
\hline
\end{tabular}


WHC-EP-0673

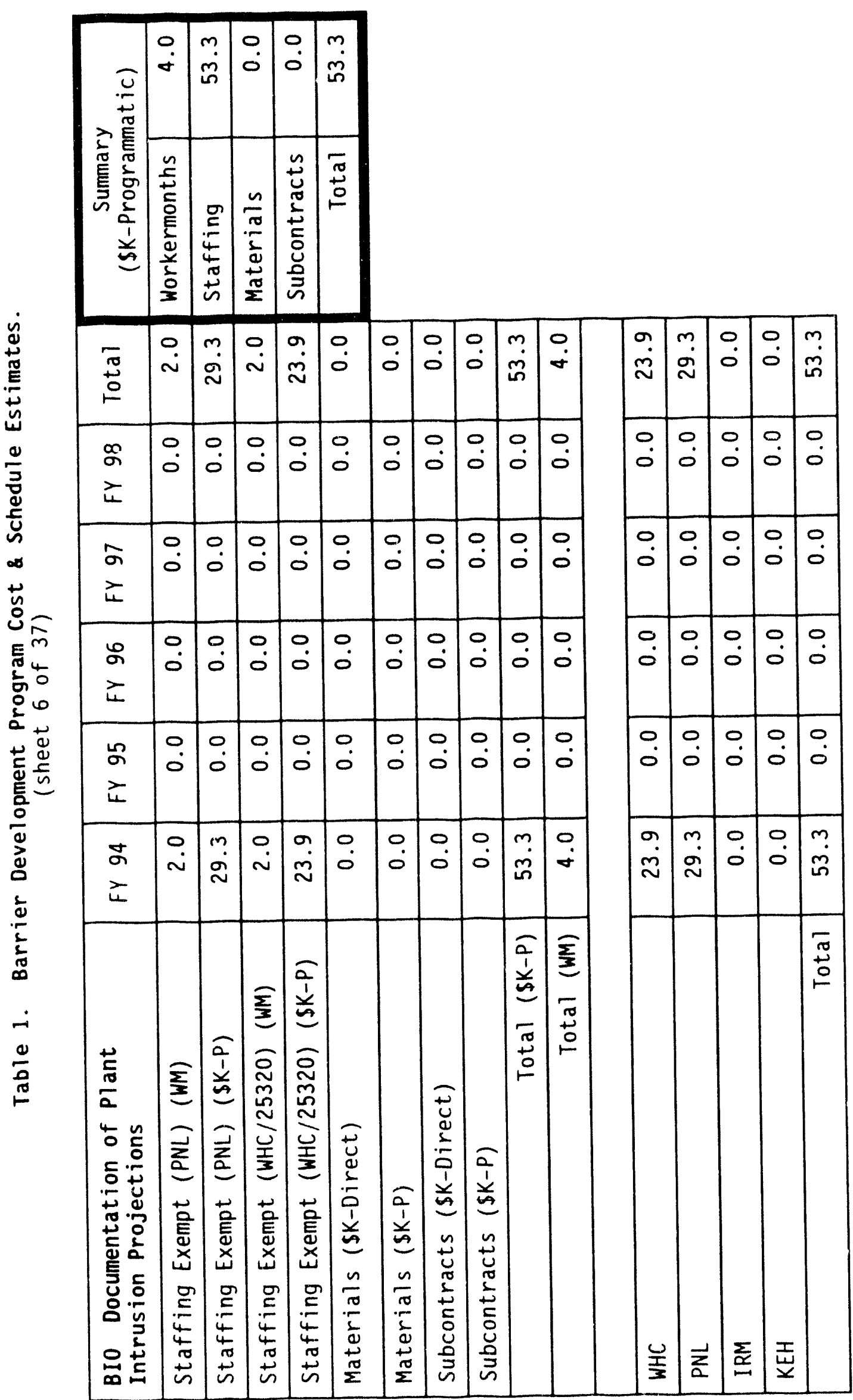


Table 1. Barrier Development Program Cost \& Schedule Estimates. (sheet 7 of 37 )

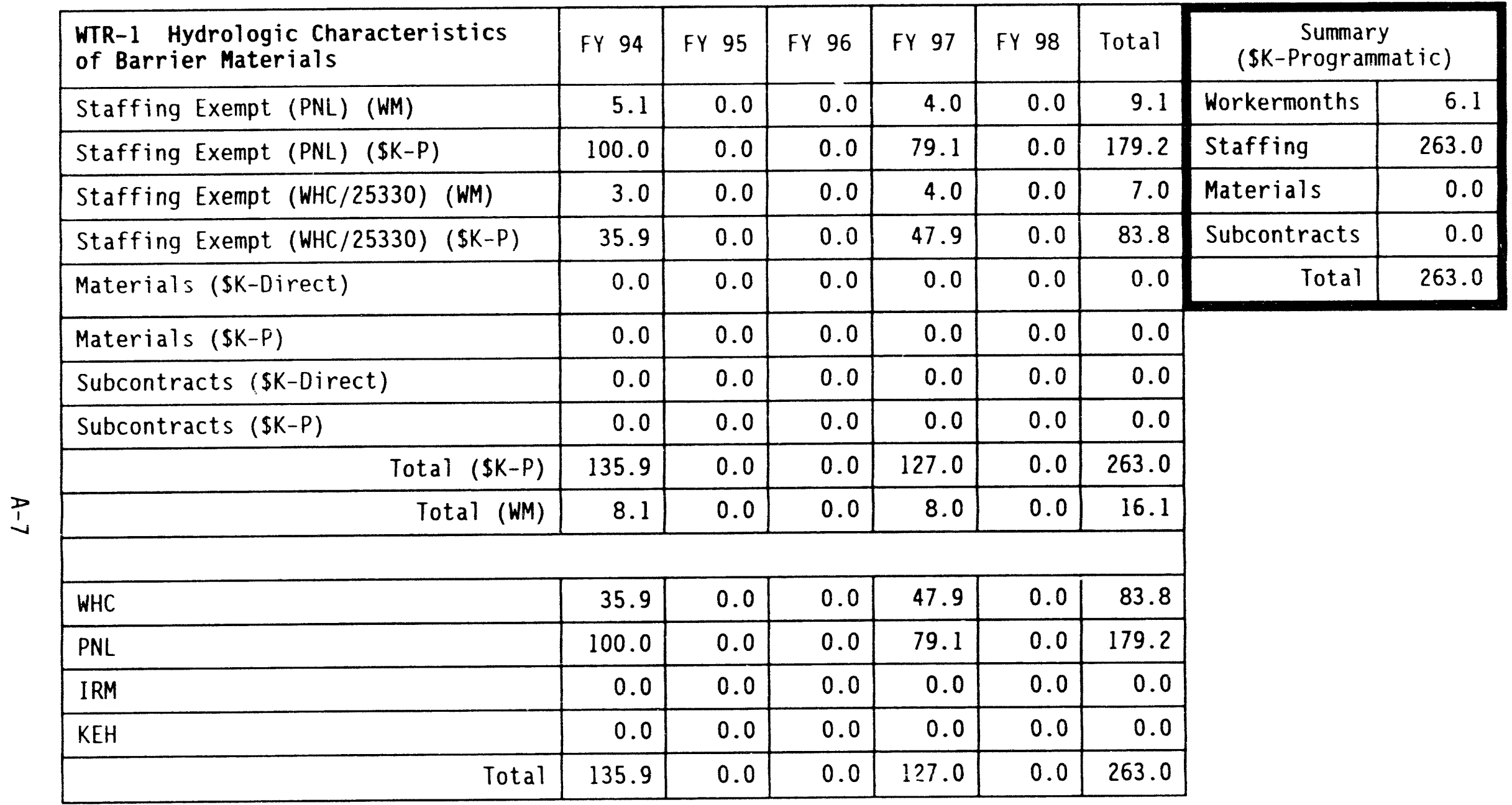


Table 1. Barrier Development Program Cost \& Schedule Estimates. (sheet 8 of 37 )

\begin{tabular}{|c|c|c|c|c|c|c|c|c|}
\hline $\begin{array}{l}\text { WTR-2 Field Lysimeter Test } \\
\text { Facility and Other Lysimeters }\end{array}$ & FY 94 & FY 95 & FY 96 & FY 97 & FY 98 & Total & \multicolumn{2}{|c|}{$\begin{array}{c}\text { Summary } \\
\text { (SK-Programmatic) }\end{array}$} \\
\hline Staffing Exempt (PNL) (WM) & 2.0 & 2.0 & 2.0 & 2.0 & 0.0 & 8.0 & Workermonths & 73.6 \\
\hline Staffing Exempt (PNL) (\$K-P) & 39.6 & 39.6 & 39.6 & 39.6 & 0.0 & 158.3 & Staffing & $1,116.5$ \\
\hline Staffing Exempt (PNL) (WM) & 1.0 & 1.0 & 1.0 & 1.0 & 0.0 & 4.0 & Materials & 40.0 \\
\hline Staffing Exempt (PNL) (\$K-P) & 15.9 & 15.9 & 15.9 & 15.9 & 0.0 & 63.5 & Subcontracts & 0.0 \\
\hline Staffing Exempt (PNL) (WM) & 2.0 & 2.0 & 2.0 & 2.0 & 0.0 & 8.0 & Total & $1,156.5$ \\
\hline Staffing Exempt (PNL) (\$K-P) & 39.6 & 39.6 & 39.6 & 39.6 & 0.0 & 158.3 & & \\
\hline Staffing Nonexempt (PNL) (WM) & 17.6 & 12.0 & 12.0 & 12.0 & 0.0 & 53.6 & & \\
\hline Staffing Nonexempt (PNL) (SK-P) & 241.7 & 164.9 & 164.9 & 164.9 & 0.0 & 736.4 & & \\
\hline Staffing Exempt (WHC/25320) (WM) & 0.0 & 0.0 & 0.0 & 0.0 & 0.0 & 0.0 & & \\
\hline Staffing Exempt (WHC/25320) (\$K-P) & 0.0 & 0.0 & 0.0 & 0.0 & 0.0 & 0.0 & & \\
\hline Materials (SK-Direct) & 0.0 & 0.0 & 0.0 & 0.0 & 0.0 & 0.0 & & \\
\hline Materials (\$K-P) & 20.0 & 10.0 & 5.0 & 5.0 & 0.0 & 40.0 & & \\
\hline Subcontracts (\$K-Direct) & 0.0 & 0.0 & 0.0 & 0.0 & 0.0 & 0.0 & & \\
\hline Subcontracts $(\$ K-P)$ & 0.0 & 0.0 & 0.0 & 0.0 & 0.0 & 0.0 & & \\
\hline Total (\$K-P) & 356.8 & 269.9 & 264.9 & 264.9 & 0.0 & $1,156.5$ & & \\
\hline Total (WM) & 22.6 & 17.0 & 17.0 & 17.0 & 0.0 & 73.6 & & \\
\hline WHC & 0.0 & 0.0 & 0.0 & 0.0 & 0.0 & 0.0 & & \\
\hline PNL & 356.8 & 269.9 & 264.9 & 264.9 & 0.0 & $1,156.5$ & & \\
\hline IRM & 0.0 & 0.0 & 0.0 & 0.0 & 0.0 & 0.0 & & \\
\hline KEH & 0.0 & 0.0 & 0.0 & 0.0 & 0.0 & 0.0 & & \\
\hline Total & 356.8 & 269.9 & 264.9 & 264.9 & 0.0 & $1,156.5$ & & \\
\hline
\end{tabular}


Table 1. Barrier Development Program Cost \& Schedule Estimates. (sheet 9 of 37)

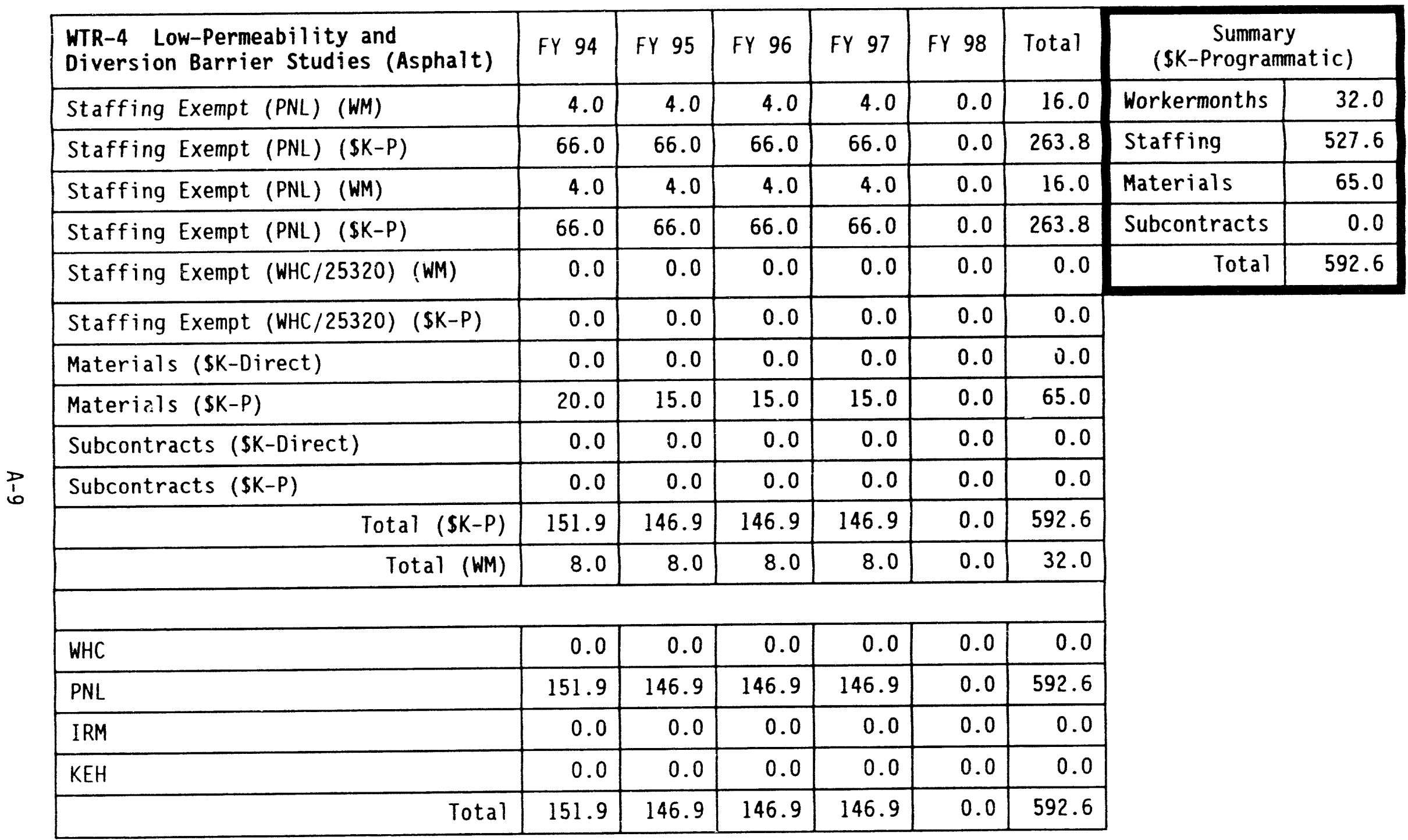


Table 1. Barrier Development Program Cost \& Schedule Estimates.

(sheet 10 of 37)

\begin{tabular}{|c|c|c|c|c|c|c|c|c|}
\hline $\begin{array}{l}\text { PHYS-1 Assessment of Potentially } \\
\text { Disruptive Natural Events }\end{array}$ & FY 94 & FY 95 & FY 96 & FY 97 & FY 98 & Total & \multicolumn{2}{|c|}{$\begin{array}{c}\text { Summary } \\
\text { (\$K-Programmatic) }\end{array}$} \\
\hline Staffing Exempt (PNL) (WM) & 1.0 & 0.0 & 0.0 & 0.0 & 0.0 & 1.0 & Workermonths & 6.0 \\
\hline Staffing Exempt (PNL) (\$K-P) & 16.6 & 0.0 & 0.0 & 0.0 & 0.0 & 16.6 & Staffing & 78.8 \\
\hline Staffing Exempt (WHC/25320) (WM) & 3.0 & 0.0 & 0.0 & 0.0 & 0.0 & 3.0 & Materials & 0.0 \\
\hline Staffing Exempt (WHC/25320) (SK-P) & 35.9 & 0.0 & 0.0 & 0.0 & 0.0 & 35.9 & Subcontracts & 0.0 \\
\hline Staffing Exempt (KEH) (WM) & 2.0 & 0.0 & 0.0 & 0.0 & 0.0 & 2.0 & Total & 78.8 \\
\hline Staffing Exempt (KEH) (\$K-P) & 26.2 & 0.0 & 0.0 & 0.0 & 0.0 & 26.2 & & \\
\hline Materials (\$K-Direct) & 0.0 & 0.0 & 0.0 & 0.0 & 0.0 & 0.0 & & \\
\hline Materials ( $\$ K-P)$ & 0.0 & 0.0 & 0.0 & 0.0 & 0.0 & 0.0 & & \\
\hline Subcontracts (\$K-Direct) & 0.0 & 0.0 & 0.0 & 0.0 & 0.0 & 0.0 & & \\
\hline Subcontracts $(\$ K-P)$ & 0.0 & 0.0 & 0.0 & 0.0 & 0.0 & 0.0 & & \\
\hline Total (\$K-P) & 78.8 & 0.0 & 0.0 & 0.0 & 0.0 & 78.8 & & \\
\hline Total (WM) & 6.0 & 0.0 & 0.0 & 0.0 & 0.0 & 6.0 & & \\
\hline WHC & 35.9 & 0.0 & 0.0 & 0.0 & 0.0 & 35.9 & & \\
\hline PNL & 16.6 & 0.0 & 0.0 & 0.0 & 0.0 & 16.6 & & \\
\hline IRM & 0.0 & 0.0 & 0.0 & 0.0 & 0.0 & 0.0 & & \\
\hline KEH & 26.2 & 0.0 & 0.0 & 0.0 & 0.0 & 26.2 & & \\
\hline Total & 78.8 & 0.0 & 0.0 & 0.0 & 0.0 & 78.8 & & \\
\hline
\end{tabular}


Table 1. Barrier Development Program Cost \& Schedule Estimates. (sheet 11 of 37)

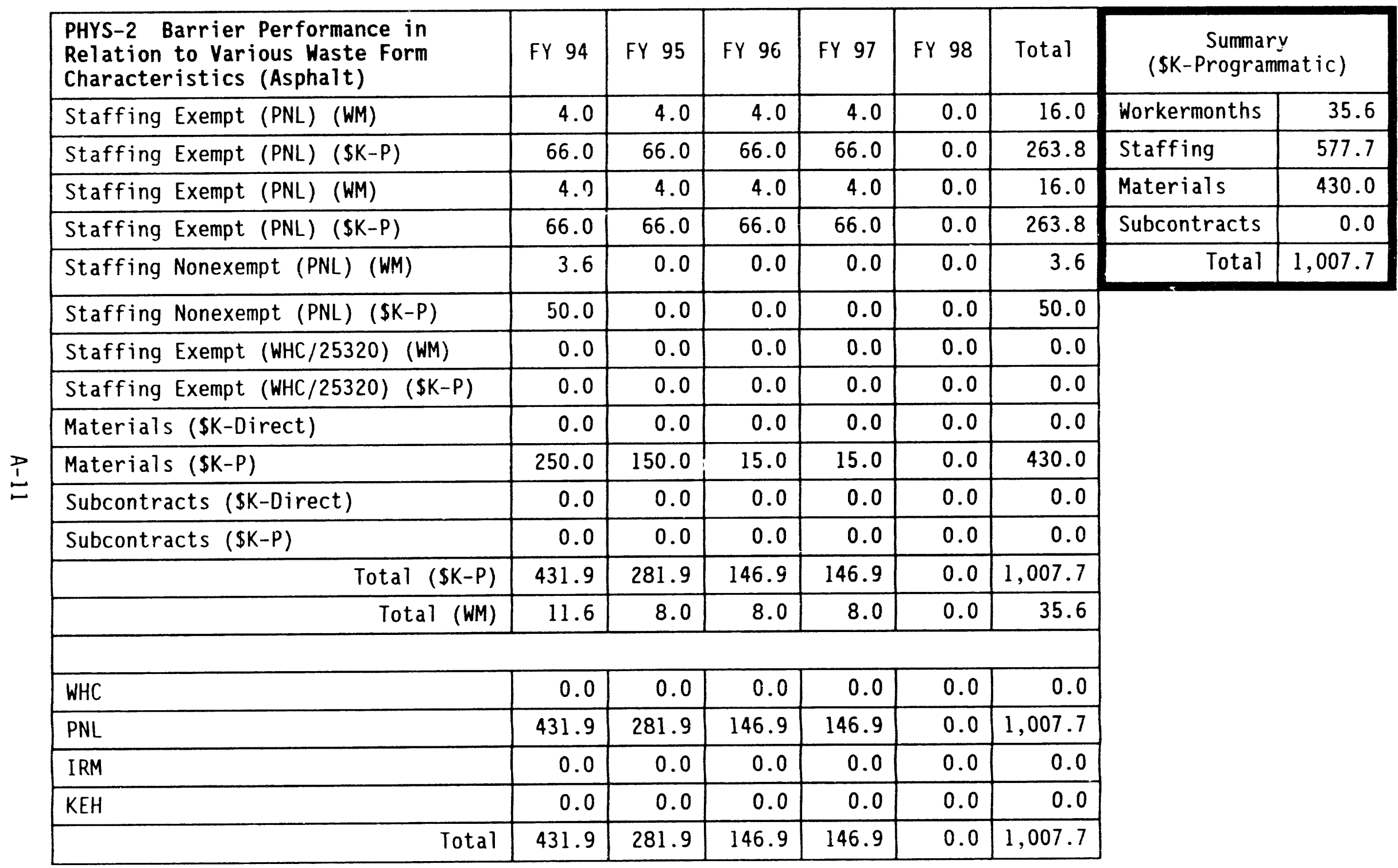


Table 1. Barrier Development Program Cost Schedule Estimates.

(sheet 12 of 37 )

\begin{tabular}{|c|c|c|c|c|c|c|c|c|}
\hline $\begin{array}{l}\text { BAR-3 Prototype Barier Testing } \\
\text { and Monitoring }\end{array}$ & FY 94 & FY 95 & FY 96 & FY 97 & FY 98 & Total & \multicolumn{2}{|c|}{$\begin{array}{c}\text { Summary } \\
(\$ K-\text { Programmatic) }\end{array}$} \\
\hline $\mathrm{BDT} / \mathrm{BTAB}$ & & & & & & & Workermonths & 266.2 \\
\hline $\begin{array}{l}\text { Test Plan, Coordination, and } \\
\text { Status Report Preparation }\end{array}$ & & & & & & & Staffing & $4,524.6$ \\
\hline Staffing Exempt (PNL) (WM) & 3.0 & 3.0 & 3.0 & 3.0 & 0.0 & 12.0 & Materials & 95.0 \\
\hline Staffing Exempt (PNL) $(\$ K-P)$ & 59.4 & 59.4 & 59.4 & 59.4 & 0.0 & 237.4 & Subcontracts & 0.0 \\
\hline $\begin{array}{l}\text { Records Management and Data } \\
\text { Archival }\end{array}$ & & & & & & & Total & $4,619.6$ \\
\hline Staffing Exempt (PNL) (WM) & 9.0 & 12.0 & 12.0 & 12.0 & 0.0 & 45.0 & & \\
\hline Staffing Exempt (PNL) (\$K-P) & 144.9 & 193.2 & 193.2 & 193.2 & 0.0 & 724.4 & & \\
\hline $\begin{array}{l}\text { Water Infiltration Testing and } \\
\text { Monitoring }\end{array}$ & & & & & & & & \\
\hline Staffing Exempt (PNL) (WM) & 10.0 & 20.0 & 20.0 & 20.0 & 0.0 & 70.0 & & \\
\hline Staffing Exempt (PNL) (\$K-P) & 197.9 & 395.7 & 395.7 & 395.7 & 0.0 & $1,385.0$ & & \\
\hline \multicolumn{7}{|l|}{ Side Slope-Evaporation } & & \\
\hline Staffing Exempt (PNL) (WM) & 8.5 & 3.8 & 3.8 & 2.5 & 0.0 & 18.6 & & \\
\hline Staffing Exempt (PNL) (\$K-P) & 168.2 & 75.2 & 75.2 & 49.5 & 0.0 & 368.0 & & \\
\hline $\begin{array}{l}\text { Water Erosion/Soil Surface } \\
\text { Monitoring }\end{array}$ & & & & & & & & \\
\hline Staffing Exempt (PNL) (WM) & 1.7 & 2.3 & 2.4 & 2.5 & 0.0 & 8.8 & & \\
\hline Staffing Exempt (PNL) (\$K-P) & 24.1 & 33.0 & 34.5 & 36.6 & 0.0 & 128.2 & & \\
\hline Staffing Exempt (PNL) (WM) & 1.7 & 2.3 & 2.4 & 2.5 & 0.0 & 8.8 & & \\
\hline Staffing Exempt (PNL) $(\$ K-P)$ & 24.1 & 33.0 & 34.5 & 36.6 & 0.0 & 128.2 & & \\
\hline $\begin{array}{l}\text { Water Erosion/Control Area } \\
\text { Monitoring }\end{array}$ & & & & & & & & \\
\hline
\end{tabular}


Table 1. Barrier Development Program Cost \& Schedule Estimates.

(sheet 13 of 37 )

\begin{tabular}{|c|c|c|c|c|c|c|}
\hline Staffing Exempt (PNL) (WM) & 3.2 & 2.0 & 2.1 & 2.2 & 0.0 & 9.5 \\
\hline Staffing Exempt (PNL) (\$K-P) & 46.5 & 29.5 & 31.0 & 32.5 & 0.0 & 139.5 \\
\hline Staffing Exempt (PNL) (WM) & 3.2 & 2.0 & 2.1 & 2.2 & 0.0 & 9.5 \\
\hline Staffing Exempt (PNL) (\$K-P) & 46.5 & 29.5 & 31.0 & 32.5 & 0.0 & 139.5 \\
\hline \multicolumn{7}{|l|}{ Wind Erosion } \\
\hline Staffing Exempt (PNL) (WM) & 8.0 & 8.0 & 9.0 & 13.5 & 0.0 & 38.5 \\
\hline Staffing Exempt (PNL) (\$K-P) & 133.1 & 133.1 & 149.8 & 224.6 & 0.0 & 640.7 \\
\hline \multicolumn{7}{|l|}{ Biointrusion } \\
\hline Staffing Exempt (PNL) (WM) & 7.5 & 11.3 & 8.5 & 6.1 & 0.0 & 33.4 \\
\hline Staffing Exempt (PNL) (\$K-P) & 109.9 & 165.0 & 125.0 & 90.0 & 0.0 & 490.0 \\
\hline $\begin{array}{l}\text { Staffing Exempt (WHC/25320) } \\
\text { (WM) }\end{array}$ & 2.0 & 2.0 & 2.0 & 2.0 & 0.0 & 8.0 \\
\hline $\begin{array}{l}\text { Staffing Exempt (WHC/25320) } \\
\text { (\$K-P) }\end{array}$ & 23.9 & 23.9 & 23.9 & 23.9 & 0.0 & 95.8 \\
\hline \multicolumn{7}{|l|}{$\begin{array}{l}\text { Engineering Oversight During } \\
\text { Construction }\end{array}$} \\
\hline $\begin{array}{l}\text { Staffing Exempt (WHC/25320) } \\
\text { (WM) }\end{array}$ & 4.0 & 0.0 & 0.0 & 0.0 & 0.0 & 4.0 \\
\hline $\begin{array}{l}\text { Staffing Exempt (WHC/25320) } \\
(\$ K-P)\end{array}$ & 47.9 & 0.0 & 0.0 & 0.0 & 0.0 & 47.9 \\
\hline KEH & & & & & & \\
\hline \multicolumn{7}{|l|}{ Constructability Data Report } \\
\hline Staffing Exempt (KEH) (WM) & 0.0 & 0.0 & 0.0 & 0.0 & 0.0 & 0.0 \\
\hline Staffing Exempt (KEH) (\$K-P) & 0.0 & 0.0 & 0.0 & 0.0 & 0.0 & 0.0 \\
\hline \multicolumn{7}{|l|}{ Constructability Data Collection } \\
\hline Staffing Nonexempt (KEH) (WM) & 0.0 & 0.0 & 0.0 & 0.0 & 0.0 & 0.0 \\
\hline
\end{tabular}


Table 1. Barrier Development Program Cost \& Schedule Estimates.

(sheet 14 of 37 )

\begin{tabular}{|c|c|c|c|c|c|c|}
\hline Staffing Nonexempt (KEH) (\$K-P) & 0.0 & 0.0 & 0.0 & 0.0 & 0.0 & 0.0 \\
\hline \multicolumn{7}{|l|}{ Materials } \\
\hline Materials (\$K-Direct) & 0.0 & 0.0 & 0.0 & 0.0 & 0.0 & 0.0 \\
\hline Materials (\$K-P) & 50.0 & 15.0 & 15.0 & 15.0 & 0.0 & 95.0 \\
\hline \multicolumn{7}{|l|}{$\begin{array}{l}\text { Consultants (Expert Technical } \\
\text { Peer Reviewers) }\end{array}$} \\
\hline Subcontracts (\$K-Direct) & 0.0 & 0.0 & 0.0 & 0.0 & 0.0 & 0.0 \\
\hline Subcontracts $(\$ K-P)$ & 0.0 & 0.0 & 0.0 & 0.0 & 0.0 & 0.0 \\
\hline \multicolumn{7}{|l|}{ Construction Contractor } \\
\hline Subcontracts (\$K-Direct) & 0.0 & 0.0 & 0.0 & 0.0 & 0.0 & 0.0 \\
\hline Subcontracts (\$K-P) & 0.0 & 0.0 & 0.0 & 0.0 & 0.0 & 0.0 \\
\hline Total (\$K-P) & $1,076.4$ & $1,185.7$ & $1,168.2$ & $1,189.3$ & 0.0 & $4,619.6$ \\
\hline Total (WM) & 61.7 & 58.6 & 67.3 & 68.6 & 0.0 & 266.2 \\
\hline WHC & 71.8 & 23.9 & 23.9 & 23.9 & 0.0 & 143.6 \\
\hline PNL & $1,004.6$ & $1,161.7$ & $1,144.2$ & $1,165.4$ & 0.0 & $4,475.9$ \\
\hline IRM & 0.0 & 0.0 & 0.0 & 0.0 & 0.0 & 0.0 \\
\hline KEH & 0.0 & 0.0 & 0.0 & 0.0 & 0.0 & 0.0 \\
\hline Total & $1,076.4$ & $1,185.7$ & $1,168.2$ & $1,189.3$ & 0.0 & $4,619.6$ \\
\hline
\end{tabular}


Table 1. Barrier Development Program Cost \& Schedule Estimates. (sheet 15 of 37)

\begin{tabular}{|c|c|c|c|c|c|c|c|c|}
\hline $\begin{array}{l}\text { MOD-1 Application of Computer } \\
\text { Models }\end{array}$ & FY 94 & FY 95 & FY 96 & FY 97 & FY 98 & Total & \multicolumn{2}{|c|}{$\begin{array}{c}\text { Summary } \\
\text { (\$K-Programmatic) }\end{array}$} \\
\hline Staffing Exempt (PNL) (WM) & 2.3 & 2.3 & 2.3 & 2.3 & 0.0 & 9.0 & Workermonths & 9.0 \\
\hline Staffing Exempt (PNL) (\$K-P) & 35.7 & 35.7 & 35.7 & 35.7 & 0.0 & 143.0 & Staffing & 143.0 \\
\hline Staffing Exempt (PNL) (WM) & 0.0 & 0.0 & 0.0 & 0.0 & 0.0 & 0.0 & Materials & 32.6 \\
\hline Staffing Exempt (PNL) (\$K-P) & 0.0 & 0.0 & 0.0 & 0.0 & 0.0 & 0.0 & Subcontracts & 0.0 \\
\hline Materials (\$K-Direct) & 0.0 & 0.0 & 0.0 & 0.0 & 0.0 & 0.0 & Total & 175.6 \\
\hline Materials $(\$ K-P)$ & 8.1 & 8.1 & 8.1 & 8.1 & 0.0 & 32.6 & & \\
\hline Subcontracts (\$K-Direct) & 0.0 & 0.0 & 0.0 & 0.0 & 0.0 & 0.0 & & \\
\hline Subcontracts (\$K-P) & 0.0 & 0.0 & 0.0 & 0.0 & 0.0 & 0.0 & & \\
\hline Total (\$K-P) & 43.9 & 43.9 & 43.9 & 43.9 & 0.0 & 175.6 & & \\
\hline Total (WM) & 2.3 & 2.3 & 2.3 & 2.3 & 0.0 & 9.0 & & \\
\hline WHC & 0.0 & 0.0 & 0.0 & 0.0 & 0.0 & 0.0 & & \\
\hline PNL & 43.9 & 43.9 & 43.9 & 43.9 & 0.0 & 175.6 & & \\
\hline IRM & 0.0 & 0.0 & 0.0 & 0.0 & 0.0 & 0.0 & & \\
\hline KEH & 0.0 & 0.0 & 0.0 & 0.0 & 0.0 & 0.0 & & \\
\hline Total & 43.9 & 43.9 & 43.9 & 43.9 & 0.0 & 175.6 & & \\
\hline
\end{tabular}


Taóle 1. Barrier Development Program Cast \& Schedule Estimates.

(sheet 16 of 37 )

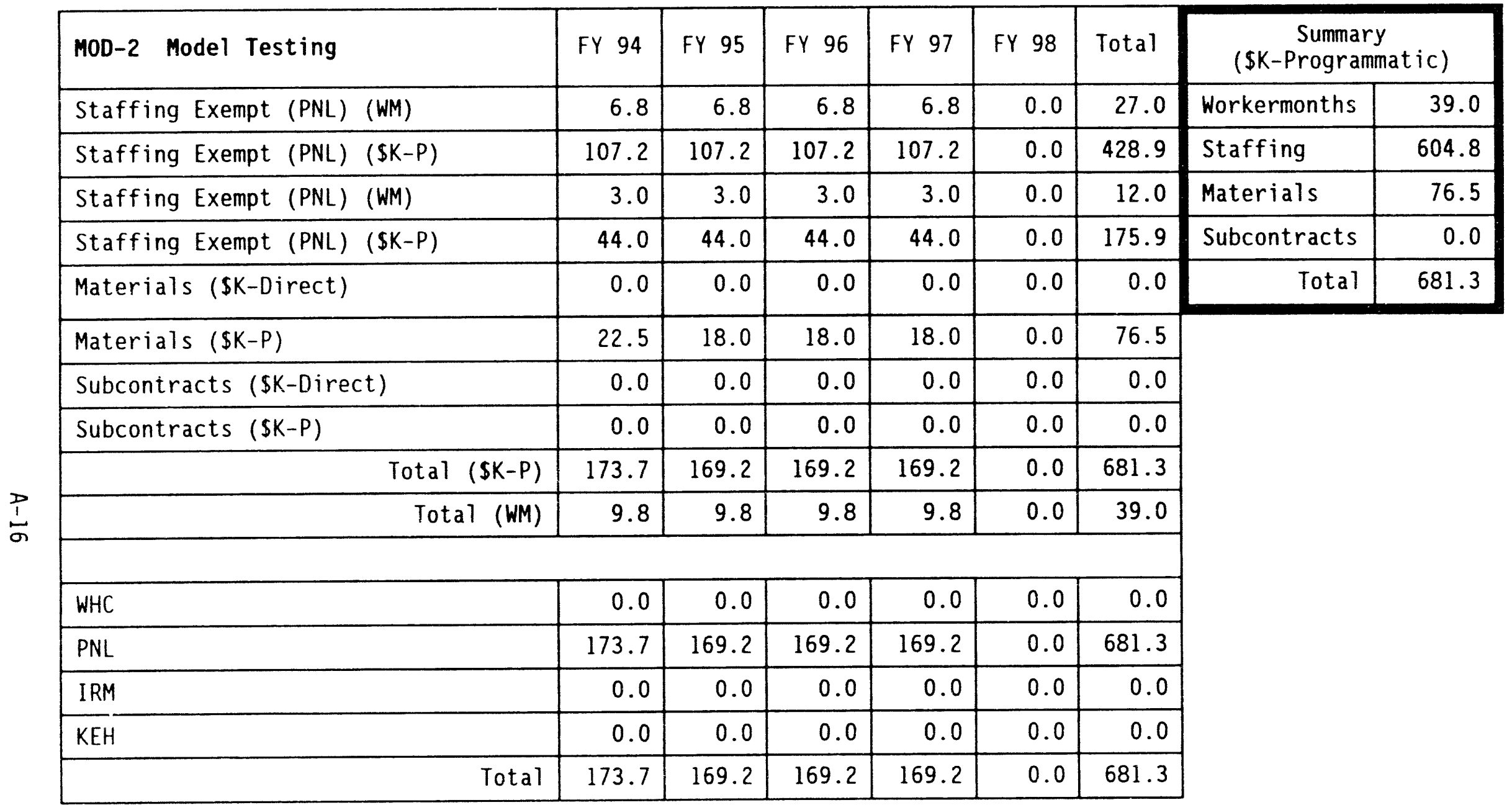


Table 1. Barrier Development Program Cost \& Schedule Estimates.

(sheet 17 of 37 )

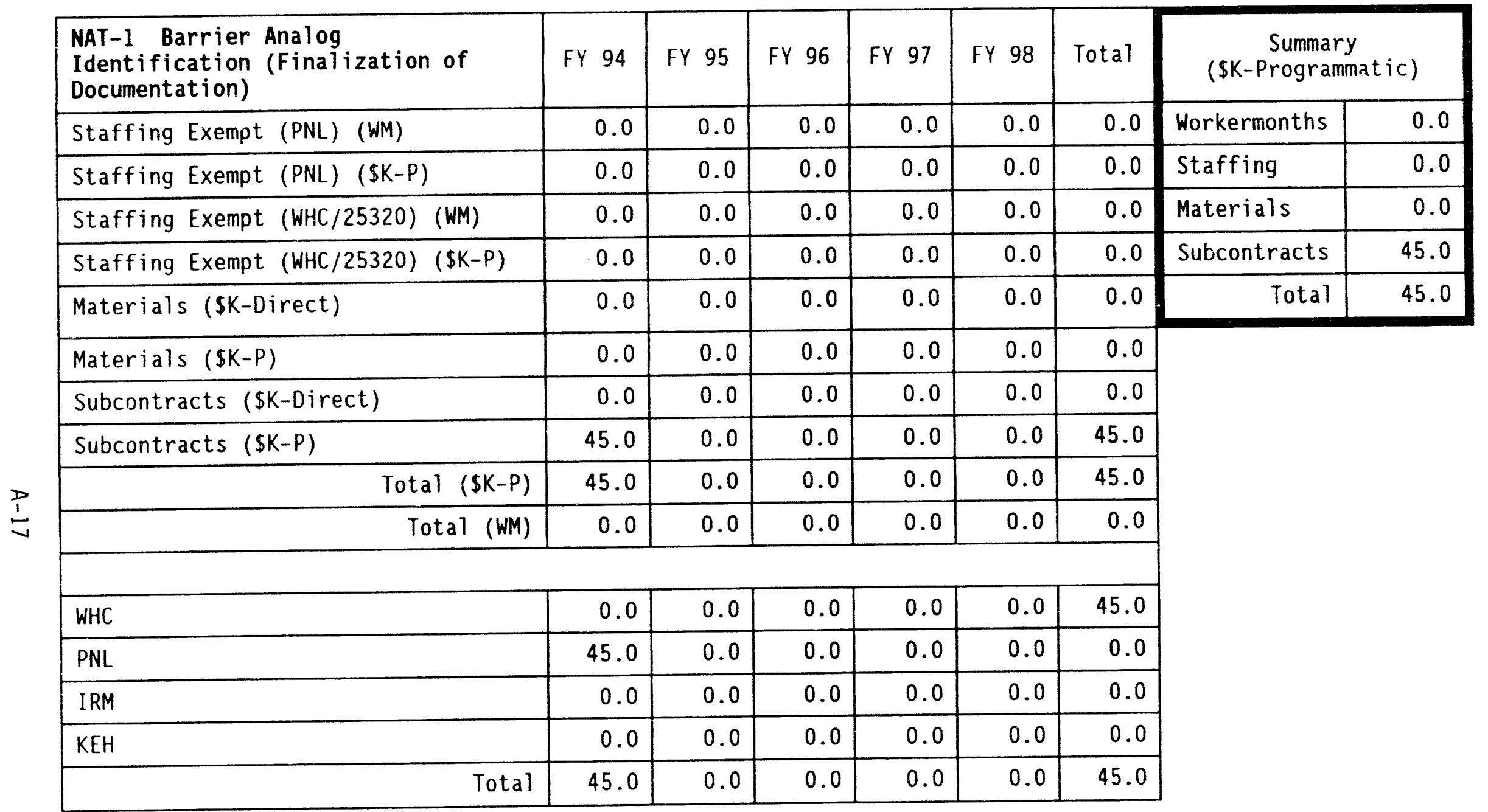


Table 1. Barrier Development Program Cost \& Schedule Estimates. (sheet 18 of 37 )

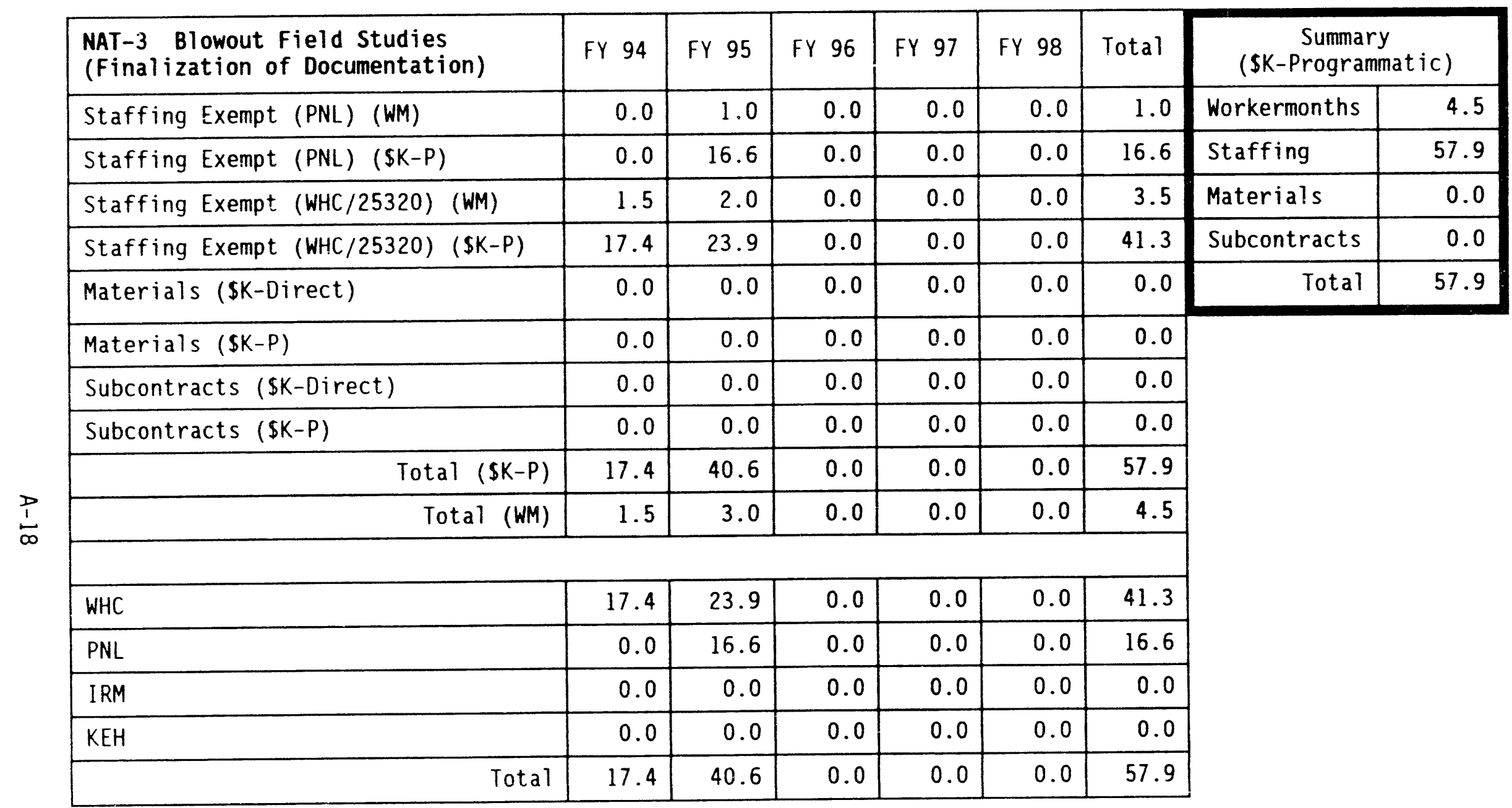


Table 1. Barrier Development Program Cost \& Schedule Estimates. (sheet 19 of 37)

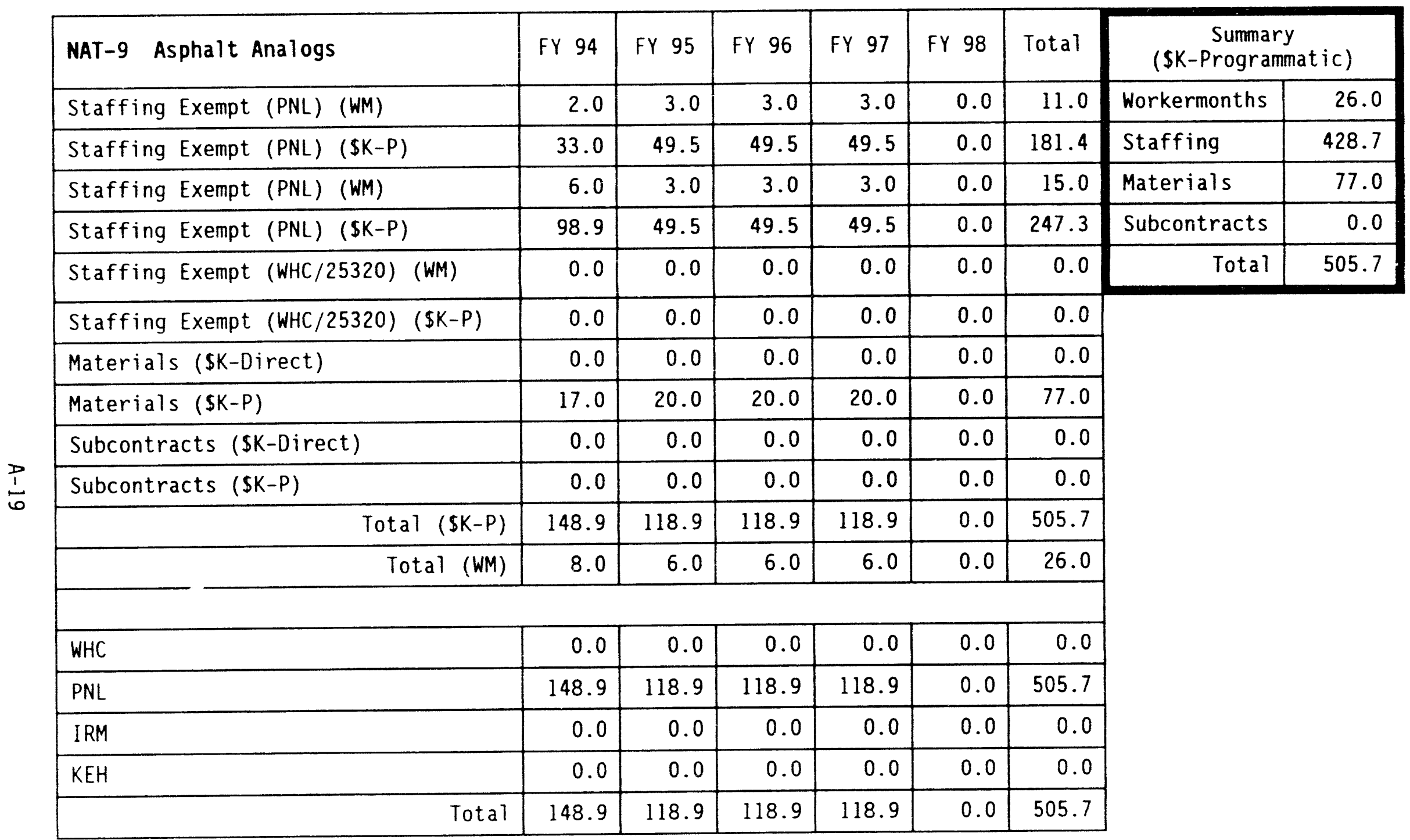


Table 1. Barrier Development Program Cost Schedule Estimates. (sheet 20 of 37 )

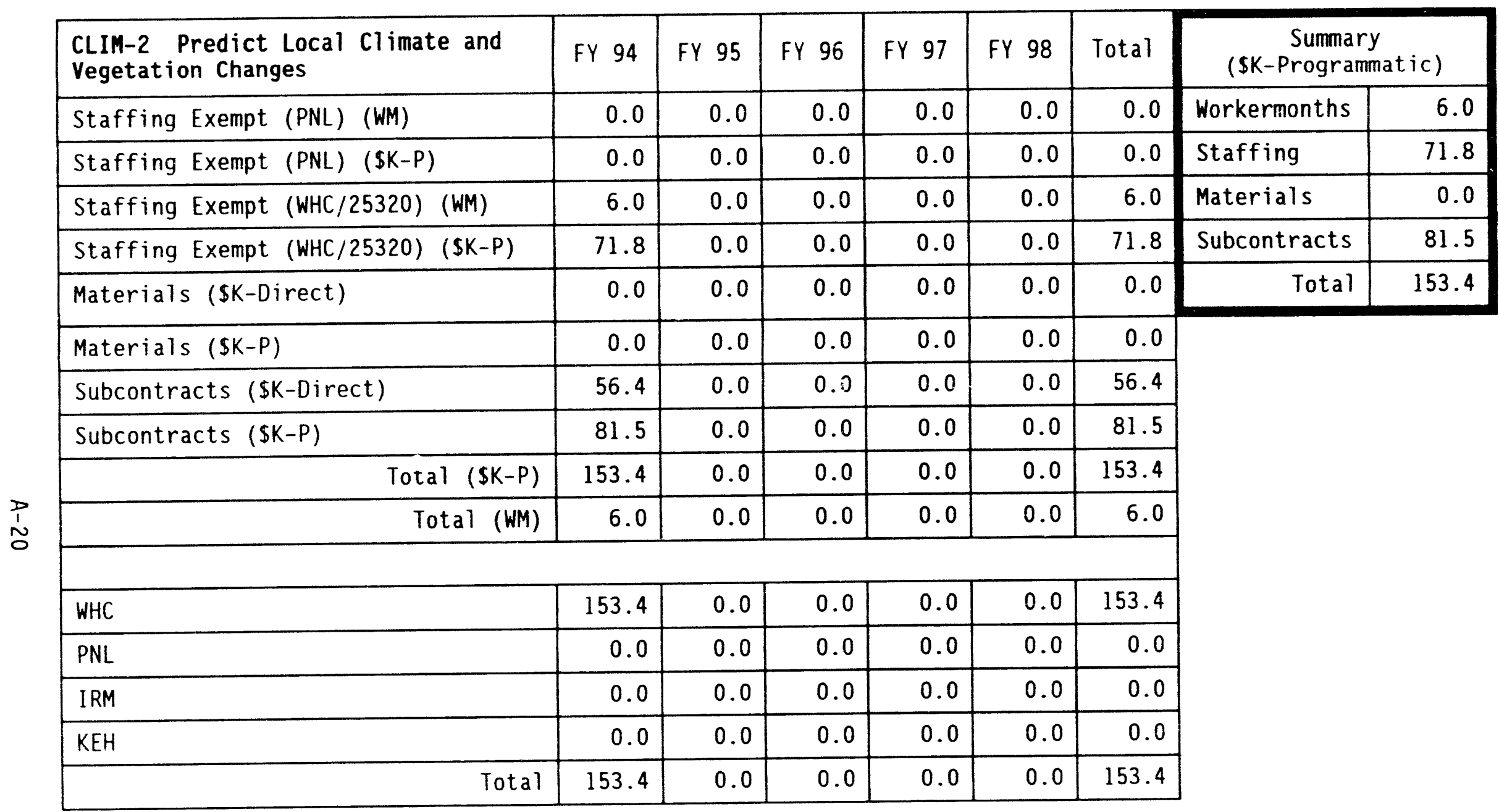


Table 1. Barrier Development Program Cost \& Schedule Estimates. (sheet 21 of 37)

\begin{tabular}{|c|c|c|c|c|c|c|c|c|}
\hline $\begin{array}{l}\text { REG Interface with Regulatory } \\
\text { Agencies }\end{array}$ & FY 94 & FY 95 & FY 96 & FY 97 & FY 98 & Total & \multicolumn{2}{|c|}{$\begin{array}{c}\text { Summary } \\
\text { (\$K-Programmatic) }\end{array}$} \\
\hline Staffing Exempt (PNL) (WM) & 0.5 & 0.5 & 0.5 & 0.5 & 0.5 & 2.5 & Workermonths & 7.5 \\
\hline Staffing Exempt (PNL) (SK-P) & 10.7 & 10.7 & 10.7 & 10.7 & 10.7 & 53.7 & Staffing & 113.5 \\
\hline Staffing Exempt (WHC/25320) (WM) & 1.0 & 1.0 & 1.0 & 1.0 & 1.0 & 5.0 & Materials & 0.0 \\
\hline Staffing Exempt (WHC/25320) (SK-P) & 12.0 & 12.0 & 12.0 & 12.0 & 12.0 & 59.9 & Subcontracts & 0.0 \\
\hline Materials (SK-Direct) & 0.0 & 0.0 & 0.0 & 0.0 & 0.0 & 0.0 & Total & 113.5 \\
\hline Materials ( $\$ K-P)$ & 0.0 & 0.0 & 0.0 & 0.0 & 0.0 & 0.0 & & \\
\hline Subcontracts (\$K-Direct) & 0.0 & 0.0 & 0.0 & 0.0 & 0.0 & 0.0 & & \\
\hline Subcontracts $(S K-P)$ & 0.0 & 0.0 & 0.0 & 0.0 & 0.0 & 0.0 & & \\
\hline Total (\$K-P) & 22.7 & 22.7 & 22.7 & 22.7 & 22.7 & 113.5 & & \\
\hline Total (WM) & 1.5 & 1.5 & 1.5 & 1.5 & 1.5 & 7.5 & & \\
\hline WHC & 12.0 & 12.0 & 12.0 & 12.0 & 12.0 & 59.9 & & \\
\hline PNL & 10.7 & 10.7 & 10.7 & 10.7 & 10.7 & 53.7 & & \\
\hline IRM & 0.0 & 0.0 & 0.0 & 0.0 & 0.0 & 0.0 & & \\
\hline KEH & 0.0 & 0.0 & 0.0 & 0.0 & 0.0 & 0.0 & & \\
\hline Total & 22.7 & 22.7 & 22.7 & 22.7 & 22.7 & 113.5 & & \\
\hline
\end{tabular}


Table 1. Barrier Development Program Cost \& Schedule Estimates.

(sheet 22 of 37 )

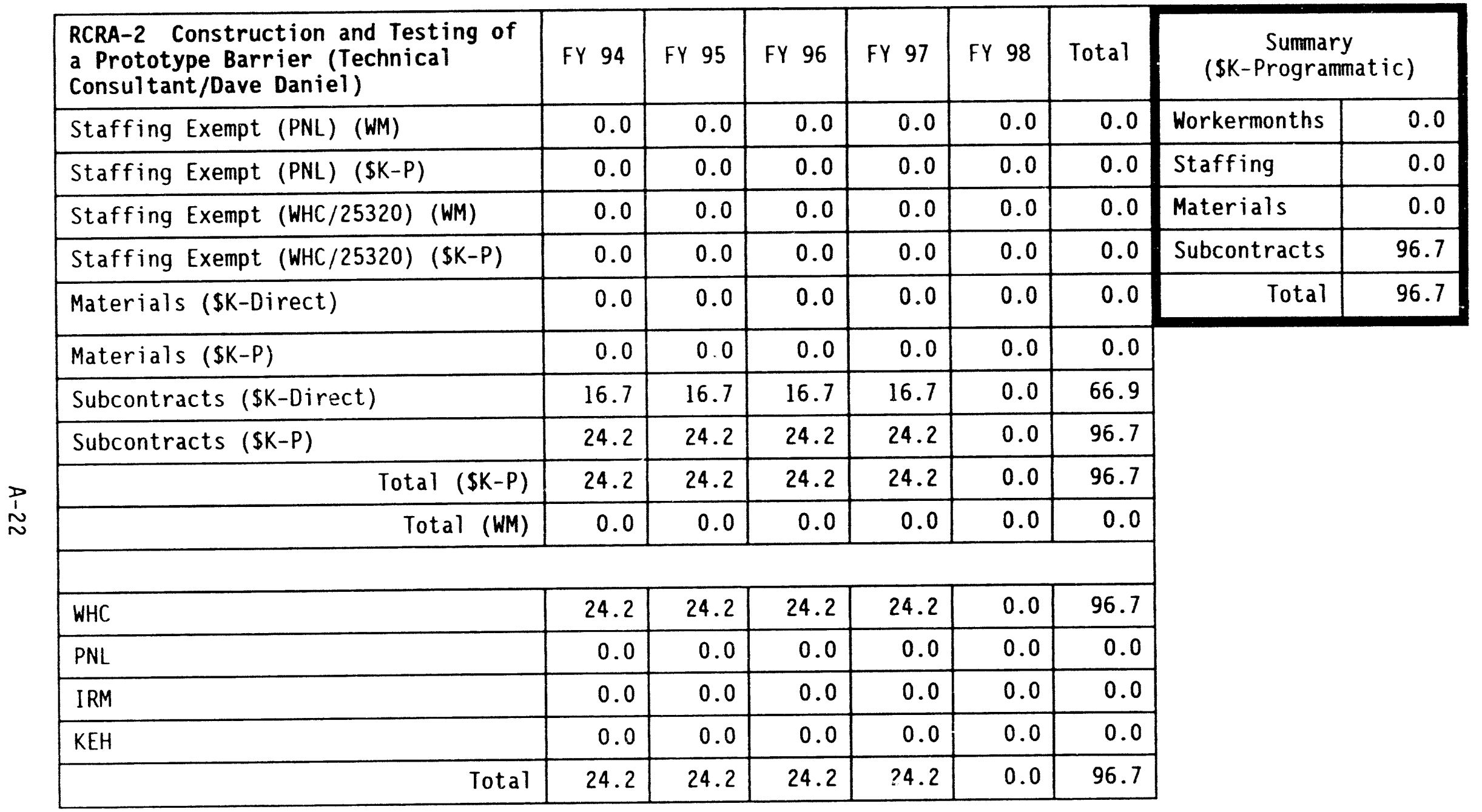


Table 1. Barrier Development Program Cost \& Schedule Estimates.

(sheet 23 of 37 )

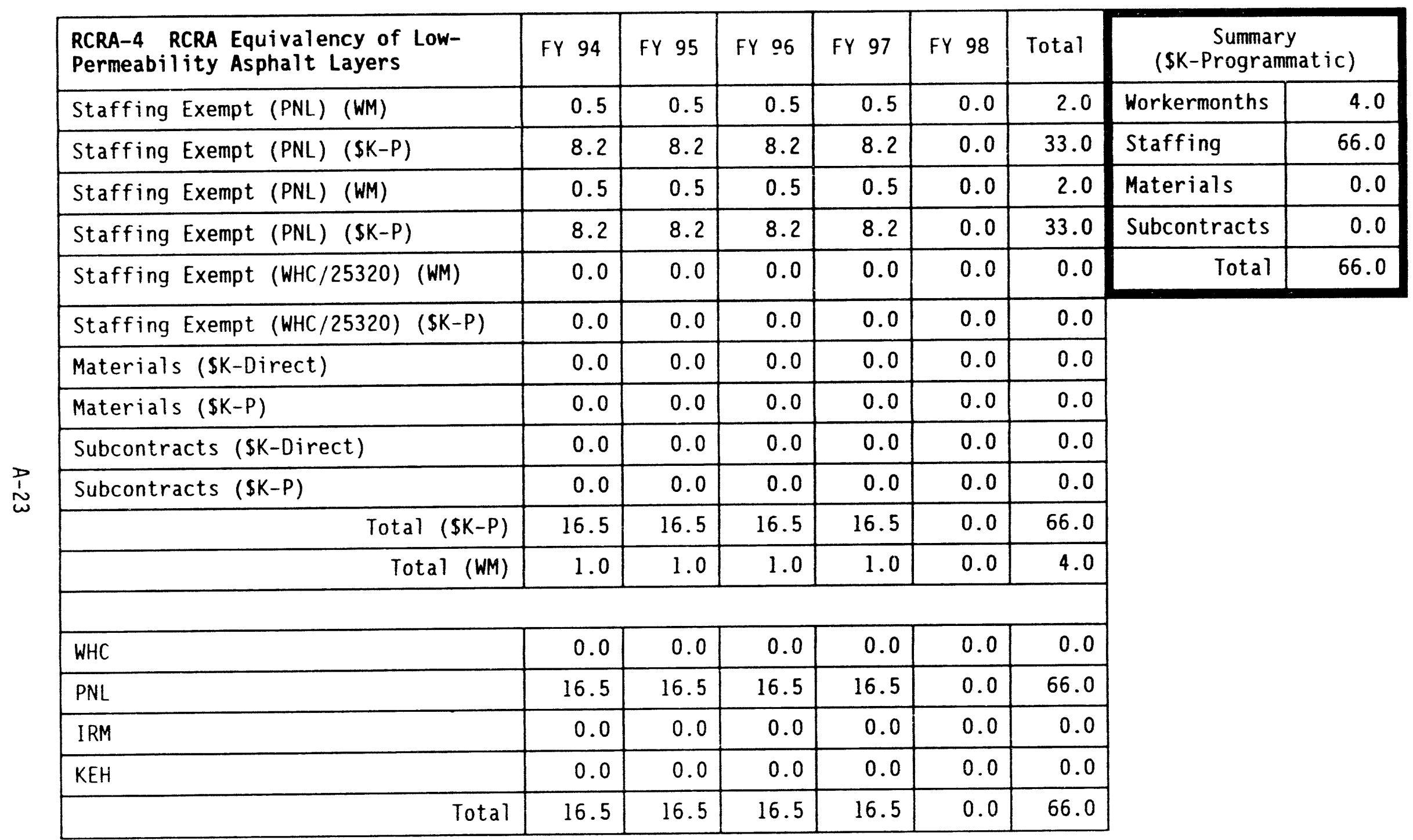


Table 1. Barrier Development Program Cost \& Schedule Estimates.

(sheet 24 of 37 )

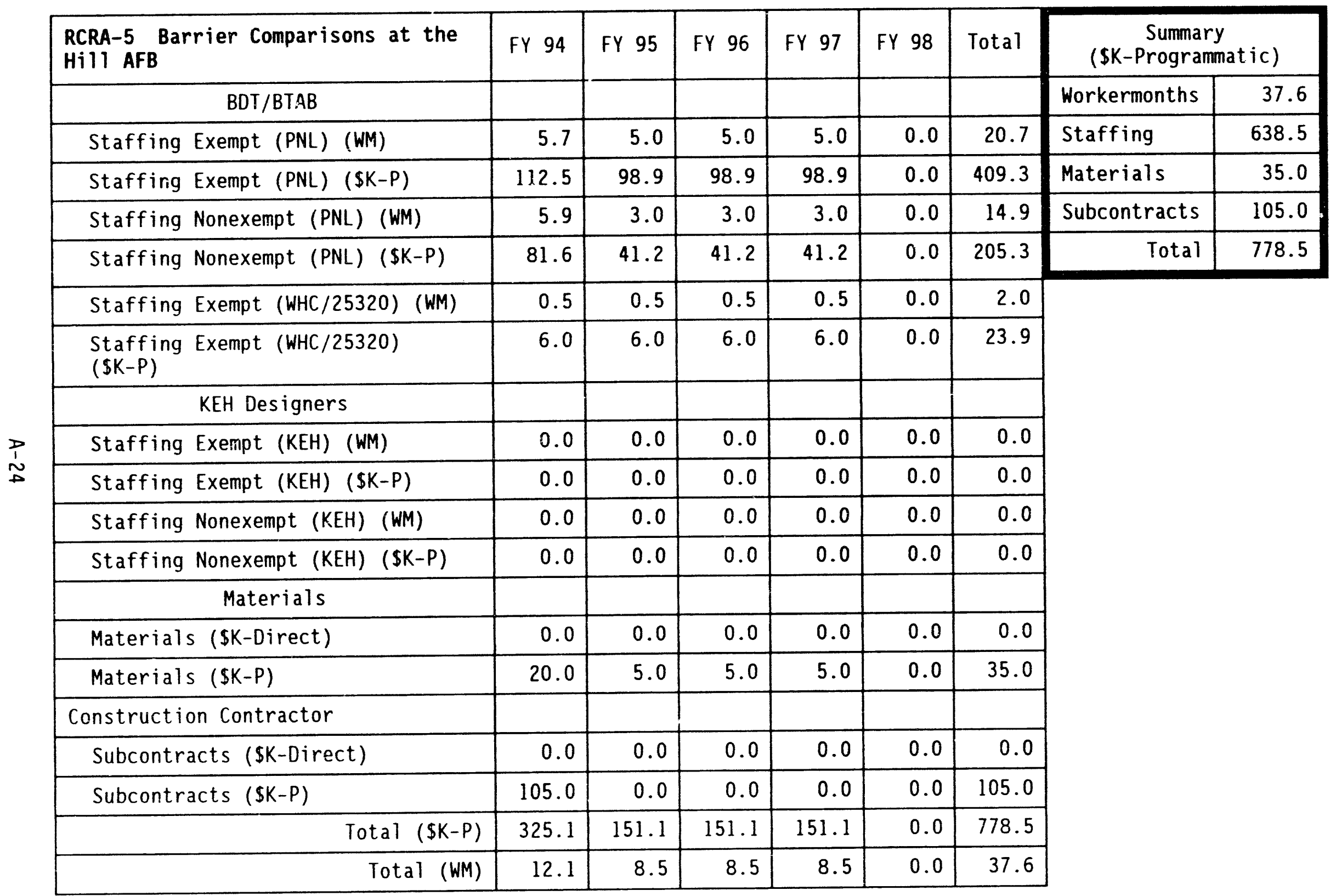


Table 1. Barrier Development Program Cost \& Schedule Estimates. (sheet 25 of 37 )

\begin{tabular}{|c|c|c|c|c|c|c|}
\hline WHC & 6.0 & 6.0 & 6.0 & 6.0 & 0.0 & 23.9 \\
\hline PNL & 319.1 & 145.2 & 145.2 & 145.2 & 0.0 & 754.6 \\
\hline IRM & 0.0 & 0.0 & 0.0 & 0.0 & 0.0 & 0.0 \\
\hline KEH & 0.0 & 0.0 & 0.0 & 0.0 & 0.0 & 0.0 \\
\hline Total & 325.1 & 151.1 & 151.1 & 151.1 & 0.0 & 778.5 \\
\hline
\end{tabular}

$\frac{P}{1}$ 
Table 1. Barrier Development Program Cost Schedule Estimates.

(sheet 26 of 37 )

\begin{tabular}{|c|c|c|c|c|c|c|c|c|}
\hline $\begin{array}{l}\text { TECH-1 Barrier Development Program } \\
\text { Documentation }\end{array}$ & FY 94 & FY 95 & FY 96 & FY 97 & FY 98 & Total & \multicolumn{2}{|c|}{$\begin{array}{c}\text { Summary } \\
(\$ K-\text { Programmatic) }\end{array}$} \\
\hline Staffing Exempt (PNL) (WM) & 1.0 & 1.0 & 1.0 & 1.0 & 1.0 & 5.0 & Workermonths & 16.5 \\
\hline Staffing Exempt (PNL) (\$K-P) & 21.5 & 21.5 & 21.5 & 21.5 & 21.5 & 107.4 & Staffing & 347.8 \\
\hline Staffing Nonexempt (PNL) (WM) & 1.0 & 2.0 & 2.0 & 2.0 & 2.0 & 9.0 & Materials & 0.0 \\
\hline Staffing Nonexempt (PNL) ( $\$ K-P)$ & 13.7 & 27.5 & 27.5 & 27.5 & 27.5 & 123.7 & Subcontracts & 0.0 \\
\hline Staffing Exempt (WHC/25320) (WM) & 0.5 & 0.5 & 0.5 & 0.5 & 0.5 & 2.5 & Total & 347.8 \\
\hline Staffing Exempt (WHC/25320) (SK-P) & 6.0 & 6.0 & 6.0 & 6.0 & 6.0 & 29.9 & & \\
\hline Staffing Nonexempt (WHC/25320) (WM) & 3.0 & 3.0 & 3.0 & 3.0 & 3.0 & 15.0 & & \\
\hline $\begin{array}{l}\text { Staffing Nonexempt (WHC/25320) } \\
(\$ K-P)\end{array}$ & 17.4 & 17.4 & 17.4 & 17.4 & 17.4 & 86.8 & & \\
\hline Materials (\$K-Direct) & 0.0 & 0.0 & 0.0 & 0.0 & 0.0 & 0.0 & & \\
\hline Materials $(\$ K-P)$ & 0.0 & 0.0 & 0.0 & 0.0 & 0.0 & 0.0 & & \\
\hline Subcontracts (\$K-Direct) & 0.0 & 0.0 & 0.0 & 0.0 & 0.0 & 0.0 & & \\
\hline Subcontracts $(\$ K-P)$ & 0.0 & 0.0 & 0.0 & 0.0 & 0.0 & 0.0 & & \\
\hline Total (\$K-P) & 58.6 & 72.3 & 72.3 & 72.3 & 72.3 & 347.8 & & \\
\hline Total (WM) & 5.5 & 6.5 & 6.5 & 6.5 & 6.5 & 31.5 & & \\
\hline WHC & 23.3 & 23.3 & 23.3 & 23.3 & 23.3 & 116.7 & & \\
\hline PNL & 35.2 & 49.0 & 49.0 & 49.0 & 49.0 & 231.1 & & \\
\hline IRM & 0.0 & 0.0 & 0.0 & 0.0 & 0.0 & 0.0 & & \\
\hline KEH & 0.0 & 0.0 & 0.0 & 0.0 & 0.0 & 0.0 & & \\
\hline Total & 58.6 & 72.3 & 72.3 & 72.3 & 72.3 & 347.8 & & \\
\hline
\end{tabular}


Table 1. Barrier Development Program Cost \& Schedule Estimates.

(sheet 27 of 37)

\begin{tabular}{|c|c|c|c|c|c|c|c|c|}
\hline $\begin{array}{l}\text { TECH-2 Consultation on Special } \\
\text { Barrier-Related Topics }\end{array}$ & FY 94 & FY 95 & FY 96 & FY 97 & FY 98 & Total & \multicolumn{2}{|c|}{$\begin{array}{c}\text { Summary } \\
\text { (\$K-Programmatic) }\end{array}$} \\
\hline Staffing Exempt (PNL) (WM) & 0.5 & 0.5 & 0.5 & 0.5 & 0.5 & 2.5 & Workermonths & 11.0 \\
\hline Staffing Exempt (PNL) (\$K-P) & 10.7 & 10.7 & 10.7 & 10.7 & 10.7 & 53.7 & Staffing & 163.8 \\
\hline Staffing Exempt (PNL) (WM) & 0.5 & 0.5 & 0.5 & 0.5 & 0.5 & 2.5 & Materials & 0.0 \\
\hline Staffing Exempt (PNL) (\$K-P) & 7.9 & 7.9 & 7.9 & 7.9 & 7.9 & 39.7 & Subcontracts & 0.0 \\
\hline Staffing Exempt (WHC/25320) (WM) & 1.0 & 1.0 & 1.0 & 1.0 & 1.0 & 5.0 & Total & 163.8 \\
\hline Staffing Exempt (WHC/25320) (\$K-P) & 12.0 & 12.0 & 12.0 & 12.0 & 12.0 & 59.9 & & \\
\hline - :affing Exempt (WHC/25350) (WM) & 0.5 & 0.0 & 0.0 & 0.0 & 0.0 & 0.5 & & \\
\hline Staffing Exempt (WHC/25350) (\$K-P) & 6.0 & 0.0 & 0.0 & 0.0 & 0.0 & 6.0 & & \\
\hline Staffing Exempt (WHC/81320) (WM) & 0.5 & 0.0 & 0.0 & 0.0 & 0.0 & 0.5 & & \\
\hline Staffing Exempt (WHC/81320) (\$K-P) & 4.5 & 0.0 & 0.0 & 0.0 & 0.0 & 4.5 & & \\
\hline Materials (\$K-Direct) & 0.0 & 0.0 & 0.0 & 0.0 & 0.0 & 0.0 & & \\
\hline Materials (\$K-P) & 0.0 & 0.0 & 0.0 & 0.0 & 0.0 & 0.0 & & \\
\hline Subcontracts (\$K-Direct) & 0.0 & 0.0 & 0.0 & 0.0 & 0.0 & 0.0 & & \\
\hline Subcontracts $(\$ K-P)$ & 0.0 & 0.0 & 0.0 & 0.0 & 0.0 & 0.0 & & \\
\hline Total (\$K-P) & 41.2 & 30.7 & 30.7 & 30.7 & 30.7 & 163.8 & & \\
\hline Total (WM) & 3.0 & 2.0 & 2.0 & 2.0 & 2.0 & 11.0 & & \\
\hline WHC & 22.5 & 12.0 & 12.0 & 12.0 & 12.0 & 70.4 & & \\
\hline PNL & 18.7 & 18.7 & 18.7 & 18.7 & 18.7 & 93.4 & & \\
\hline IRM & 0.0 & 0.0 & 0.0 & 0.0 & 0.0 & 0.0 & & \\
\hline $\mathrm{KEH}$ & 0.0 & 0.0 & 0.0 & 0.0 & 0.0 & 0.0 & & \\
\hline Total & 41.2 & 30.7 & 30.7 & 30.7 & 30.7 & 163.8 & & \\
\hline
\end{tabular}


Table 1. Barrier Development Program Cost \& Schedule Estimates.

(sheet 28 of 37 )

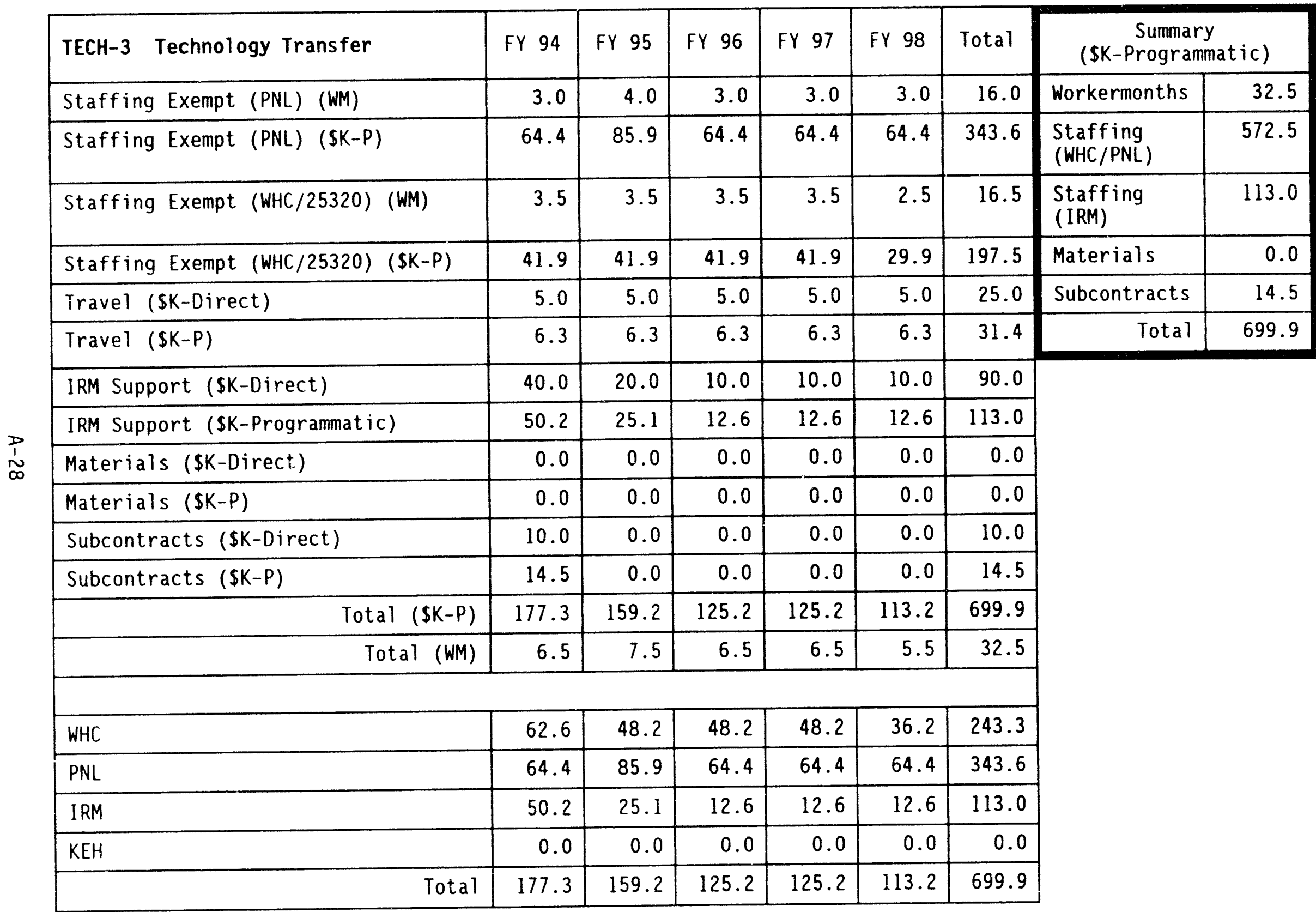


Table 1. Barrier Development Program Cost \& Schedule Estimates. (sheet 29 of 37)

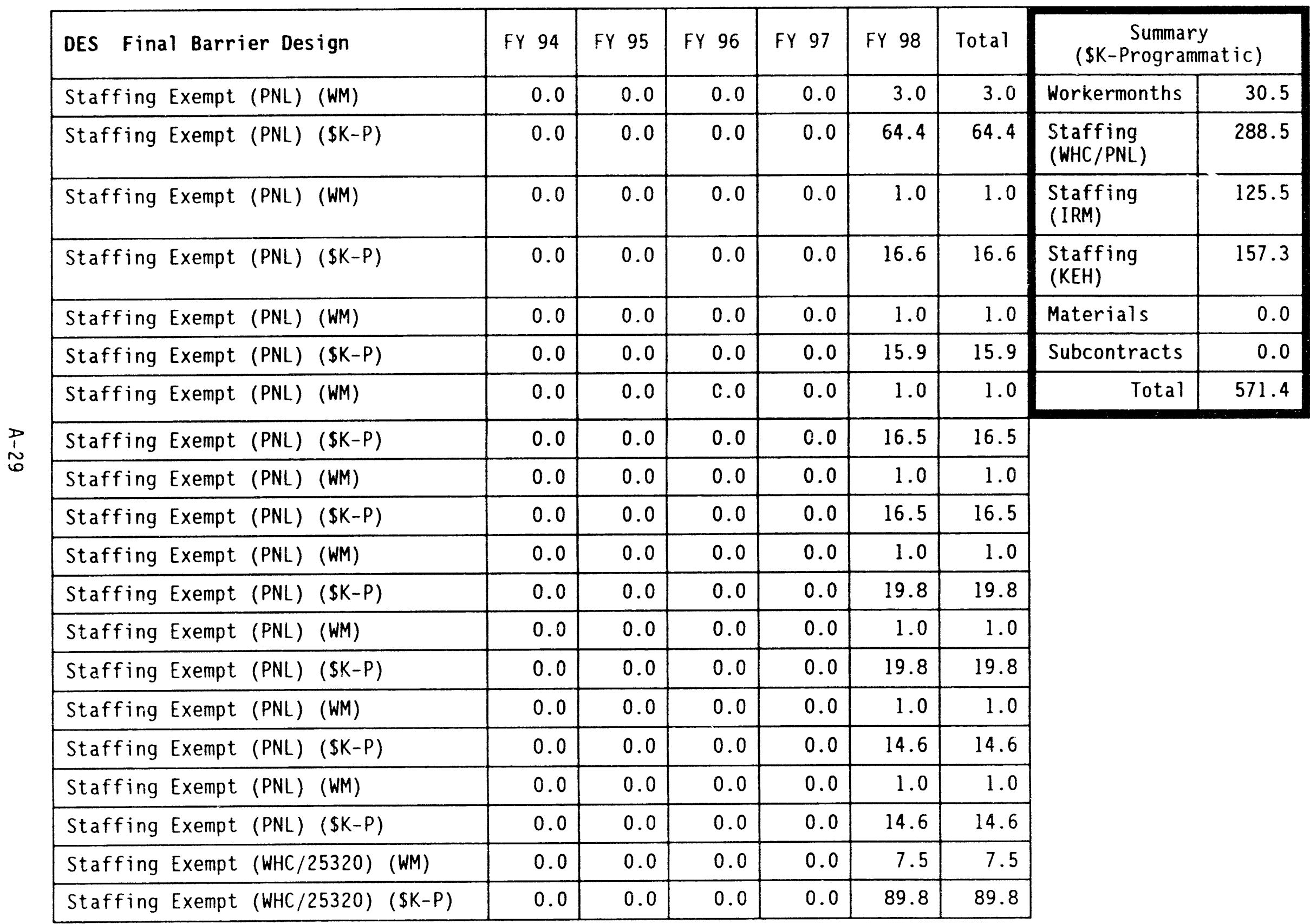


Table 1. Barrier Development Program Cost \& Schedule Estimates.

(sheet 30 of 37 )

\begin{tabular}{|l|r|r|r|r|r|r|}
\hline Staffing Exempt (KEH) (WM) & 0.0 & 0.0 & 0.0 & 0.0 & 12.0 & 12.0 \\
\hline Staffing Exempt (KEH) (\$K-P) & 0.0 & 0.0 & 0.0 & 0.0 & 157.3 & 157.3 \\
\hline IRM Support (\$K-Direct) & 0.0 & 0.0 & 0.0 & 0.0 & 100.0 & 100.0 \\
\hline IRM Support (\$K-Programmatic) & 0.0 & 0.0 & 0.0 & 0.0 & 125.5 & 125.5 \\
\hline Materials (\$K-Direct) & 0.0 & 0.0 & 0.0 & 0.0 & 0.0 & 0.0 \\
\hline Materials (\$K-P) & 0.0 & 0.0 & 0.0 & 0.0 & 0.0 & 0.0 \\
\hline Subcontracts (\$K-Direct) & 0.0 & 0.0 & 0.0 & 0.0 & 0.0 & 0.0 \\
\hline Subcontracts (\$K-P) & 0.0 & 0.0 & 0.0 & 0.0 & 0.0 & 0.0 \\
\hline \multicolumn{1}{|r|}{ Total (\$K-P) } & 0.0 & 0.0 & 0.0 & 0.0 & 571.4 & 571.4 \\
\hline & 0.0 & 0.0 & 0.0 & 0.0 & 30.5 & 30.5 \\
\hline \multirow{2}{*}{ Total (WM) } & & & & & \\
\hline WHC Total & 0.0 & 0.0 & 0.0 & 0.0 & 571.4 & 571.4 \\
\hline PNL & 0.0 & 0.0 & 0.0 & 0.0 & 198.8 & 198.8 \\
\hline IRM & 0.0 & 0.0 & 0.0 & 0.0 & 125.5 & 125.5 \\
\hline KEH & 0.0 & 0.0 & 0.0 & 0.0 & 157.3 & 157.3 \\
\hline
\end{tabular}


Table 1. Barrier Development Program Cost \& Schedule Estimates.

(sheet 31 of 37)

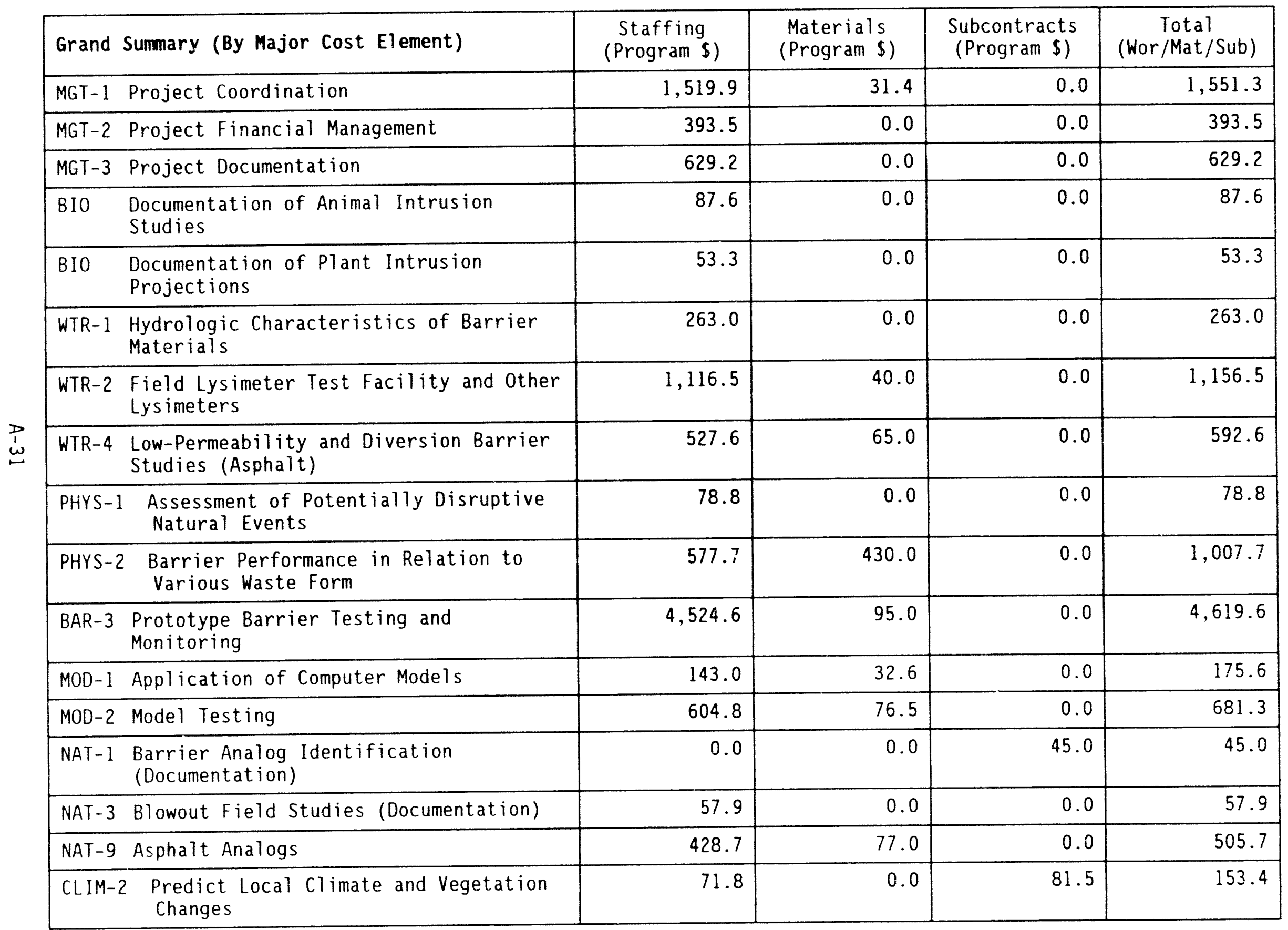


Table 1. Barrier Development Program Cost \& Schedule Estimates.

(sheet 32 of 37 )

\begin{tabular}{|c|c|c|c|c|}
\hline REG Interface with Regulatory Agencies & 113.5 & 0.0 & 0.0 & 113.5 \\
\hline $\begin{array}{l}\text { RCRA-2 } \begin{array}{l}\text { Construction and Testing of a } \\
\text { Prototype (Consultant) }\end{array} \\
\end{array}$ & 0.0 & 0.0 & 96.7 & 96.7 \\
\hline $\begin{array}{l}\text { RCRA-4 RCRA Equivalency of Low-Permeability } \\
\text { Asphalt Layers }\end{array}$ & 66.0 & 0.0 & 0.0 & 66.0 \\
\hline RCRA-5 Barrier Comparisons at the Hill AFB & 638.5 & 35.0 & 105.0 & 778.5 \\
\hline $\begin{array}{c}\text { TECH-1 Barrier Development Program } \\
\text { Documentation }\end{array}$ & 347.8 & 0.0 & 0.0 & 347.8 \\
\hline $\begin{aligned} & \text { TECH-2 } \text { Consultation on Special } \\
& \text { Barrier-Related Topics } \\
&\end{aligned}$ & 163.8 & 0.0 & 0.0 & 163.8 \\
\hline TECH-3 Technology Transfer & 685.5 & 0.0 & 14.5 & 699.9 \\
\hline DES Final Barrier Design & 571.4 & 0.0 & 0.0 & 571.4 \\
\hline Total & $13,664.1$ & 882.5 & 342.7 & $14,889.2$ \\
\hline
\end{tabular}


Table 1. Barrier Development Program Cost \& Schedule Estimates. (sheet 33 of 37 )

\begin{tabular}{|c|c|c|c|c|c|c|}
\hline Grand Summary by Fiscal Year & FY 94 & FY 95 & FY 96 & FY 97 & FY 98 & Total \\
\hline MGT-1 Project Coordination & 293.9 & 314.3 & 314.3 & 314.3 & 314.3 & $1,551.3$ \\
\hline MGT-2 Project Financial Management & 78.7 & 78.7 & 78.7 & 78.7 & 78.7 & 393.5 \\
\hline MGT-3 Project Documentation & 182.7 & 95.5 & 117.0 & 117.0 & 117.0 & 629.2 \\
\hline $\begin{array}{ll}\text { BIO Documentation of Animal } \\
\text { Intrusion Studies }\end{array}$ & 87.6 & 0.0 & 0.0 & 0.0 & 0.0 & 87.6 \\
\hline $\begin{array}{ll}\text { BIO Documentation of Plant Intrusion } \\
\text { Projections }\end{array}$ & 53.3 & 0.0 & 0.0 & 0.0 & 0.0 & 53.3 \\
\hline $\begin{array}{ll}\text { WTR-1 } & \text { Hydrologic Characteristics of } \\
& \text { Barrier Materials }\end{array}$ & 135.9 & 0.0 & 0.0 & 127.0 & 0.0 & 263.0 \\
\hline $\begin{array}{l}\text { WTR-2 Field Lysimeter Test Facility } \\
\text { and Other Lysimeters }\end{array}$ & 356.8 & 269.9 & 264.9 & 264.9 & 0.0 & $1,156.5$ \\
\hline $\begin{array}{c}\text { WTR-4 Low-Permeability and Diversion } \\
\text { Barrier Studies (Asphalt) }\end{array}$ & 151.9 & 146.9 & 146.9 & 146.9 & 0.0 & 592.6 \\
\hline $\begin{aligned} \text { PHYS-1 } & \begin{array}{l}\text { Assessment of Potentially } \\
\text { Disruptive Natural Events }\end{array}\end{aligned}$ & 78.8 & 0.0 & 0.0 & 0.0 & 0.0 & 78.8 \\
\hline $\begin{array}{l}\text { PHYS-2 Barrier Performance in } \\
\text { Relation to Various Waste Form }\end{array}$ & 431.9 & 281.9 & 146.9 & 146.9 & 0.0 & $1,007.7$ \\
\hline $\begin{array}{ll}\text { BAR-3 } & \begin{array}{l}\text { Prototype Barrier Testing and } \\
\text { Monitoring }\end{array}\end{array}$ & $1,076.4$ & $1,185.7$ & $1,168.2$ & $1,189.3$ & 0.0 & $4,619.6$ \\
\hline MOD-1 Application of Computer Models & 43.9 & 43.9 & 43.9 & 43.9 & 0.0 & 175.6 \\
\hline MOD-2 Model Testing & 173.7 & 169.2 & 169.2 & 169.2 & 0.0 & 681.3 \\
\hline $\begin{array}{l}\text { NAT-1 Barrier Analog Identification } \\
\text { (Documentation) }\end{array}$ & 45.0 & 0.0 & 0.0 & 0.0 & 0.0 & 45.0 \\
\hline $\begin{array}{cl}\text { NAT-3 Blowout Field Studies } \\
\text { (Documentation) }\end{array}$ & 17.4 & 40.6 & 0.0 & 0.0 & 0.0 & 57.9 \\
\hline NAT-9 Asphalt Analogs & 148.9 & 118.9 & 118.9 & 118.9 & 0.0 & 505.7 \\
\hline $\begin{array}{c}\text { CLIM-2 Predict Local Climate and } \\
\text { Vegetation Changes }\end{array}$ & 153.4 & 0.0 & 0.0 & 0.0 & 0.0 & 153.4 \\
\hline
\end{tabular}


Table 1. Barrier Development Program Cost \& Schedule Estimates.

(sheet 34 of 37 )

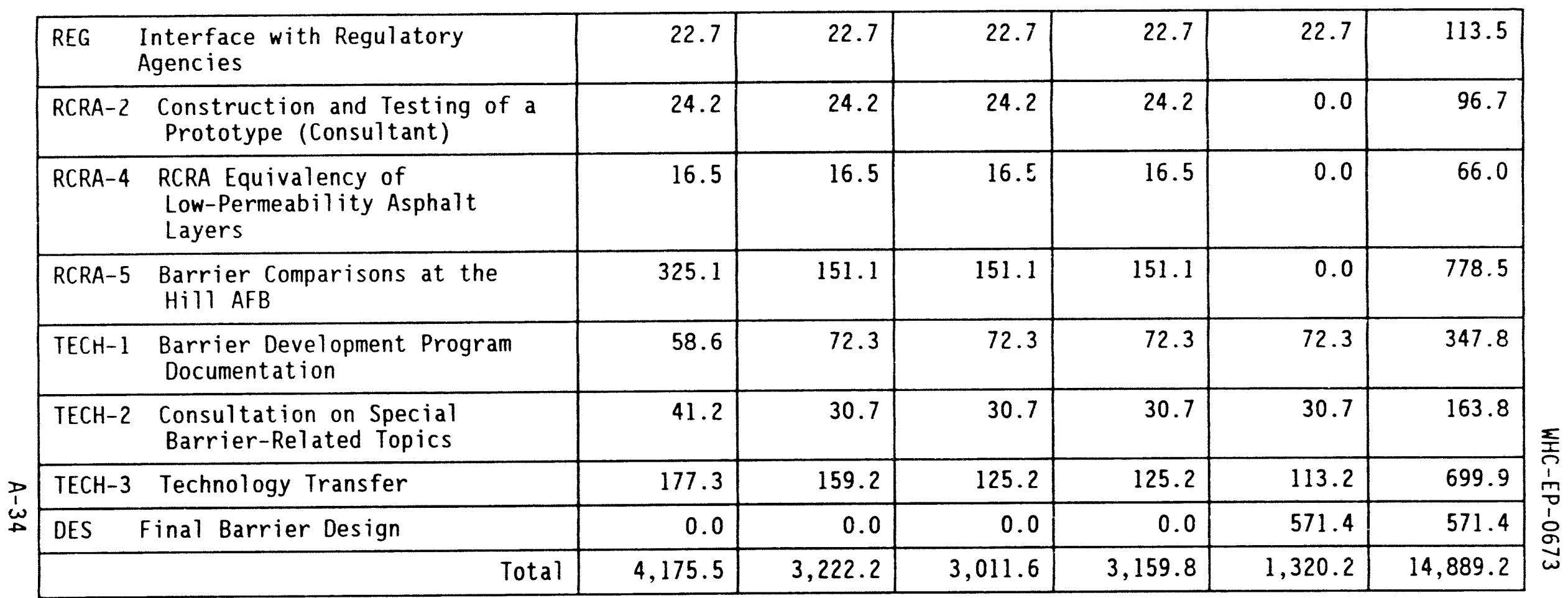


Table 1. Barrier Development Program Cost \& Schedule Estimates.

(sheet 35 of 37 )

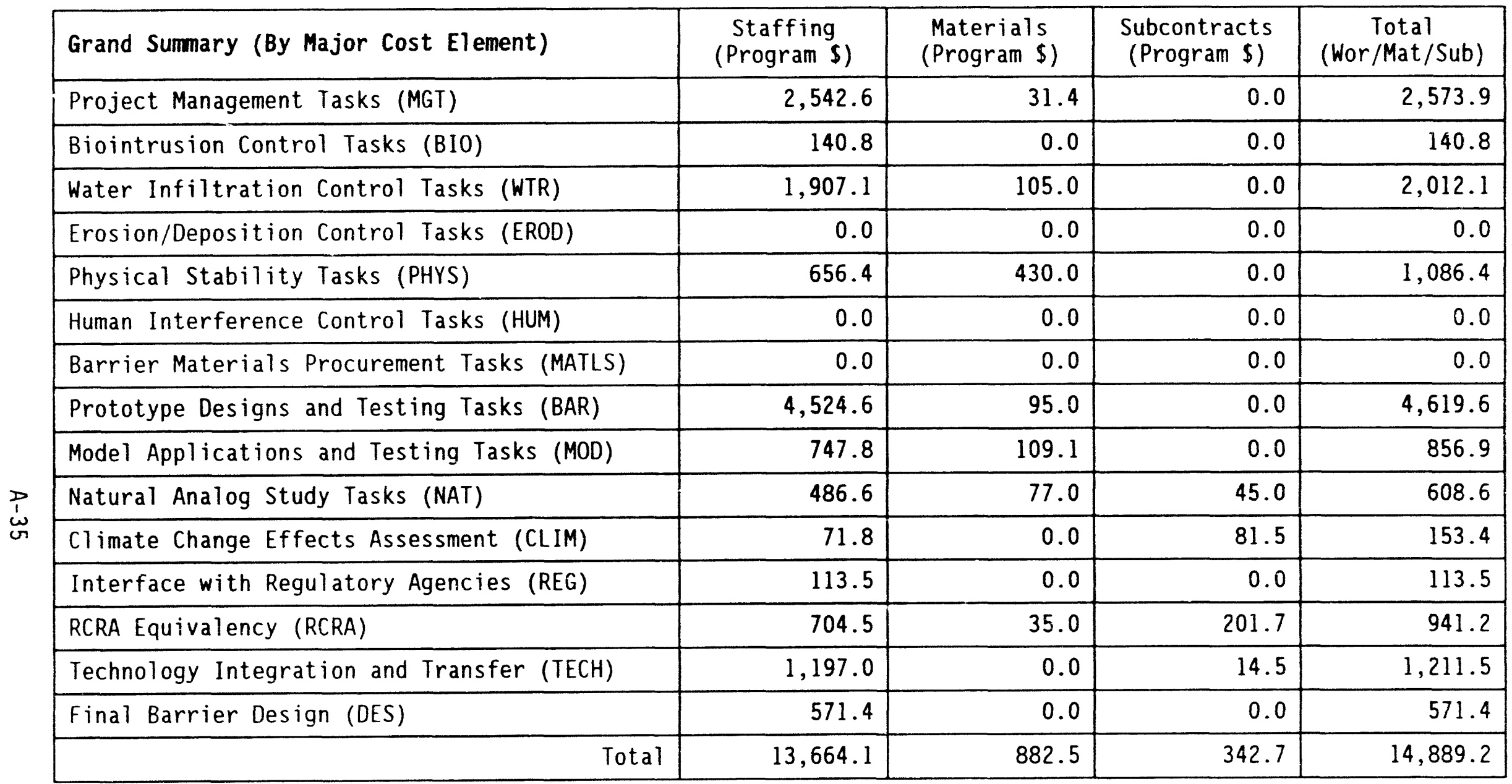


Table 1. Barrier Development Program Cost Schedule Estimates.

(sheet 36 of 37 )

\begin{tabular}{|c|c|c|c|c|c|c|}
\hline Grand Summary by Fiscal Year & FY 94 & FY 95 & FY 96 & FY 97 & FY 98 & Total \\
\hline Project Management Tasks (MGT) & 555.3 & 488.6 & $510 . C$ & 510.0 & 510.0 & $2,573.9$ \\
\hline Biointrusion Control Tasks (BIO) & 140.8 & 0.0 & 0.0 & 0.0 & 0.0 & 140.8 \\
\hline Water Infiltration Control Tasks (WTR) & 644.6 & 416.8 & 411.8 & 538.9 & 0.0 & $2,012.1$ \\
\hline $\begin{array}{l}\text { Erosion/Deposition Control Tasks } \\
\text { (EROD) }\end{array}$ & 0.0 & 0.0 & 0.0 & 0.0 & 0.0 & 0.0 \\
\hline Physical Stability Tasks (PHYS) & 510.7 & 281.9 & 146.9 & 146.9 & 0.0 & $1,086.4$ \\
\hline Human Interference Control Tasks (HUM) & 0.0 & 0.0 & 0.0 & 0.0 & 0.0 & 0.0 \\
\hline $\begin{array}{l}\text { Barrier Materials Procurement Tasks } \\
\text { (MATLS) }\end{array}$ & 0.0 & 0.0 & 0.0 & 0.0 & 0.0 & 0.0 \\
\hline $\begin{array}{l}\text { Prototype Designs and Testing Tasks } \\
\text { (BAR) }\end{array}$ & $1,076.4$ & $1,185.7$ & $1,168.2$ & $1,189.3$ & 0.0 & $4,619.6$ \\
\hline $\begin{array}{l}\text { Model Applications and Testing Tasks } \\
\text { (MOD) }\end{array}$ & 217.6 & 213.1 & 213.1 & 213.1 & 0.0 & 856.9 \\
\hline Natural Analog Study Tasks (NAT) & 211.3 & 159.5 & 118.9 & 118.9 & 0.0 & 608.6 \\
\hline $\begin{array}{l}\text { Climate Change Effects Assessment } \\
(\text { CLIM) }\end{array}$ & 153.4 & 0.0 & 0.0 & 0.0 & 0.0 & 153.4 \\
\hline $\begin{array}{l}\text { Interface with Regulatory Agencies } \\
\text { (REG) }\end{array}$ & 22.7 & 22.7 & 22.7 & 22.7 & 22.7 & 113.5 \\
\hline RCRA Equivalency (RCRA) & 365.8 & 191.8 & 191.8 & 191.8 & 0.0 & 941.2 \\
\hline $\begin{array}{l}\text { Technolngy Integration and Transfer } \\
\text { (TECH) }\end{array}$ & 277.0 & 262.1 & 228.1 & 228.1 & 216.1 & $1,211.5$ \\
\hline Final Barrier Design (DES) & 0.0 & 0.0 & 0.0 & 0.0 & 571.4 & 571.4 \\
\hline Total & $4,175.5$ & $3,222.2$ & $3,011.6$ & $3,159.8$ & $1,320.2$ & $14,889.2$ \\
\hline
\end{tabular}


Table 1. Barrier Development Program Cost \& Schedule Estimates. (sheet 37 of 37 )

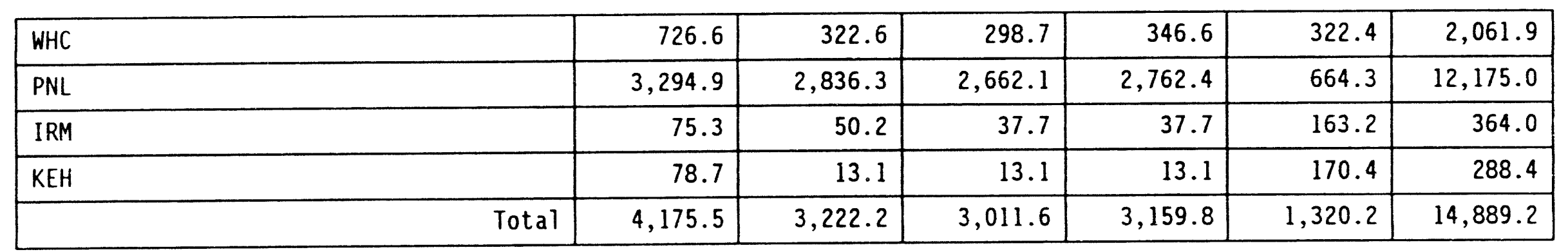

$\stackrel{p}{\stackrel{1}{w}}$ 


\section{DISTRIBUTION}

Number of copies

OFFSITE

1

U.S. Department of Energy

San Francisco Operations office

1333 Broadway

Oakland, CA 94612

F. T. Fong

3

U.S. Department of Energy

785 DOE P1 ace

Idaho Falls, ID 83402

0. D. Markham

R. C. Morris

T. E. Reynolds

1

U.S. Department of Energy

1580 Sawtelle Drive

Idaho Falls, ID 83403

S. Evans

1

U.S. Department of Energy, Headquarters

5301 Central Avenue NE,

Suite 1700

Albuquerque, NM 87108

J. Lommler

2 U.S. Department of Energy-Albuquerque Operations office P.0. Box 5400, MS ERPO

Albuquerque, NM 87185-5400

K. Bitner

G. J. Rael

$1 \quad$ U.S. Department of Energy

West Valley Project Office

P.0. Box 191

West Valley, NY 14171

E. Maestas 
WHC-EP-0673

\section{DISTRIBUTION (cont inued)}

Number of copies

OFFSITE

2 U.S. Department of Energy

Savannah River Operations

office

P.0. Box A

Aik, SC 29801

W. J. Brumley

D. Bruegennjohann

$1 \quad$ U.S. Department of Energy

0ak Ridge Operations

P.0. Box E

Oak Ridge, TN 37830

M. R. Jugan

$1 \quad$ U.S. Department of Energy

Morgantown Energy Technology Center

P.0. Box 880

Morgantown, WV 26505

R. C. Letcher

1

Argonne National Laboratory

P.0. Box 2528

Idaho Falls, ID 83401

C. S. Abrams

1

Argonne National Laboratory

9700 South Cass Avenue

Argonne, IL 60439

M. J. Steindler

3

Battelle Memorial Institute

Project Management

Division

$505 \mathrm{King}$ Avenue

Columbus, $\mathrm{OH} 43201$

W. A. Carbeiner

W. S. Madia

Technical Library

Distr-2 
WHC-EP-0673

\section{DISTRIBUTION (continued)}

Number of copies

OFFSITE

1

Bechtel-FUSRAP

P.0. Box 350

Oak Ridge, TN 37830

M. Benge

5

Chem Nuclear Geotech

P.0. Box 14000

Grand Junction, CO 81502

J. Duray

J. Elmer

V. Ponc

C. L. Sundblad

W. J. Waugh

1

Dames and Moore

Suite 108

4220 S. Maryl and Parkway

Las Vegas, NV 89119

W. G. Spaulding

1 Department of Health Radiation Protection Division Airdustrial Park

BIdg. 5, MS LE-13

O1ympia, WA 98504

A. Rainey

2

Desert Research Institute

P.0. Box 60220

Reno, NV 89506

J. T. Ball

S. W. Tyler

1 Dyn McDermott Petroleum

Services

850 South Clearview Parkway

New Orleans, LA 70123

C. Reith 


\section{DISTRIBUTION (continued)}

Number of copies

OFFSITE

2

EBASCO

1201 Jadwin

Richland, WA 99352

W. Riggsbee

R. L. Treat

5

Environmental Protection Agency

Hanford Project office

712 Swift, MS B5-01

Richland, WA 99352

P. R. Beaver

D. A. Faulk

L. E. Gadbois

P. S. Innis

D. R. Sherwood

1 EG\&G, Rock Flats

P.0. Box 464, Building 080

Golden, CO 80402

S. Needler

1 Electric Power Research Institute

3412 Hillview Avenue

Palo Alto, CA 94304

R. Shaw

1 Geraghty \& Miller. Inc.

5425 Holl ister Ave.,

Suite 100

Santa Barbara, CA

L. G. Everett

1 Gonzaga University

Civil Engineering Dept

E. 502 Boone

Spokane, WA 99258-0001

J. B. Stong 


\section{DISTRIBUTION (continued)}

Number of copies

OFFSITE

Hill Air Force Base

Environmental Management Directorate $00-A L C / E M^{*}$

7276 Wardleigh Road

Hill AFB, UT 84056-5127

B. Elliot

D. Stone

1 Idaho Department of Health and Welfare Division of Environmental Quality $900 \mathrm{~N}$ Skyline Idaho Falls, ID 83404

T. M. Stoops

9

Idaho National Engineering Laboratory P.0. Box 1625

Idaho Falls, ID 83415

R. J. Bargelt

J. E. Conner

J. Hubbell

M. A. Knecht

K. M. Kostelnik

S. Magnusson

D. L. McElroy

J. B. Sisson

Technical Library

3

Jacobs Engineering Group. Inc. 5301 Central Avenue NE Suite 1700

Albuquerque, NM 87108

T. Goering

M. Kyllo

F. Titus 
WHC-EP-0673

DISTRIBUTION (continued)

Number of copies

OFFSITE

6

Los Alamos National Laboratory

P.0. Box 1663

Los Alamos, NM 87545

F. Barnes

K. V. Bostick

T. E. Hakonson

J. W. Nyhan

T. D. Oakley

E. Springer

1 New Mexico State University

Department of Mechanical Engineering

Box 30001

La Cruces, NM 88003

R. G. Hills

$1 \quad$ New Mexico State University Agricultural Experiment Station

Box 3BF

Las Cruces, NM 88003

T. L. Jones

$1 \quad$ NYSERDA

P.0. Box 191

West Valley, NY 14171

M. Weishan

3

Oak Ridge National Laboratory

P.0. Box 2008

Oak Ridge, TN 37831

J. Kuhaida

M. Marietta

G. Suter II

$3 \quad$ Oak Ridge National Laboratory

P.0. Box Y

Oak Ridge, TN 37830

J. 0. Blomeke

W. D. Burch

R. T. Jubin 
WHC-EP-0673

\section{DISTRIBUTION (continued)}

Number of copies

OFFSITE

1 Sandia National Laboratories

P.0. Box 5800

Aibuquerque, NM 87185

R. W. Lunch

1 SNL, Eastman Cherrington

P.0. Box 10129

Santa Fe, NM 87504

C. Keller

$1 \quad$ Spokane Research Center

U.S. Bureau of Mines

East Montgomery

Spokane, WA 99207

J. 01 son

1

University of Arizona

Department of Soil \& Water

429 Shantz Building

Tucson, AZ 85721

P. J. Wierenga

1 University of California

at Riverside

Department of Soils

Riverside, CA 92502

W. A. Jury

1

University of Texas

Department of Civil Engineering

Austin, TX 78712

D. E. Daniel

1

U.S. Army Engineer Waterways Experiment Station 3909 Halls Ferry Road

Vicksburg, MS 39180-6199

R. D. Bennett 


\section{DISTRIBUTION (continued)}

Number of copies

OFFSITE

1

US Ecology

509 E. 12th

0lympia, WA 98501

B. Bede

1

US Ecology

3855 Atherton Road

Suite 5

Rocklin, CA 95765

J. A. Shaffner

2

US Ecology

5333 Westheimer

Suite 1000

Houston, TX 77056-5407

A. Palmer

L. D. Irwin

1

U.S. Environmental Protection Agency

1200 Sixth Avenue

Seattle, WA 98101

C. Massimino

1

U.S. Geological Survey

Federal Center Mi 413

Denver, CO 80225

E. P. Weeks

2

U.S. Geological Survey

333 W. Nye Lane

Carson City, NV 89706

B. J. Andraski

D. E. Prudic 
DISTRIBUTION (continued)

Number of copies

OFFSITE

3

U.S. Geological Survey

Low-Level Radioactive Waste Program

Water Resources Division

12201 Sunrise Valley Drive

Reston, VA 22092

P. Stevens

N. Trask

I. Winograd

2

U.S. Geological Survey

1201 Pacific Ave.,

Suite 600

Tacoma, WA 98402

W. R. Bidlake

W. Staubitz

1 U.S. Nuclear Regulatory Commission Division of Fuel Material Safety Washington, D.C. 20555

A. T. Clark

3 U.S. Nuclear Regulatory Commission

Division of Engineering Safety

Waste Management Branch

5650 Nicholson Lane

Rockville, MD 29852

T. J. Nicholson

E. O'Donnell

M. Silberberg

1 Washington State Department of Ecology

High-Level Waste Management

Olympia, WA 98504

J. Rense1, MS PV-11 
WHC-EP-0673

\section{DISTRIBUTION (continued)}

Number of copies

\section{OFFSITE}

2

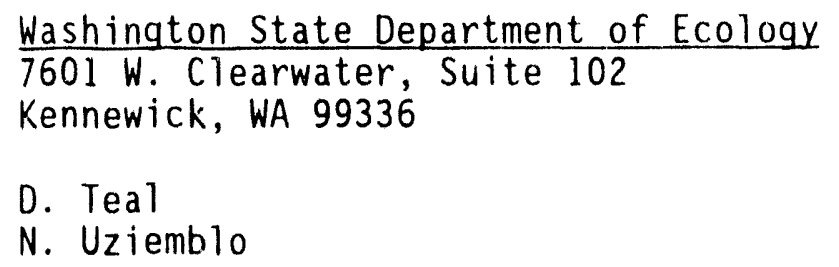

3

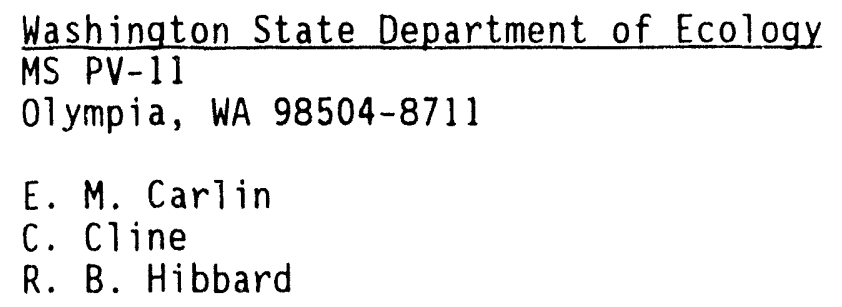

Washington State University Pullman, WA 99164
A. J. Busacca
G. S. Campbe11
D. Gaylord
K. Keller
P. J. Mehringer

1 Westinghouse Idaho Nuclear Company P.0. Box 4000 Idaho Falls, ID 83403

D. A. Knecht

11 Westinghouse Savannah River Company P.0. Box 616 Aiken, SC 29802

M. D. Boersma

J. Cook

M. Flora

L. Huber

J. R. Knight

S. R. McMullin

E. Norton

M. J. Plodinec

C. T. Randall

E. Schiefer

M. G. Serrato 
WHC-EP-0673

\section{DISTRIBUTION (continued)}

Number of copies

OFFSITE

4

West Valle: Nuclear Service Company

P.0. Box 191

West Valley, NY 14171

R. R. Borisch

J. Buggy

J. M. Pope

R. A. Thomas

$1 \quad$ WINCO

P.0. Box 4000, MS 1572

Idaho Falls, ID 83404

C. Mascarenas

FORE IGN

1

BRGM

Department "Environment"

BP 6009

45060 Orleans Cedex

FRANCE

M. Barrès

1

British Nuclear Fuels plc

Waste Management Unit

Sellafield

Seascale, Cumbria CA201PG

ENGLAND

P. Grimwood

Institut für Bodenkunde der Universität Hamburg Allende-Platz 2, D-2000

Hamburg 13

FEDERAL REPUBLIC OF GERMANY

S. Melchior 


\title{
DISTRIBUTION (continued)
}

Number of copies

FOREIGN

1

\author{
Intera Information Technologies \\ Chiltern House \\ 45 Station Road \\ Henley-on-Thames \\ Oxfordshire RG9 IAT \\ UNITED KINGDOM
}

G. M. Smith

ONSITE

11 DOE Richland Operations office
G. J. Bracken
A4-02
J. J. Broderick
A7 -27
R. D. Freeberg
A5- 19
R. E. Gerton
A4-02
J. D. Goodenough
A5- 19
A. C. Harris
A5 -19
R. D. Izatt
A3 -42
P. M. Pak
A5 -19
R. K. Stewart
A5- 19
D. E. Trader
A5 -90
DOR-RL Reading Room Al-65

2

U.S. Army Corps of Engineers
T. Gardner-Clayson
A5- 19
W. L. Greenwald
A5-20
J. H. Jacobson
A3 -61

Kaiser Engineers Hanford Company
S. D. Consort
E6-31
D. L. Fort
E6-50
L. A. Gladdis
R. I. Watkins
E6-41 
WHC-EP-0673

DISTRIBUTION (continued)

Number of copies

ONSITE

42

Westinghouse Hanford Company

M. R. Adams H6-01

H. Babad R2-78

R. J. Bliss B3-04

M. A. Buckmaster H6-03

J. W. Cammann H4-14

R. A. Carlson H6-03

C. C. Chamberlain H6-28

A. P. Church H6-01

H. D. Downey H6-27

W. F. Heine B3-63

C. E. Hodge A5-56

R. W. Hookfin H6-28

G. W. Jackson H6-21

K. N. Jordan H6-28

C. J. Kemp H4-14

M. K. Korenko B3-08

D. S. Landeen H4-14

M. J. Lauterbach H6-01

R. E. Lerch B3-63

H. E. McGuire B3-63

D. R. Myers SO-14

D. J. Newl and B1-58

K. L. Petersen H4-14

R. W. Powell H4-14

R. C. Roos H6-04

M. R. Sackschewsky H4-14

W. A. Skelly H6-03

J. C. Sonnichsen H4-14

J. A. Voogd R4-03

G. F. Williamson R4-01

N. R. Wing H4-14

T. M. Wintczak H6-27

D. D. (Don) Wodrich B1-59

R. D. Wojtasek H6-27

D. E. Wood HO-32

J. G. Woolard H6-05

Document Processing

Central Files L8-04

Environmental Data

Management Center (2) H4-22

Information Release H4-17 
WHC-EP-0673

DISTRIBUTION (continued)

Number of copies

ONSITE

25

Pacific Northwest Laboratory

L. L. Cadwell

P7-54

M. D. Campbel1

K6-77

J. L. Downs

P7-54

M. J. Fayer

K6-77

D. Felmy

M. G. Foley

H. D. Freeman

G. W. Gee

M. J. Graham

P. C. Hays

$K 6-77$

K6-84

P8-38

K6-77

$K 6-78$

C. T. Kincaid

$K 6-86$

$\mathrm{K} 6-77$

R. R. Kirkham

K6-77

G. V. Last

K6-84

M. W. Ligotke

P7 -54

S. 0. Link

P7 -54

G. P. O'Connor

P7 -54

J. C. Ritter

M. L. Rockhold

K6-77

K6-77

L. E. Rogers

P7 -54

R. A. Romine

P8-38

M. A. Simmons

R. L. Skaggs

M. E. Thiede

P7 -54

K6-77

K6-13

J. M. Thomas

P7-54

W. H. Walters

K6-06

C. L. Widrig

B1 -40 

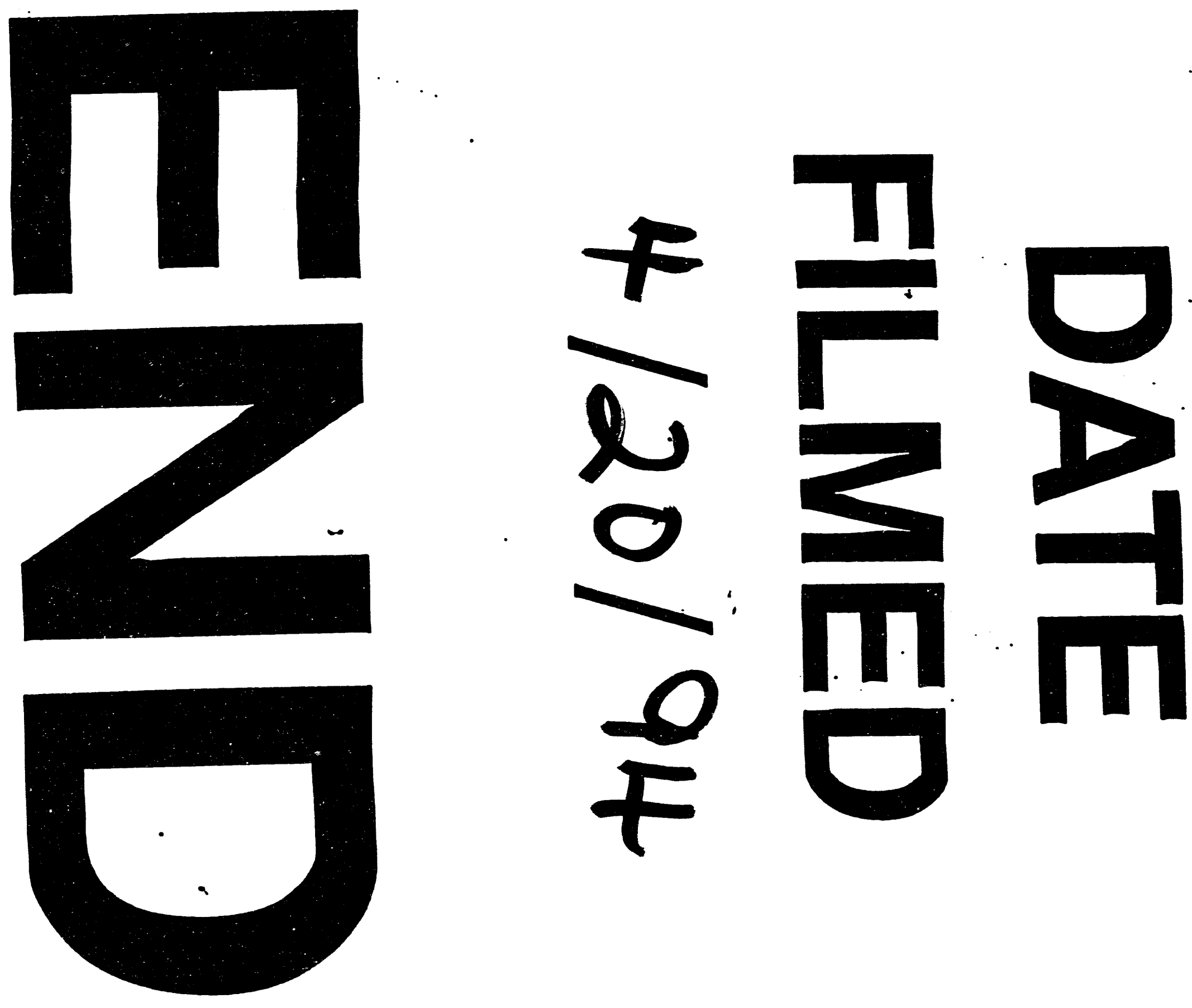


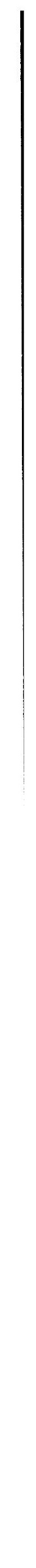

